Aus der Klinik für Thorax-, Herz-, und Gefäßchirurgie

Prof. Dr. med. Ingo Kutschka

der Medizinischen Fakultät der Universität Göttingen

\title{
Das Langzeitergebnis von Rattenaortentransplantaten nach protrahierter Kältekonservierung in der Gefäßprotektionslösung TiProtec®
}

\author{
INAUGURAL - DISSERTATION \\ zur Erlangung des Doktorgrades \\ der Medizinischen Fakultät der \\ Georg-August-Universität zu Göttingen
}

vorgelegt von

Narges Waezi

aus

Kabul/Afghanistan

Göttingen 2018 
Dekan:

Referent:

Ko-Referent:
Prof. Dr. rer. nat. H. K. Kroemer

Prof. Dr. med. T. Stojanovic

PD Dr. med. U. Raaz

Datum der mündlichen Prüfung: 06.03.2019 
Hiermit erkläre ich, die Dissertation mit dem Titel " Das Langzeitergebnis von Rattenaortentransplantaten nach protrahierter Kältekonservierung in der Gefäßprotektionslösung TiProtec $\AA^{\circledR}$ " eigenständig angefertigt und keine anderen als die von mir angegebenen Quellen und Hilfsmittel verwendet zu haben.

Göttingen, den 16.07.2018............ 


\section{Inhaltsverzeichnisverzeichnis}

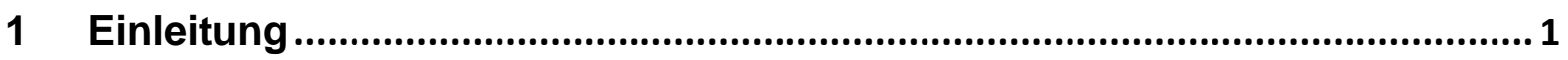

1.1 Periphere arterielle Verschlusskrankheit .....................................................................1

1.1.1 Definition und Epidemiologie.......................................................................... 1

1.1.2 Klinik und Einteilung der Schweregrade ………………………………….....2

1.1.3 Diagnostik .............................................................................................

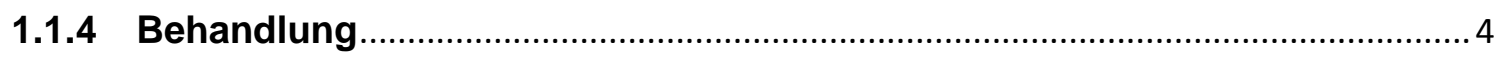

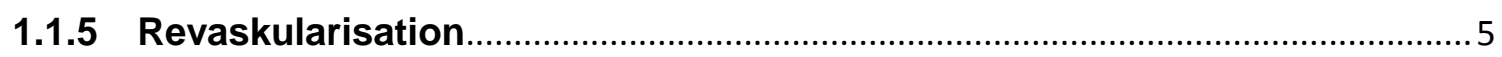

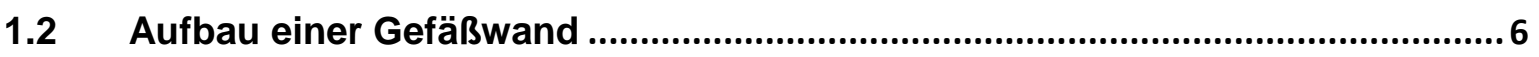

1.3 Endothelfunktion, Endotheldysfunktion .........................................................

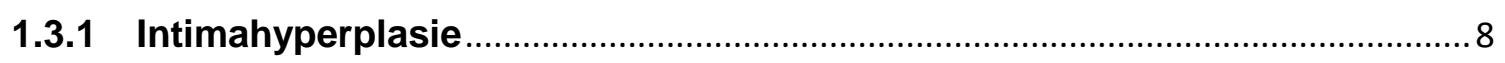

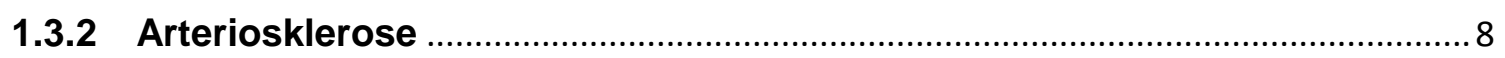

1.4 Gefäßkonservierung ......................................................................................

1.4 .1 Kaltlagerung .........................................................................................

1.4.2 Konservierungslösungen, Organprotektionslösungen ……………………....11

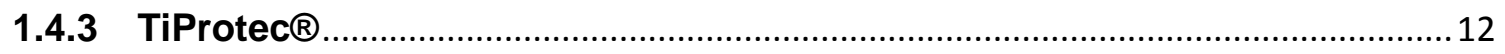

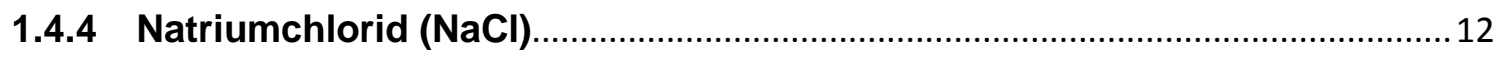

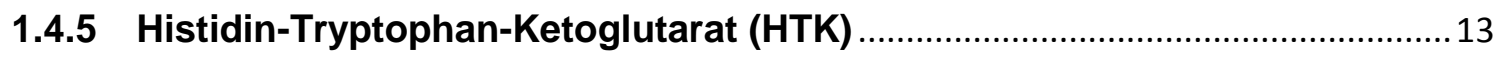

1.4.6 Kryokonservierung ..................................................................................

$1.5 \quad$ Fragestellung dieser Arbeit ........................................................................... 15

2 Materialien und Methoden …………………............................................ 16

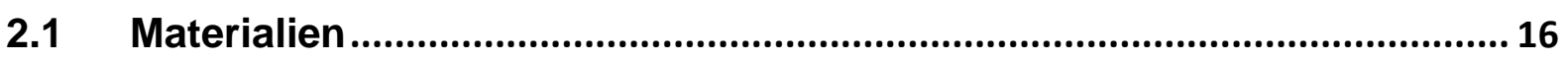

2.1.1 Chemikalien, Medikamente .............................................................................16

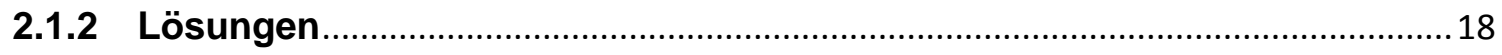

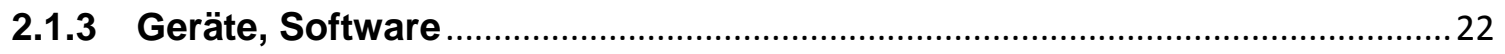

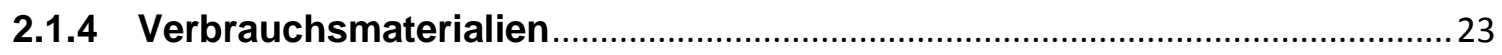

2.2 Methoden ........................................................................................................... 23

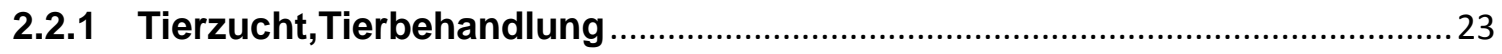

2.2.2 Explantation der Aortentransplantate ……………………………………....2

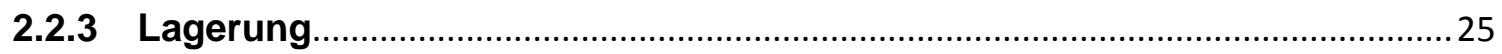




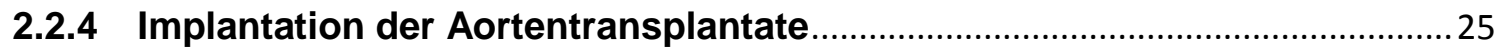

2.2.5 Explantation der Aortenpräparate aus Empfänger ……………....................26

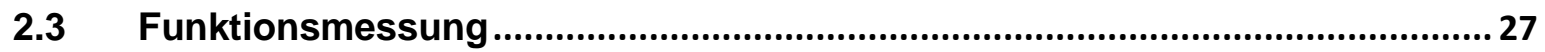

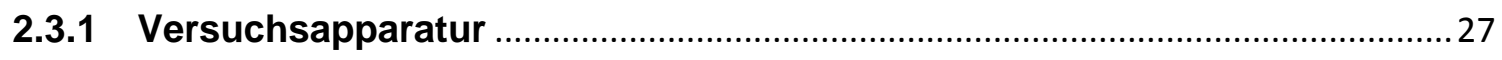

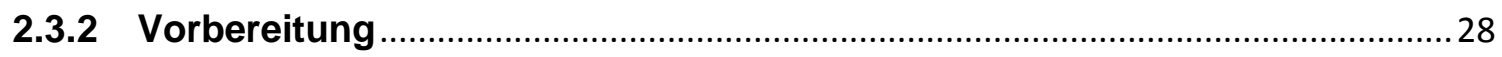

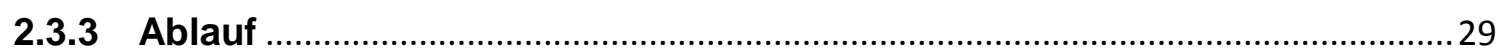

2.3.4 Rezeptorunabhängige Kontraktion mit Kaliumchlorid $(\mathrm{KCl})$........................29

2.3.5 Rezeptorabhängige Kontraktion mit Phenylephrin (PE) ..................................30

2.3.6 Endothelunabhängige Dilatation mit Sodium- Nitroprussid (SNP) ...............30

2.3.7 Endothelabhängige Dilatation mit Acetylcholin (Ach) .................................. 30

2.3.8 Messung im Organbad mit Krebs-Henseleit-Puffer ......................................... 31

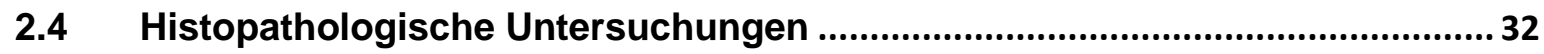

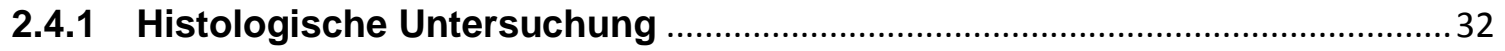

2.4.2 Immunhistochemische Untersuchung …...................................................... 33

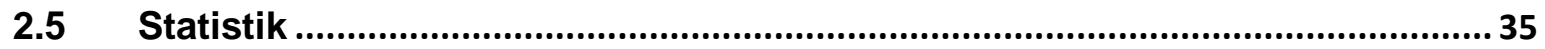

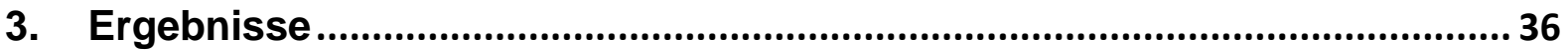

3.1 Überleben, operative und demographische Daten der Tiere .......................... 36

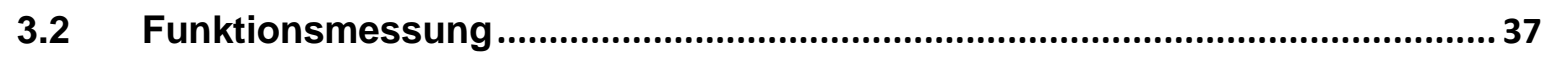

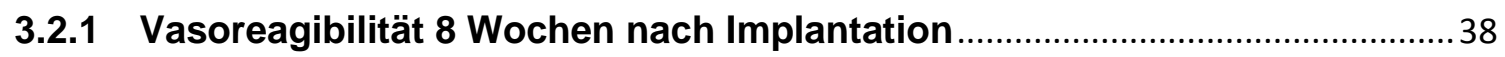

3.2.2 Vasoreagibilität 16 Wochen nach Implantation................................................ 42

3.2.3 Vasoreagibilität 26 Wochen nach Implantation ............................................... 46

3.3 Histomorphologische Auswertung der Aortensegmente ...............................50

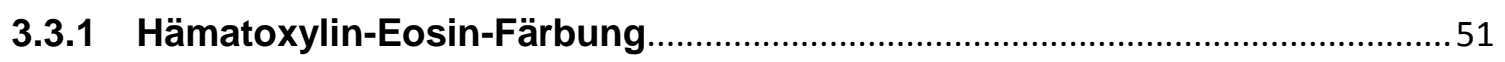

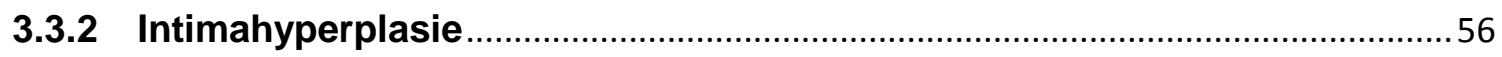

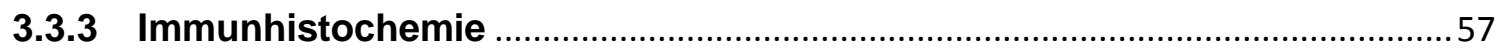

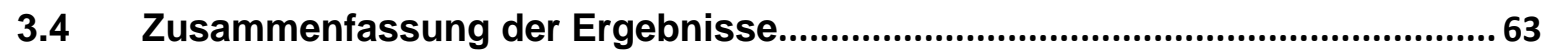

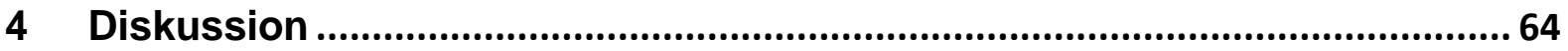

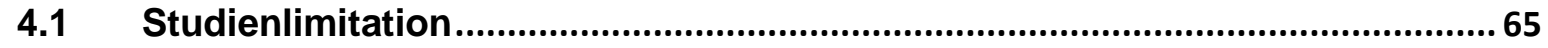

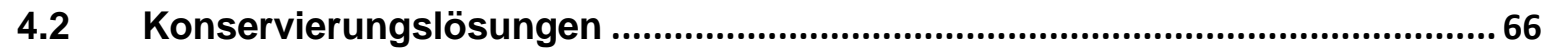

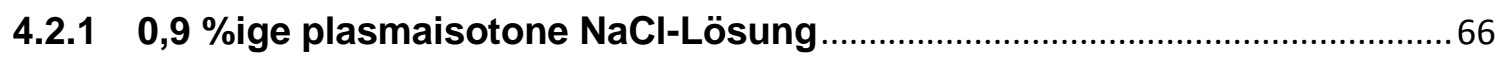

4.2.2 Histidin-Tryptophan-Ketoglutarat (HTK/Custodiol囚/Bretschneider's) ........67

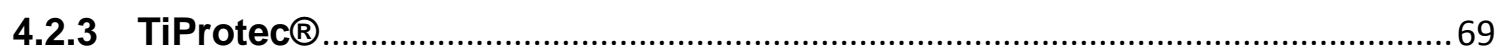

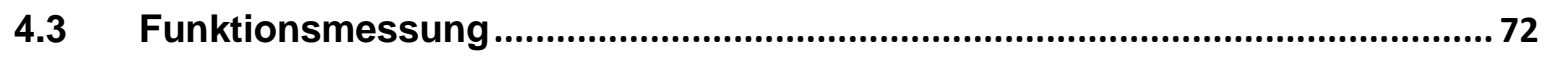

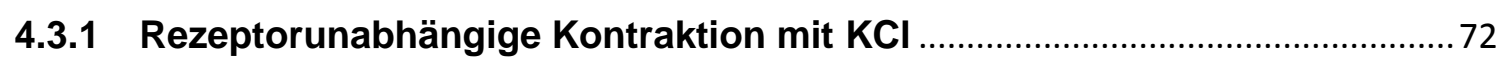


4.3.2 Rezeptorabhängige Kontraktion mit Phenylephrin ....................................... 73

4.3.3 Endothelunabhängige Dilatation mit Nitroprussid ........................................ 74

4.3.4 Endothelabhängige Dilatation mit Acetylcholin.............................................75

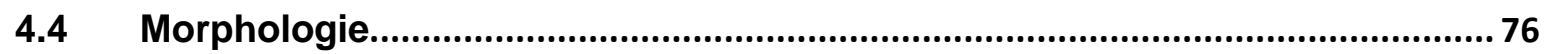

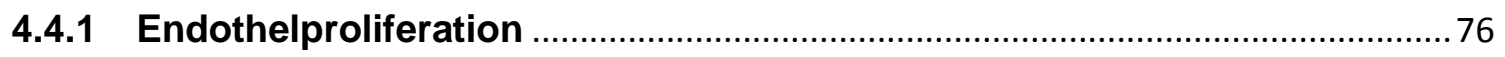

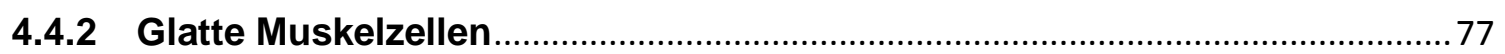

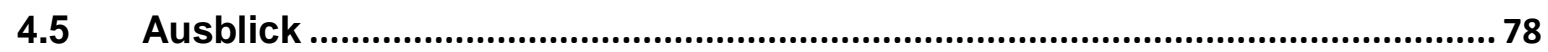

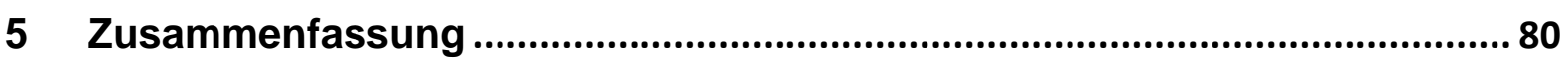

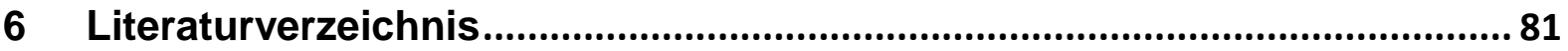




\section{Einleitung}

\subsection{Periphere arterielle Verschlusskrankheit}

\subsubsection{Definition und Epidemiologie}

Bei der peripheren arteriellen Verschlusskrankheit (pAVK) handelt es sich um eine Durchblutungseinschränkung der Extremitätenarterien beziehungsweise der Aorta (Diehm et al. 2004a; Espinola-Klein und Savvidis 2009). Dabei kommt es zu einer progressiven Stenose oder Okklusion der Arterien. Ursächlich ist in den meisten Fällen die chronische Arteriosklerose (Hirsch et al. 2001). Zu den selteneren Ursachen gehören Takayasu-Syndrom als Vaskulitis (Numano und Kobayashi 1999) und Thrombangiitis obliterans (Buerger 2009). Besonders betroffen sind die Gefäße der unteren Extremitäten (Wilkins 2006). Es wird dabei je nach betroffener Gefäßregion in absteigender Häufigkeit zwischen Becken-, Oberschenkelund Unterschenkeltyp unterschieden (Herold 2010). Je nachdem, ob nur eine Gefäßregion oder gleichzeitig mehrere Gefäßregionen betroffen sind, wird dabei von einer Einetagenoder Mehretagenerkrankung gesprochen. Die Restdurchblutung der Extremitäten ist abhängig von der Stenose- oder Verschlusslänge, Anzahl der betroffenen Gefäßetagen sowie der vorhandenen Kollateralgefäße (Herold 2010). Als Leitsymptom kommt es bei den Betroffenen in den Anfangsstadien ischämiebedingt $\mathrm{zu}$ belastungsabhängigen Muskelschmerzen, die in Ruhe sistieren (Norgren et al. 2007). Nach einer bestimmten Gehstrecke sind die Patienten gezwungen, eine Pause einzuhalten. Dieses Phänomen wird als Claudicatio intermittens bezeichnet. $\mathrm{Zu}$ den Risikofaktoren der pAVK gehören arterielle Hypertonie, Hyperlipoproteinämie, Diabetes mellitus und Nikotinabusus (Diehm et al. 2004a; Fowkes et al. 2013; Hirsch et al. 2001; Murabito et al. 2002; Ostchega et al. 2007). Die Betroffenen haben dabei einen oder mehrere dieser Risikofaktoren (Selvin und Erlinger 2004). Patienten mit einer auch asymptomatischen pAVK leiden häufiger an kardio- und zerebrovaskulären Erkrankungen (Stoffers et al. 1996; Newman et al. 1993; Fowkes et al. 1991). Atherosklerotische Veränderungen der unteren Extremität können z. B. mit einer asymptomatischen Carotisstenose assoziiert sein (Rancić et al. 2002). PAVK- Erkrankte haben auch ein erhöhtes Risiko, an kardiovaskulären Ereignissen zu sterben (Criqui et al. 1992; Diehm et al. 2006; Leng et al. 1996a). Ferner beschreibt Verhaeghe, dass die Mortalitätsrate bei den Patienten mit einer chronischen Extremitätenischämie 20 Prozent pro Jahr beträgt (Verhaeghe 1998). In den vergangenen Jahren hat die Prävalenz der pAVK 
weltweit deutlich zugenommen (Fowkes et al. 2013). Mit steigendem Lebensalter und vor allem bei Patienten älter als 70 Jahre (Hiatt et al. 1995; Selvin und Erlinger 2004) steigt die Prävalenz geschlechtsunabhängig auf etwa $20 \%$ (Diehm et al. 2004b; Ostchega et al. 2007; Meijer et al. 1998; Hirsch et al. 2001). Die globale Prävalenz der pAVK, definiert als Knöchel-Arm-Index $\leq$ 0,9, wurde 2010 auf 202 Millionen Menschen geschätzt (Leitlinie pAVK 2015; Fowkes et al. 2013). Angesichts des demografischen Wandels wird sich in den kommenden Jahren die moderne Medizin mit der Prävention und Therapie der pAVK zunehmend befassen müssen (Fowkes et al. 2013).

\subsubsection{Klinik und Einteilung der Schweregrade}

Die pAVK wird klinisch nach der Stadien-Einteilung von Fontaine eingeteilt (Leitlinie pAVK 2015). Im amerikanischen Raum sowie international wissenschaftlich wird jedoch die Einteilung nach Rutherford verwendet (s. Tabelle 1) (Rutherford et al. 1997). In den meisten Fällen bleibt die Erkrankung bei ausreichender Gefäßkollateralversorgung oder fehlender Belastbarkeit (Norgren et al. 2007) asymptomatisch (Hirsch et al. 2001; Criqui et al. 1985; Fowkes et al. 1991). Man spricht vom Anfangsstadium der pAVK. In den fortgeschrittenen Stadien treten zunächst belastungsabhängige Muskelschmerzen distal der verengten Gefäßregion auf. Nur ein geringer Anteil der Betroffenen leidet an dieser sogenannten Claudicatio intermittens (Meijer et al. 1998). Das Auftreten dieser Beschwerden ist mit einem hohen Sterberisiko verbunden (Bainton et al. 1994). Im Spätstadium kommt es bei circa 25 Prozent der symptomatischen Patienten zu Ruheschmerzen und im Endstadium bestehen zusätzlich Ulcerationen und Nekrosen als Zeichen einer kritischen Ischämie, was möglicherweise eine Amputation notwendig macht(Dormandy et al. 1999; Hertzer 1991; Meijer et al. 1998). Vor allem bei Diabetikern kommt es zu hohen Amputations- und Sterberaten (Malyar et al. 2016; Jude et al. 2010). 
Tabelle 1 Stadien-Einteilung der pAVK nach Fontaine und Rutherford (Leitlinie pAVK 2015). CLI: Claudicatio intermittens

\begin{tabular}{|l|l|l|l|l|}
\hline Fontaine & & \multicolumn{2}{|l|}{ Rutherford } & \\
\hline Stadium & klinisches Bild & Grad & Kategorie & klinisches Bild \\
\hline I & Asymptomatisch & 0 & 0 & Asymptomatisch \\
\hline Ill & Gehstrecke $>200 \mathrm{~m}$ & I & 1 & leichte CLI \\
\hline IIb & Gehstrecke $<200 \mathrm{~m}$ & I & 2 & mäßige CLI \\
\hline & & I & 3 & schwere CLI \\
\hline III & Ruheschmerz & II & 4 & ischämischer Ruheschmerz \\
\hline IV & Ulcus, Gangrän & III & 5 & kleinflächige Nekrose \\
\hline & & III & 6 & großflächige Nekrose \\
\hline
\end{tabular}

\subsubsection{Diagnostik}

Die Diagnostik basiert auf der Anamnese, der klinischen Untersuchung und dem KnöchelArm-Index (engl.: Ankle Brachial Index, ABI) (Diehm et al. 2004a; Hirsch et al. 2001; Leitlinie pAVK 2015). Dabei wird der systolische Blutdruck an beiden Oberarmen (Arteria brachialis) und distalen Unterschenkeln (Arteria tibialis posterior und Arteria dorsalis pedis) gemessen und das Verhältnis zwischen Knöchel und Oberarm der jeweiligen Seite ermittelt (Greenland et al. 2001; Crawford et al. 2016). Ein ABI höher 0,9 wird dabei als normal, kleiner 0,9 als Durchblutungsstörung angesehen, und zwar mit einer 95\%igen Sensitivität und 100\%igen Spezifität im Vergleich zur Angiographie (Fowkes 1988). Ein ABI von unter 1,40 zählt als Normalwert (Resnick et al. 2004). Von einer leichten Durchblutungsstörung wird gesprochen, wenn der ABI-Wert zwischen 0,9-0,75 liegt. Zwischen 0,75-0,5 ist von einer mittelschweren und bei Werten kleiner 0,5 von einer schweren Durchblutungsstörung auszugehen (Herold 2010). Bei Patienten mit Diabetes oder Niereninsuffizienz können Werte höher als 1,4 gemessen werden, da die Arterien dabei auf Grund von Mediasklerose auch bei Drücken von $300 \mathrm{mmHg}$ nicht zu komprimieren sind (Norgren et al. 2007). Der ABI wird auch zum pAVK-Screening empfohlen (Leng et al. 1996b; Hirsch et al. 2001; Allison et al. 2007). Ein reduzierter ABI weist auf eine schlechte kardiovaskuläre Prognose hin und sollte eine Abklärung und gegebenenfalls Therapie anderer atherosklerotischer Erkrankungen zur 
Folge haben (McKenna et al. 1991). Als bildgebendes Verfahren kommt die farbkodierte Duplexsonografie als Methode der ersten Wahl zum Einsatz (Leitlinie pAVK 2015). Die Sensibilität der Duplexsonographie wurde von Whelan et al. bezüglich einer Okklusion und Stenose mit $95 \%$ und $92 \%$, die Spezifität mit $99 \%$ und $97 \%$ angegeben (Whelan et al. 1992). Auch die postoperative Kontrolle vor allem der Vena saphena magna- Bypässe kann mittels Ultraschalluntersuchung erfolgen (Szilagyi et al. 1973). Eine Limitation der Sonographie stellen aber Tandemstenosen (Allard et al. 1994) sowie periphere Unterschenkelgefäße (Larch et al. 1997) dar. Liefert die farbkodierte Duplexsonographie keine eindeutigen Befunde, kommen zusätzliche bildgebende Verfahren in Frage (Leitlinie pAVK 2015). Die konventionelle Angiographie zählt als Goldstandard der Gefäßdarstellung, die es ermöglicht, die Lokalisation, die Ausdehnung und den Schweregrad der pAVK zu evaluieren (Oser et al. 1995; Xu et al. 2010). In den vergangenen Jahren wird aber diese jedoch als rein diagnostische Ma nahme aufgrund der hohen Sensitivität und Spezifitait von nicht-invasiven Verfahren wie Magnetresonanz-Angiographie, Duplexsonographie, und CTAngiographie zunehmend verdrängt (Collins et al. 2007; Loewe et al. 2002; Kreitner et al. 2000; Rofsky et al. 1997; Ouwendijk et al. 2005).

\subsubsection{Behandlung}

Die Behandlung der pAVK beinhaltet konservative Maßnahmen wie z. B. Gehtraining, Pharmakotherapie und Nikotinkarenz (Girolami et al. 1999; Mihaylova et al. 2005; Jones et al. 2013; Ameli et al. 1989; Quick und Cotton 1982; Aronow et al. 2003; Hirsch et al. 2006). Primärbehandlung sollte vor allem gegen die generalisierte Arteriosklerose gerichtet sein (Espinola-Klein et al. 2002). Mit zunehmender Symptomatik, Ruheschmerz, Ulcerationen oder Gangrän wird ein Extremitätenverlust wahrscheinlicher. Eine Ballonangioplastie ggf. mit Stentanlage oder offen chirurgische Revaskularisierung sollte bei diesen Patienten mit einer kritischen Extremitätenischämie erwogen werden (Dhaliwal und Mukherjee 2007; Aronow 2004). Welche Intervention durchgeführt werden muss, ist abhängig von den anatomischen Gegebenheiten der stenosierenden oder okkludierenden Läsion. Perkutane transluminale Angioplastie ist die Therapie der Wahl, wenn die Stenose fokal und kurzstreckig ist, längere Läsionen dagegen sollten mittels chirurgischer Revaskularisierung behandelt werden, um bessere Langzeitergebnisse zu erzielen (Ouriel 2001). Bei einem 
fortgeschrittenen Befund sollte eine Revaskularisation mittels Bypassanlage durchgeführt werden (Owen und Rob 1956).

\subsubsection{Revaskularisation}

Als Bypassmaterial und zur Gefäßrekonstruktion eignen sich mit besten Ergebnissen autologe Venen, darunter die Vena saphena magna(VSM)(Norgren et al. 2007; Tangelder et al. 2000; Arvela et al. 2012; Hunink et al. 1994). Diese kann dabei als free graft oder aber In-situBypass verwendet werden (Mamode und Scott 2000). Die VSM gilt dabei als besser geeignetes Graftmaterial bei Bypassanlagen unterhalb des Knies (Veith et al. 1986; Bergan et al. 1982). Des Weiteren fungieren frisch entnommene Venenstücke als Patches zur Gefäßrekonstruktion bei Gefäßdefekten (Kawase et al. 2016) oder traumatischen Gefäßverletzungen (Jawas et al. 2013). Auch nach einer Thrombendarteriektomie kann eine Patchplastik sinnvoll sein (Kalender et al. 2016). Ein weiteres Einsatzgebiet stellen die Tumor- und Transplantationschirurgie dar (Dirican et al. 2014; Orlić et al. 2008). Auch in der Koronarchirurgie verwendet man autologe Venen und Arterien als Bypassgrafts (Deb et al. 2012; Drouin et al. 2013). Nicht alle Patienten haben aber geeignete Gefäße zum autologen Transplantieren (Archie 1994). Sie können z. B. im Rahmen einer aortokoronaren VenenBypassoperation bereits entnommen sein. Variköse Gefäße können nicht verwendet werden und sind unter Umständen bereits gestrippt. Steht das autologe Gefäßmaterial auf Grund von Voroperationen oder Missmatch nicht zur Verfügung, wird in der Gefäßchirurgie gezwungenermaßen auf Kunststoffprothesen zurückgegriffen (Klinkert et al. 2004; Sayers et al. 1998; Takagi et al. 2010; Hayes et al. 2001; Naylor et al. 2004). Die Verwendung von Gefäßprothesen bringt aber einige Schwierigkeiten mit sich. Während der Einsatz der synthetischen Prothesen im Bereich größerer Gefäße gute Ergebnisse zeigt (O'Riordain et al. 1992), bleiben Langzeitergebnisse der kleinkalibrigen Gefäße ernüchternd (Albers et al. 2003). Ein Problem in diesem Zusammenhang stellt auch eine Protheseninfektion dar (Zeltsman et al. 1999). Multimorbide Patienten haben hier ein erhöhtes Infektionsrisiko (Greenblatt et al. 2011). Liegt nach einer initialen prothetischen Versorgung der Gefäße eine Protheseninfektion vor, können kryokonservierte Homografts implantiert werden (Bisdas et al. 2010). Diese Homografts sind jedoch nicht immer und nicht für alle Gefäße verfügbar. Zusätzlich entwickeln die kryokonservierten Homografts degenerative Veränderungen, die nicht unerheblich sind (Rendal-Vázquez et al. 2012). Angesichts dieser Problematik besteht 
ein hoher Bedarf an Gefäßbanken mit optimierten Konservierungsmethoden für Venen und Arterien.

\subsection{Aufbau einer Gefäßwand}

Die Wand größerer Arterien und Venen besteht aus drei Schichten. Die Tunica intima stellt die innere Auskleidung der Gefäßwand, die aus einem einschichtigen Plattenepithel besteht, dar (s. Abbildung 1). Diese Endothelzellen sind in Blutflussrichtung ausgestreckt und liegen auf einer Basalmembran und subendothelialen Bindegewebsschicht, der Membrana elastica interna (Kühnel 2014). Die Tunica media besteht aus einer Schicht ringförmig angeordneter glatter Muskelzellen, die durch die Membrana elastica interna vom Endothel und durch die Membrana elastica externa von der Adventitia begrenzt werden (Kühnel 2014). Die Tunica adventitia ist das lockere, das Gefäß umgebende Bindegewebe, welches Blutgefäße zur Gefäßwandversorgung und Nerven enthalten kann (Witter et al. 2017). 


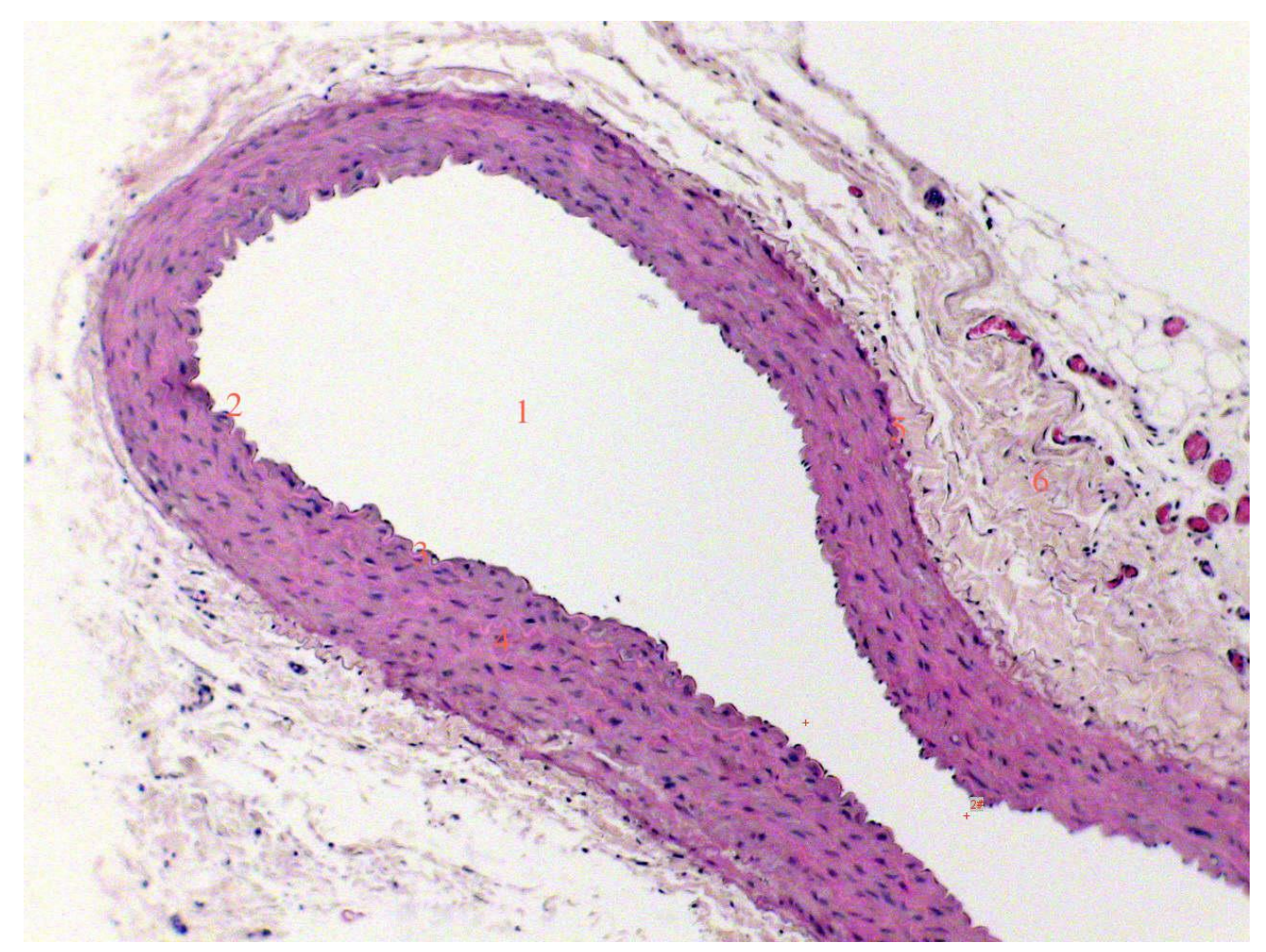

Abbildung 1: Querschnitt der Aorta abdominalis (Wistar-Ratte, Eigenpräparat, Vergrößerung: 40x). HE-Färbung. (1) Gefäßlumen, (2) Tunica intima, (3) Membrana elastica interna, (4) Tunica media, (5) Membrana elastica externa, (6) Tunica adventitia.

\subsection{Endothelfunktion, Endotheldysfunktion}

Das Endothel spielt eine entscheidende Rolle bei der Interaktion zwischen dem Gefäß und dem darin fließenden Blut (Lüscher und Barton 1997). Es produziert vasoaktive Mediatoren und enthält verschiedene gefäßtonusregulierende Rezeptoren. Diese Rezeptoren aktivieren Endothelzellen, die wiederum weitere Mediatoren ausschütten (Mombouli und Vanhutte 1999). Vane beschreibt, dass die Endothelzellen durch Interaktion mit weißen Blutkörperchen, Thrombozyten, Plasmabestandteilen oder aber durch Blutdruckveränderungen zur Sekretion angeregt werden (Vane und Botting 1992). Dadurch kann die Kontraktion der glatten Gefäßmuskelzellen aktiviert oder inhibiert werden (Gris et al. 1991). Solche Mediatoren sind z. B. das Endothelin mit vasokonstriktorischem Effekt und Prostacyclin oder endothelium-derived relaxation factors (EDRF) mit vasodilatatorischem Effekt (Botting und Vane 1989). Prostazyklin und EDRF, der als Stickstoffmonoxid (NO) identifiziert wurde und von der NO-Synthase aus Arginin gebildet wird, inhibieren zusätzlich die Thombozyten- und Leukozytenaggregation und -adhäsion (Vane und Botting 1992; 
Warner 1996). Das Endothel ist somit ein komplexes Organ mit seinen drei Hauptmediatoren: Endothelin, Prostazyklin und tissue-plasminogen activator (tPA), das nicht nur an der Gefäßtonusregulation sondern auch an der Endothelpermeablität, Blutkoagulation, Leukozyten- und Thrombozyten- Reaktivität, Hemmung der Gefäßmuskelproliferation, Fibrinolyse, Angiogenese und Phagozytose beteiligt ist (Thiemermann 1991; Gryglewski 1995). Endothelfunktionstörungen sind mit kardiovaskulären Erkrankungen und Artherosklerose assoziert (Cahill und Redmond 2016). Es kommt zu funktionellen und morphologischen Veränderungen des Endothels mit erhöhter Permeablität und Thrombogenität sowie Interaktionen zwischen den Blutzellen (Faggiotto et al. 1984). Eine intakte Endothelschicht ist somit für die Gefäßfunktion von großer Bedeutung. Eine unversehrte Intima kann folglich bei Gefäßtransplantationen mit einem besseren Outcome einhergehen (Adcock et al. 1984). Daher hat der Schutz des Endothels und damit der Intima während einer Lagerung höchste Priorität.

\subsubsection{Intimahyperplasie}

Endothelzellen spielen eine wichtige Rolle bei der Entwicklung von Intimahyperplasie (Schwartz et al. 1990). Im Rahmen einer Manipulation an der Gefäßwand z. B. durch eine Angioplastie oder Bypassoperation kommt es zwangsläufig zur Endothelverletzung (Ip et al. 1990). Dies führt im weiteren Verlauf zur Migration und Ablagerung der glatten Gefäßmuskelzellen von der Media in die betroffene Intimaregion (Dilley et al. 1992; Newby und Zaltsman 2000). Durch die Ablagerung von glatten Gefäßmuskelzellen und Fibroblasten in der Intima kommt es zu einer Gefäßlumenreduktion (Geary et al. 1994; Zubilewicz et al. 2001). Diese Intimaläsionen entstehen üblicherweise innerhalb der ersten sechs Monate nach einem Eingriff und können später nach Thrombenablagerungen arteriosklerotische Plaques verursachen (Clagett et al. 1986). Infolge dieser Ablagerungen kann es zu einer Gefäßokklusion und damit einem Bypassversagen kommen (Davies und Hagen 1994).

\subsubsection{Arteriosklerose}

Endothelverletzungen führen infolge des Heilungsversuchs zu einem Prozess, der Arteriosklerose verursachen kann (Ross und Harker 1976). Es kommt dabei zunächst zu einem lokalen Endothelverlust, Freilegung des subendothelialen Gewebes sowie 
Plättchenadhäsion. Durch Interaktion zwischen Thrombozyten, Endothelzellen und subendothelialer Schicht sezernieren die Thrombozyten platelet-derived growth factor (PDGF), der die Desoxyribonukleinsäure(DNA)-Synthese, die Proliferation der glatten Gefäßmuskelzellen sowie der Fibroblasten (Ross 1979; Ross et al. 1977) induziert. Die glatten Muskelzellen produzieren und sezernieren wiederum Kollagen, Elastin und Proteoglykane als Bestandteile der atheromatösen Plaques (Munro und Cotran 1988). Chronische Hyperlipidämie kann dabei verantwortlich für die Endothelschädigung sein (Ross und Harker 1976). Weitere Risikofaktoren wie z. B. Rauchen, arterielle Hypertonie oder Infektionen können ebenfalls ursächlich für diesen Schaden sein (Harker et al. 1981). Hyperlipidämie selbst kann aber auch ohne weitere Risikofaktoren durch Invasion der Monozyten und Makrophagen in die Zellwand (Campbell und Campbell 1989) und Ablagerung der Lipoproteine in der Intima (Moore 1985) zur Entstehung der atheromatösen Plaques beitragen.

\subsection{Gefäßkonservierung}

\subsubsection{Kaltlagerung}

Die ersten Versuche einer isolierten Organkonservierung und Organperfusion wurden bereits Mitte bis Ende des 19. Jahrhunderts unternommen. Loebel 1849 und Langendorf 1895 gehörten zu den Vorreitern auf diesem Gebiet. Lindbergh und Carrel beschrieben Anfang des 20. Jahrhunderts erstmalig eine Kaltlagerung der Organe und entwickelten eine Perfusionsapparatur (Mouzas 1967). Mitte des 20. Jahrhunderts wurden in der ehemaligen UdSSR Transplantationen von Extremitäten und Nieren durchgeführt, die zuvor bei $2-4{ }^{\circ} \mathrm{C}$ kaltgelagert waren (Lapchinsky 1960). 1967 etablierten Belzer und seine Kollegen eine kontinuierliche Maschinenperfusion mit University-of-Winsconsin-Lösung und konnten damit eine verlängerte Konservierung der Nieren und in den folgenden Jahren Leber und Pankreas erreichen (Belzer und Southard 1988). Collins et al. beschrieben 1969 die einfache Kaltlagerung zur Organkonservierung in einer von ihnen zusammengesetzten Lösung, genannt „Collins solution“ (Collins et al. 1969). Die einfache Anwendung dieser Methode

führte dazu, dass diese von vielen Transplantationszentren weltweit übernommen wurde (Belzer und Southard 1988). Perfusionslagerung beinhaltet eine kontinuierliche Infusion einer 
kalten Konservierungslösung durch das entnommene Organ (Wicomb et al. 1982). Zahlreiche experimentelle Studien haben bisher die Überlegenheit dieser Methode gegenüber der einfachen Kaltlagerung in einer Konservierungslösung gezeigt (Qayumi et al. 1991; Nutt et al. 1992). Dennoch ist die einfache Kaltlagerung heute in der Klinik weit verbreitet.

Hypothermie soll die Stoffwechselprozesse in der Zelle verlangsamen und einem Substratmangel entgegenwirken (Buckberg 1991). Neuere Untersuchungen zeigen jedoch, dass Kaltlagerung selbst zu einem Endothelschaden führen kann (s. Abbildung 2). Diese kälteinduzierte Endothelschädigung wird durch oxidative Wirkung von Eisen verursacht (Wille et al. 2008; Zatschler et al. 2009; Radovits et al. 2008).

\section{Hypothermie $0-4{ }^{\circ} \mathrm{C}$}
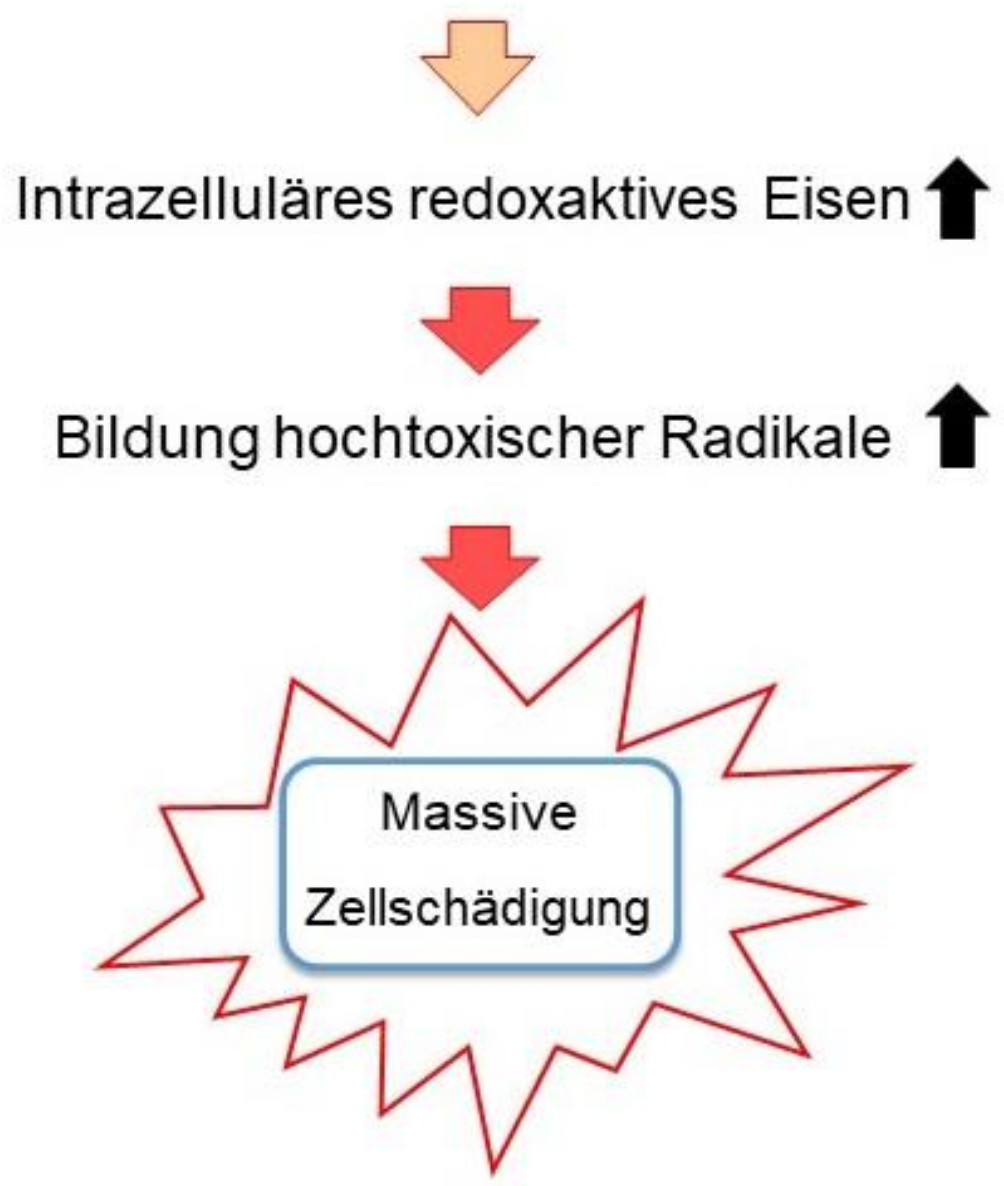

Abbildung 2: Mechanismus der kälteinduzierten eisenabhängigen Schädigung. (modifiziert nach Wille et al. 2008) 


\subsubsection{Konservierungslösungen, Organprotektionslösungen}

Die Zusammensetzung der ersten Konservierungslösungen hatte drei Ziele. Die Verlangsamung des Metabolismus durch Hypothermie, die Sicherstellung einer physikalisch und biochemisch lebensfähigen Umgebung für das Gewebe sowie die Minimierung des Reperfusionstraumas (Belzer und Southard 1988). Konservierungslösungen zur Kaltlagerung werden abhängig von ihrer Natrium- und Kaliumionenkonzentration in intrazelluläre und extrazelluläre Zusammensetzungen eingeteilt (Jahania et al. 1999). Weitere Zusätze und Puffer, angepasst an die Bedürfnisse einzelner Organe, sollen den Hypothermie- und Hypoxieschaden gering halten. Die Zellen befinden sich normalerweise in einer extrazellulären Umgebung mit hoher Natrium- und niedriger Kaliumkonzentration. Dieses Verhältnis wird durch die Natrium-/Kalium-ATPase unter Energie- bzw. ATP-Verbrauch aufrechterhalten. Während der anaeroben Kaltlagerung und bei fehlender Energie kann dieses Ionenverhältnis nicht mehr sichergestellt werden. Natrium und Chlorid durchdringen die Zellen entlang des Konzentrationsgefälles, gefolgt vom Wasser. Dies führt zu einem Zellödem (Belzer und Southard 1988; Hochachka 1986). Die Konservierungslösungen enthalten daher Kolloide, um den osmotischen Druck um die Zelle stabil zu halten und somit einer Ödembildung entgegenzuwirken. Während der Ischämiezeit ist zusätzlich die anaerobe Glykolyse stimuliert. Es kommt zu einer vermehrten Laktatbildung, die nicht nur zu einer Zellschädigung, sondern auch Makrophagenaktivierung führen kann. Dies kann wiederum eine Zytokinausschüttung und schließlich eine inflammatorische Reaktion zur Folge haben (Jahania et al. 1999). Mittels Pufferzugabe wie Natriumbicarbonat, Magnesiumsulfat oder Histidin in die Konservierunglösung kann die Lactatdehydrogenase und somit die Laktatbildung gedrosselt werden. Die angesammelten anaeroben Metaboliten bilden schließlich während der Reperfusion mit wiederhergestellter Sauerstoffversorgung freie Sauerstoffradikale (Rauen und de Groot 2004). In der Gefäß- sowie Koronarchirurgie werden Gefäßtransplantate kurzzeitig in der kalten physiologischen Kochsalzlösung, im autologen, heparinisierten Vollblut oder in Ringerlösung konserviert (Desai et al. 2007; Schaeffer et al. 1997). Ziel ist dabei, eine Endothelaktivierung mit resultierender chronischer Inflammation und schließlich einen Gefäßverschluss zu verhindern (Schaeffer et al. 1997). Zahlreiche Invitro- sowie tierexperimentelle Studien zeigen jedoch keine eindeutige Überlegenheit von heparinisiertem Vollblut gegenüber der 0,9\%igen Natriumchloridlösung zur Gefäßkonservierung (Tsakok et al. 2012). Ferner konnte in mehreren Studien gezeigt werden, dass keine der beiden Lösungen einen ausreichenden Endothelschutz gegen kalte Ischämie 
und warme Reperfusion bieten kann (Veres et al. 2015; Wilbring et al. 2011). Alternativ werden auch Konservierungslösungen, die aus der Transplantationschirurgie bekannt sind, verwendet (Abrahamse et al. 2002). Zatschler konnte zeigen, dass die Histidin-TryptophanKetoglutarat-Lösung (HTK) nicht zur längeren Gefäßkonservierung geeignet ist (Zatschler et al. 2009). Auch die University-of-Wisconsin-Solution konnte einen erheblichen Endothelschaden nicht verhindern (Wille et al. 2008). Um den Erfordernissen der Gefäßprotektion gerecht zu werden, entwickelte die Gruppe um Wille und Rauen 2008 auf dem Boden der HTK-Lösung mit weiteren Zusätzen zur längeren Gefäßkonservierung die neue Gefäßprotektionslösung TiProtec $\AA$.

\subsubsection{TiProtec $®$}

Die auf der Basis von der Histidin-Tryptophan-Ketoglutarat-Lösung (HTK) und modifizierten HTK-N hergestellte TiProtec $®$-Lösung ist speziell zur Gefäßkonservierung weiterentwickelt worden. Der darin enthaltene lipophile Eisenchelator LK 614 bindet intrazelluläres Eisen (Wille et al. 2008). Dadurch wird verhindert, dass durch die Kaltlagerung eisenabhängige Sauerstoffradikale entstehen und zur Zellschädigung führen. Hohe Kalium- und Chloridkonzentrationen erwiesen sich günstig zur Endothelprotektion, so dass beide Substanzen in TiProtec ${ }^{\circledR}$ höher dosiert enthalten sind (Wille et al. 2011; Zatschler et al. 2009). Aminosäuren Glycin und Alanin sollen die Porenbildung an der Zellwand und damit den Natriumeinstrom in die Zelle verhindern (Rauen und de Groot 2004). NAcetylhistidin wurde bevorzugt bei fehlender Toxizität im Vergleich zum Histidin (Rauen et al. 2007). Glukose hat sich für die glykolytisch hoch aktiven Endothelellen als nutzvoll erwiesen (Mertens et al. 1990). Schließlich wirkte sich der saure PH-Wert von 7,0 positiv auf die Zellvitalität (Nishimura et al. 1998) aus. Die positive Auswirkung von TiProtec $®$ auf die Endothelfunktion konnte bisher in einigen In-vitro-Studien gezeigt werden (Zatschler et al. 2009).

\subsubsection{Natriumchlorid $(\mathrm{NaCl})$}

Verwendung findet die plasmaisotone Natriumchloridlösung in der Klinik als häufig eingesetzte Infusionslösung (Krotkiewski 2015). Sie beinhaltet im Vergleich zum Blutserum einen hohen Anteil an Chloridionen. Dadurch kann sie unter Umständen zu einem Chloridüberschuss im Blut führen (Lobo und Awad 2014). Eine hyperchlorämische 
metabolische Azidose wäre die Folge (Dombre et al. 2016). Ferner kann ihre Verwendung mit einem akuten Nierenversagen assoziiert sein (Young et al. 2015). Auch die Natriumkonzentration der isotonen $\mathrm{NaCl}$ ist relativ hoch. Da jedoch im Blut weitere geladene Teilchen vorhanden sind, kommt es zu keiner Elektrolytverschiebung zwischen dem Intraund Extrazellularraum. Pur oder heparinisiert wird die Natriumchloridlösung auch für kurzzeitige Konservierung von frisch entnommenen Gefäßen in der kardiovaskulären Chirurgie verwendet (Schaeffer et al. 1997).

\subsubsection{Histidin-Tryptophan-Ketoglutarat (HTK)}

HTK wurde in den 1970ern von Bretschneider beschrieben (Bretschneider et al. 1975). Es handelt sich dabei um eine kristalloide Lösung mit niedriger Natrium- und Kalziumkonzentration. Eine hohe Histidinkonzentration dient als Puffer, um der Azidose durch angesammelte anaerobe Metaboliten während der Ischämiezeit entgegenzuwirken. Ketoglutarat verbessert die ATP- Bildung während der Reperfusion. Tryptophan stabilisiert die Zellmembran, Mannitol reduziert die Zellödementstehung und neutralisiert die freien Radikale (Bretschneider 1980). Custodiol ${ }^{\circledR}$ hat auch bei niedrigen Temperaturen eine niedrige Viskosität. Dies erlaubt hohe Flussraten bei der Organperfusion und ermöglicht damit eine schnelle Kühlung des Organs (Köhler Chemie 1999). Vor allem in der Kardiochirurgie ist HTK besonders attraktiv, da eine einzige Dosis einen ausreichenden Myokardschutz von über drei Stunden bieten soll (Bretschneider 1980; Gebhard et al. 1984). Diese ursprünglich in der Kardiochirurgie weit verbreitete Lösung zur Kardioplegie ist auch in der Transplantationsmedizin zur Konservierung, Perfusion und Spülung von Herz, Leber, Niere und Pankreas zugelassen und in Europa weit verbreitet (Reichenspurner et al. 1993; Hölscher und Groenewoud 1991).

\subsubsection{Kryokonservierung}

Fehlen bei kardiovaskulären Eingriffen oder im Rahmen von Transplantationen autologe Gefäße, kommen Homografts von einem fremden Spender aus Gewebebanken infrage. Es handelt sich dabei meist um Proben von einem toten Spender bei einer Multiorganentnahme. Nach der europäischen Geweberichtlinie 2004 sind dabei vorab Maßnahmen und Standards für die Spende, Beschaffung, Testung, Verarbeitung, Konservierung und Lagerung der 
Gewebeproben vorgeschrieben (Richtlinie (EU) 2015/566 2015). Nach dieser Richtlinie dürfen nur sterile Transplantate eingesetzt werden. Die Gefäße müssen daher nach Entnahme antibiotisch behandelt und auf Krankheitserreger getestet werden (Ebner et al. 2011). Nach Durchlaufen der vorgeschriebenen Sterilisierung, die mehrere Tage in Anspruch nimmt, werden die Blutgefäße nach gewebe- und zentrumspezifischen Protokollen bearbeitet und bei Temperaturen um $-190{ }^{\circ} \mathrm{C}$ tiefgefroren. Das Protokoll gibt z. Bsp. vor, welches Kryoprotektivum das Gewebe umgeben soll. Auch die Ein- und Auftaugeschwindigkeit wird festgelegt. Dabei wird das Gefäß z. B. um $-1{ }^{\circ} \mathrm{C} / \mathrm{min}$ auf ca. $-70{ }^{\circ} \mathrm{C}$ gekühlt und in flüssigen Stickstoff überführt (Müller-Schweinitzer 2009; Ramos et al. 2014). Der Zellstoffwechsel wird bei diesen Temperaturen komplett heruntergefahren. Ziel ist dabei, das Gefäß mit möglichst erhaltener Struktur und Funktion unbegrenzt haltbar zu machen (MüllerSchweinitzer et al. 1997). Die Verwendung von kryokonservierten Homografts bringt aber einige Probleme mit sich. Degenerative Veränderungen der explantierten Homografts konnten histopathologisch nachgewiesen werden. Auch Rupturen und Pseudoaneurysmen werden beschrieben (Bustamante et al. 2009). Bisdas et al. konnten im Rahmen der postoperativen Kontrolle nach AB0-inkompatiblen Homograftimplantation einen CRPAnstieg als eine frühe Immunantwort zeigen (Bisdas et al. 2011). Rendal-Vàzquez et al. beschreibt eine ausgeprägte Gefäßwandfibrose und Intimaverdickung, die durch eine Immunreaktion verursacht sind (Rendal-Vázquez et al. 2012; Vogt et al. 1999). Eine Lymphozyteninfiltration als immunologische Reaktion konnte auch in Tierversuchen nachgewiesen werden (Neves et al. 1997). 


\subsection{Fragestellung dieser Arbeit}

Ziel dieser experimentellen Arbeit ist die vergleichende Untersuchung von langzeitkonservierten Rattenaorten in Natriumchlorid, HTK (Custodiol-N®) oder der

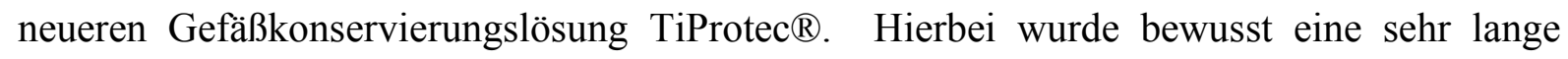
Ischämiezeit gewählt, um den protektiven Effekt sicher zeigen zu können. Anhand morphologischer Untersuchung, Funktionsmessung und immunhistochemischer Untersuchung der Aortensegmente sollen folgende Fragen beantwortet werden:

- Welche Veränderungen der Endothelschicht sind zeitabhängig nachweisbar?

- Kommt es zu Funktionseinschränkungen nach einer langen Konservierung?

- Gibt es eine immunhistochemische Korrelation zu den morphologischen und funktionellen Veränderungen?

- Bietet TiProtec $®$ als Gefäßkonservierungsmedium einen besseren Schutz für Gefäße?

- Können die Ergebnisse dieser tierexperimentellen Studie auf humane Gefäße übertragen werden 


\section{Materialien und Methoden}

\subsection{Materialien}

\subsubsection{Chemikalien, Medikamente}

Acetycholine chloride

Aqua bidestillata

Aqua destillata

Aqua Spüllösung

Buprenorphin Temgesic $®$ 0,3mg/ml

Calciumchlorid

Chloralhydrat

Chloroform

Citronensäure

$\mathrm{D}(+)$-Glucose wasserfrei

Eisessig

Entellan

Eosin

Ethanol

Formalin

Isofluran

Hämatoxylin kristallisiert

Heparin
Sigma, Taufkirchen, Deutschland

Serag-Wiessner, Naila, Deutschland

Merck Millipore, Darmstadt, Deutschland

Braun, Melsungen, Deutschland

Remedix, Koblenz, Deutschland

Sigma, Taufkirchen, Deutschland

Merck, Darmstadt, Deutschland

Merck Millipore, Darmstadt, Deutschland

Merck, Darmstadt, Deutschland

Roth, Karlsruhe, Deutschland

Merck Millipore, Darmstadt, Deutschland

Merck, Darmstadt, Deutschland

Merck, Darmstadt, Deutschland

Merck Emprove, Darmstadt, Deutschland

Merck Millipore, Darmstadt, Deutschland

ABBOTT GmbH, Wiesbaden, Deutschland

Merck, Darmstadt, Deutschland

Rotexmedica, Trittau, Deutschland 
Histidin-Tryptophan-Ketoglutarat

(Custodiol-N®)

Indometacin

Kalialaun

Kaliumchloridlösung

Magnesiumchlorid

Natriumchlorid

Natriumhydrogencarbonat

Natriumhydrogenphosphat-Dihydrat

Natrium-Jodat

Natriumsulfat

Nitroprussid-Natrium

Novaminsulfon $500 \mathrm{mg} / \mathrm{ml}$

Phenylepinephrin

Paraffin

Sauerstoff

Tiprotec ${ }^{\circledR}$

Xylol
Köhler Chemie, Bensheim, Deutschland

Sigma, Steinheim, Deutschland

Merck, Darmstadt, Deutschland

Roth, Karlsruhe, Deutschland

Roth, Karlsruhe, Deutschland

Roth, Karlsruhe, Deutschland

Sigma, Steinheim, Deutschland

Merck, Darmstadt, Deutschland

Merck, Darmstadt, Deutschland

Merck, Darmstadt, Deutschland

Sigma, Taufkirchen, Deutschland

Ratiopharm, Ulm, Deutschland

Sigma, Steinheim, Deutschland

Merck Millipore, Darmstadt, Deutschland

Air Liquide, Düsseldorf, Deutschland

Köhler Chemie, Bensheim, Deutschland

Merck Millipore, Darmstadt, Deutschland 


\subsubsection{Lösungen}

Krebs-Henseleit-Lösung:

6,785 g NaCl, 0,373 g KCl, 0,244 g MgCl 2x6 H2 1,8 g Glucose, $1,7 \mathrm{~g} \mathrm{NaHCO}_{3}, 250 \mu 1 \mathrm{M} \mathrm{CaCl}_{2}$ auf 1 Liter Aqua destillata aufgefüllt.

Mayers saures Hämatoxylin:

$1 \mathrm{~g}$ Hämatoxylin kristallisiert wurde in $750 \mathrm{ml}$ Aqua bidest. gelöst, 0,2 g Natrium-Jodat, $50 \mathrm{~g}$ Kalialaun, $50 \mathrm{~g}$ Chloralhydrat, $1 \mathrm{~g}$ Citronensäure hinzugefügt und auf $1000 \mathrm{ml}$ mit Aqua bidestillata Aufgefüllt

Histidin-Tryptophan-Ketoglutarat (HTK), Custodiol ${ }^{\circledR} \quad$ (Köhler Chemie, Bensheim), Zusammensetzung in $1000 \mathrm{ml}$ :

\begin{tabular}{lcc} 
Substanz & $\mathrm{mg}$ & $\mathrm{mmol}$ \\
\hline Natriumchlorid & 0,8766 & 15 \\
Kaliumchlorid & 0,671 & 9 \\
Magnesiumchlorid x 6 H2O & 0,8132 & 4 \\
L-Histidinchlorid x H2O & 3,7733 & 18 \\
L-Histidin & 27,9289 & 180 \\
Tryptophan & 0,4085 & 2 \\
Mannitol & 5,4651 & 30 \\
2- Oxoglutarsäure & 0,146 & 1 \\
Calciumchlorid x 2 H2O & 0,0022 & 0,015 \\
\hline
\end{tabular}

Der pH-Wert liegt bei $25^{\circ} \mathrm{C}$ bei 7,02 - 7,20. (Die Osmolalität beträgt $310 \mathrm{mosmol} / \mathrm{kg}$.)

Die fertig gelieferte Custodiol ist in Glasdurchstechflaschen zu $500 \mathrm{ml}$ oder $1000 \mathrm{ml}$ oder in Kunststoffbeutel zu 1000 ml, 2000 ml oder 5000 ml erhältlich. 
TiProtec ${ }^{\circledR}$ (Köhler Chemie, Bensheim), Zusammensetzung in 1000 ml:

\begin{tabular}{lc} 
Substanz & $\mathrm{mg} / \mathrm{l}$ \\
\hline L- Asparaginsäure & 690 \\
Deferoxamin & 50 \\
$\approx$ Deferoxamin mesilat & 53 \\
L- Tryptophan & 420 \\
Natriumchlorid & 850 \\
Magnesiumchlorid 6-Wasser & 169 \\
Kaliumchlorid & 564 \\
L-Alanin & 460 \\
Dinatrium-Hydrogenphosphat & 150 \\
Glucose wasserfrei(Zusatz) & 180 \\
$\approx$ Glucose 1-Wasser(Zusatz) & 198 \\
Calciumchlorid 2-Wasser & 1 \\
Glycin & 780 \\
2-Oxoglutarsäure & 300 \\
Acetylhistidin 1-Wasser & $671 \mathrm{n}$ \\
N-Hydroxy-3-4-dimethoxy-N-methylbenzamid & 3,5 \\
\hline
\end{tabular}

Erhältlich ist TiProtec ${ }^{\circledR}$ in Kunststoffbeuteln zu 100 oder $500 \mathrm{ml}$. Die mitgelieferte 3,7 ml oder 18,5 ml Glukoselösung soll vor Gebrauch hinzugefügt werden. 
Herstellung der Stocks von Acetylcholi, Nitroprussid, Phenylephrin:

Acetylcholin

0,54498 g Acetylcholin-Chlorid gelöst in $30 \mathrm{ml}$ Aqua destillata, Konzentration 0,1 mol/1

\section{Nitroprussid}

0,148975 g Sodium-Nitroprussid gelöst in $50 \mathrm{ml}$ Aqua destillata, Konzentration 0,01 mol/1

Phenylepinephrin

0,016721 g Phenylephrin gelöst in $10 \mathrm{ml}$ Aqua destillata, Konzentration 0,01 mol/1

Nach Herstellung von Stocklösungen wurden die jeweiligen Verdünnungsreihen schrittweise wie folgt fertiggestellt:

Durch Zugabe von $10 \mu \mathrm{l}$ Acetylcholin mit der Konzentration $1 \times 10^{-1} \mathrm{~mol} / 1$ in $990 \mu \mathrm{KHS}$ konnte eine Verdünnung mit der Endkonzentration $1 \times 10^{-3} \mathrm{~mol} / \mathrm{l}$ bereitgestellt werden. Die folgende Tabelle zeigt die gesamte Verdünnungsreihe:

Tabelle 2: Verdünnungsreihe Acetylcholin (Ach)

\begin{tabular}{|c|c|c|c|c|}
\hline Endkonzent. Ach mol/l & $\mathrm{V}$ gesamt $\mu \mathrm{l}$ & V KHS $\quad \mu \mathrm{l}$ & $\mathrm{V}$ Ach $\mu \mathrm{l}$ & $\begin{array}{l}\mathrm{c} \text { Ach } \\
\mathrm{mol} / 1\end{array}$ \\
\hline $1 \times 10^{-3}$ & 1000 & 990 & 10 & $1 \times 10^{-1}$ \\
\hline $1 \times 10^{-4}$ & 1000 & 900 & 100 & $1 \times 10^{-3}$ \\
\hline $1 \times 10^{-5}$ & 1000 & 900 & 100 & $1 \times 10^{-4}$ \\
\hline $1 \times 10^{-6}$ & 1000 & 900 & 100 & $1 \times 10^{-5}$ \\
\hline $1 \times 10^{-7}$ & 1000 & 900 & 100 & $1 \times 10^{-6}$ \\
\hline
\end{tabular}


Durch Zugabe von $50 \mu \mathrm{l}$ Sodium-Nitroprussid mit der Konzentration $1 \times 10^{-2} \mathrm{~mol} / 1$ in $450 \mu \mathrm{l}$ KHS konnte eine Verdünnung mit der Endkonzentration $1 \times 10^{-3} \mathrm{~mol} / 1$ bereitgestellt werden. Die folgende Tabelle zeigt die gesamte Verdünnungsreihe:

Tabelle 3: Verdünnungsreihen Sodium-Nitroprussid (SNP)

\begin{tabular}{ccccc}
\hline & & & \\
Endkonzen. SNP mol/1 & V gesamt $\mu \mathrm{l}$ & V KHS $\mu \mathrm{l}$ & V SNP $\mu \mathrm{c}$ & $\begin{array}{r}\mathrm{cSNP} \\
\mathrm{mol} / 1\end{array}$ \\
$1 \times 10^{-3}$ & 500 & 450 & 50 & $1 \times 10^{-2}$ \\
$1 \times 10^{-4}$ & 500 & 450 & 50 & $1 \times 10^{-3}$ \\
$1 \times 10^{-5}$ & 500 & 450 & 50 & $1 \times 10^{-4}$ \\
$1 \times 10^{-6}$ & 500 & 450 & 50 & $1 \times 10^{-5}$ \\
$1 \times 10^{-7}$ & 500 & 450 & 50 & $1 \times 10^{-6}$ \\
\hline
\end{tabular}

Durch Zugabe von $100 \mu$ Phenylephrine mit der Konzentration $1 \times 10^{-2} \mathrm{~mol} / \mathrm{l}$ in $900 \mu \mathrm{KHS}$ konnte eine Verdünnung mit der Endkonzentration $1 \times 10^{-3} \mathrm{~mol} / 1$ bereitgestellt werden. Die folgende Tabelle zeigt die gesamte Verdünnungsreihe:

Tabelle 4: Verdünnungsreihe Phenylephrine (PE)

$\begin{array}{ccccc}\text { Endkonz. PE mol/1 } & \text { V gesamt } \mu \mathrm{l} & \text { V KHS } \mu \mathrm{l} & \mathrm{V} \mathrm{PE} \mu \mathrm{l} & \mathrm{c} \mathrm{PE} \mathrm{mol} / 1 \\ & 1000 & 900 & 100 & 1 \times 10^{-2} \\ 1 \times 10^{-3} & 1000 & 900 & 100 & 1 \times 10^{-3} \\ 1 \times 10^{-4} & 1000 & 900 & 100 & 1 \times 10^{-4} \\ 1 \times 10^{-5} & 1000 & 900 & 100 & 1 \times 10^{-5} \\ 1 \times 10^{-6} & & \end{array}$




\subsubsection{Geräte, Software}

Analysis 3.2

Einbettautomat

Fotokamera

Isofluran-Verdampfer

Kühlschrank

Kühlplatte

LabView 6.0

Lichtquelle KL 1500

Mikroskop BH 2

Pinzette

Pipetten

Schlittmikrotom SM 2000R

Thermokoagulationsgerät

Timer

Vortexmischer

Waage

Wärmeplatte

Wasserbad

Wärmeschrank
Soft imaging System, Münster, Deutschland

Leica, Wetzlar, Deutschland

Olympus 4.1, Tokio, Japan

Dräger, Lübeck, Deutschland

Liebherr, Kirchdorf, Deutschland

Leica, Wetzlar, Deutschland

National Instruments, Austin, USA

Schott, Mainz, Deutschland

Olympus, Tokio, Japan

Dumont, Montignez, Schweiz

Eppendorf, Hamburg, Deutschland

Leica, Wetzlar, Deutschland

Erbe, Tübingen, Deutschland

TFA Dostmann, Wertheim, Deutschland

Scientific Industries, New York, USA

Sartorius, Göttingen, Deutschland

MEDAX Nagel, Kiel, Deutschland

Lauda, Königshofen, Deutschland

Memmert, Schwabach, Deutschland 


\subsubsection{Verbrauchsmaterialien}

$\begin{array}{ll}\text { Material } & \text { Hersteller } \\ \text { Mikrotom-Blades S35 } & \text { Feather, Osaka, Japan } \\ \text { Nylon 8/0 } & \text { Serag Wiessner, Naila, Deutschland } \\ \text { Objektträger } & \text { Menzel, Braunschweig, Deutschland } \\ \text { Safe lock tubes } & \text { Eppendorf, Hamburg, Deutschland } \\ \text { Spritzen } & \text { B. Braun, Melsungen, Deutschland } \\ \text { Vicrly } 4 / 0 & \text { Ethicon, Norderstedt, Deutschland }\end{array}$

\subsection{Methoden}

\subsubsection{Tierzucht,Tierbehandlung}

Alle im Rahmen dieser Studie durchgeführten Tierexperimente wurden nach Überprüfung durch die Ethikkommission der Universitätsmedizin Göttingen genehmigt (Tierschutzantrag G 79/09). Als Versuchstier wurde die Wistar-Ratte ausgewählt. Diese ist für chirurgische Versuche gut geeignet, und es bestehen sowohl in unserer Einrichtung als auch weltweit sehr gute Erfahrungen. Um hormonbedingte Einflüsse auf das Versuchsergbenis zu vermeiden, wurden die Tierversuche an 8 Wochen alten männlichen Ratten durchgeführt. Die Tiere waren vor den geplanten Eingriffen klinisch gesund und hatten ein Durchschnittsgewicht von circa 250-300 g. Auf eine artgerechte Haltung wurde stets geachtet. Die Versuchsbedingungen wurden zuvor exakt definiert und bei jedem Versuch eingehalten. Die perioperative Überwachung der Tiere erfolgte durch die Tierpfleger vor Ort.

\subsubsection{Explantation der Aortentransplantate}

Das Tier wurde durch eine hohe Dosis Isofluran in eine tiefe Narkose versetzt. Als Thromboseprophylaxe wurde $300 \mu \mathrm{l}$ Heparin (300 IE) subcutan gespritzt. Zusätzlich ist 0,1 mg/kg Körpergewicht Temgesic ${ }^{\circledR}$ subcutan zur Analgesie verabreicht worden. Das Fell wurde mittels eines elektrischen Rasierapparates zur besseren Übersicht entfernt. Die Desinfektion der Haut erfolgte mit Octenisept. Anschließend wurde das Abdomen eröffnet. 
Während des Eingriffes erhielt das Tier kontinuierlich geringe Mengen Isofluran, gemischt mit Sauerstoff, zur Aufrechterhaltung der Narkose. Die folgenden Arbeitsschritte wurden mithilfe eines binokularen Lichtmikroskops mit einer Vergrösserung von 16x durchgeführt. Bei der Präparation kamen feine Dumont- Pinzetten und feinchirurgische Federscheren zum Einsatz. Das Gefäß wurde möglichst nur an der Adventitia berührt. Nach Umlagern des Darmes zu einer Seite konnte nun auch das Retroperitoneum stumpf freipräpariert und das dünne Bindegewebe zwischen der Aorta abdominalis und Vena cava inferior gelöst werden. Vor Entnahme der infrarenalen Aorta abdominalis wurden zunächst die Lumbalarterien möglichst distal mit bipolarem Strom koaguliert. Anschließend ist die Aorta distal der Nierenarterien sowie kurz vor der Aortenbifurkation mit je einer Bulldog-Klemme abgeklemmt und die Aorta proximal sowie distal durchtrennt worden. Danach wurde die Aorta mit Heparin-NaCl-Lösung freigespült. Die Explantate hatten eine Durchschnittslänge von ca. $10 \mathrm{~mm}$ und konnten später für eine Implantation verwendet werden. Die frisch entnommenen Aortenringe wurden in Eppendorf-Safe Lock Tubes mit entsprechender auf 4 ${ }^{\circ} \mathrm{C}$ vorgekühlter Versuchslösung ( $\mathrm{NaCl}$, HTK oder TiProtec () ) bis zur weiteren Verarbeitung auf Eis gehalten. Zur Ermittlung der Normwerte bei der Funktionsmessung und Proliferationsbestimmung untersuchten wir frisch entnommene Aortenringe ohne vorausgehende Lagerung als Baseline-Gruppe (s. Abbildung 3). Die hierzu entnommenen Aortenringe wurden in Eppendorf-Safe Lock Tubes mit vorgekühltem $\left(4{ }^{\circ} \mathrm{C}\right)$ KrebsHenseleit-Puffer platziert und bis zur weiteren Verarbeitung auf Eis gehalten. Die Testung dieser „gesunden“ Aortensegmente sollte uns erwartungsgemäß Normwerte liefern. Anhand dieser Normwerte konnte das Proliferationsverhalten und der mögliche Funktionsverlust der Testgefäße bestimmt und verglichen werden. Die Donortiere wurden unter tiefer Narkose durch eine Durchtrennung der zentralen Gefäße getötet. 


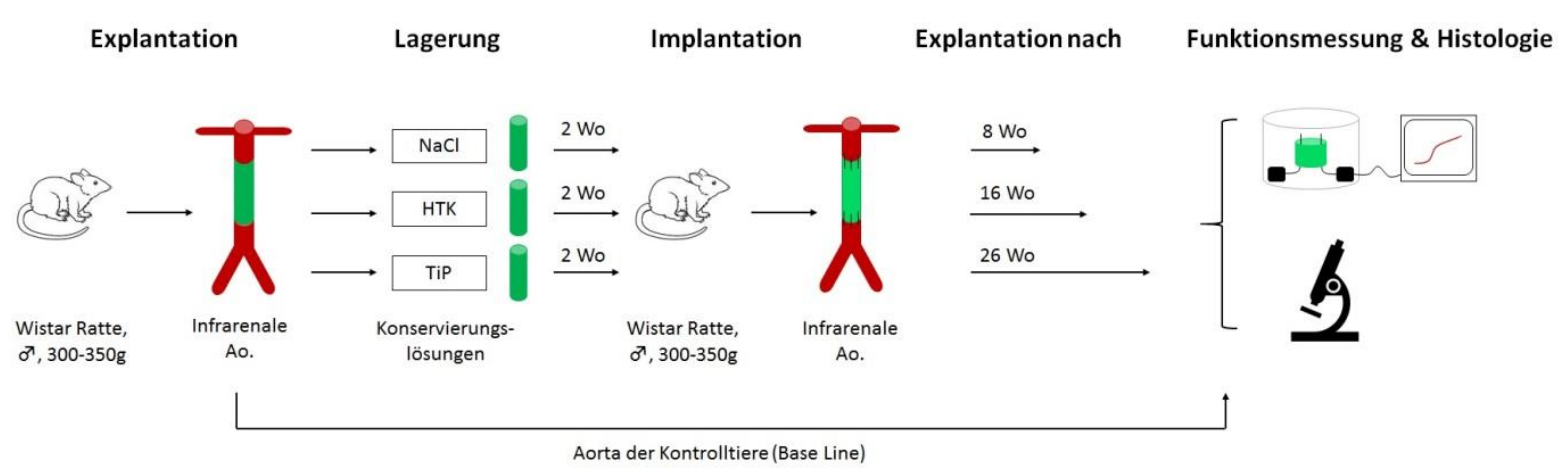

Abbildung 3: Übersichtsschema des Tierversuchsablaufs.

\subsubsection{Lagerung}

Die Baseline-Gruppe ausgenommen, wurden alle Versuchsgefäße in der jeweiligen Testlösung für 2 Wochen gelagert (s. Abbildung 3). Die Aortenexplantate wurden in einem Eppendorf- „Safe Lock Tube“ bei $4{ }^{\circ} \mathrm{C}$ im Kühlschrank aufbewahrt. Die zwei Milliliter großen Eppendorf-Gefäße enthielten $1,5 \mathrm{ml} \mathrm{NaCl}$, HTK oder TiProtec $\AA$ und überdeckten das Aortenstück komplett.

\subsubsection{Implantation der Aortentransplantate}

Nach einer vorausgehenden zweiwöchigen Aufbewahrung der Aorta abdominalis-Segmente in $\mathrm{NaCl}$, HTK oder TiProtec ${ }^{\circledR}$ wurden diese in die Aorta abdominalis der Empfängertiere implantiert (s. Abbildung 3). Die Operationsvorbereitung gestaltete sich wie unter 2.2.2 beschrieben. Um eine Auskühlung des Tieres zu vermeiden, führten wir den Eingriff auf einer Wärmeplatte, die auf $37^{\circ} \mathrm{C}$ eingestellt war, durch. Auf die Augen wurde Bepanthen ${ }^{\circledR}$ Augensalbe aufgetragen, um eine Austrocknung beim Eingriff zu verhindern. Der Darm wurde mit einer warmen sterilen NaCl-getränkten Kompresse bedeckt und nach außen (rechts) gelagert. Damit sollte ein Volumenverlust und Auskühlung des Tieres verhindert werden. Die Aorta musste anschließend sehr vorsichtig mit Hilfe von in $\mathrm{NaCl}$ getränktem Wattestäbchen vom umliegenden Bindegewebe und der Vena cava befreit werden. Auch das Retroperitoneum konnte auf gleicher Art stumpf freipräpariert und das dünne Bindegewebe zwischen der Aorta abdominalis und der Vena cava inferior gelöst werden. Die infrarenale Aorta abdominalis wurde an einem Abschnitt möglichst ohne Seitenäste/Lumbalarterien präpariert und abgesetzt. Anschließend ist die Aorta distal der Nierenarterien sowie kurz vor 
der Aortenbifurkation mit je einer Bulldog-Klemme abgeklemmt und die Aorta proximal und distal durchtrennt sowie ein Segment der Aorta entfernt worden. Nun wurde das zuvor gelagerte Aortensegment aus der jeweiligen Konservierungslösung entnommen und als Interponat in die Aorta abdominalis implantiert, wobei es proximal und distal mit einer 8.0Prolene-Naht in Einzelnahttechnik anastomosiert wurde. Nach Entlüftung vor der letzten Naht konnten die Bulldog-Klemmen zunächst distal dann proximal entfernt werden. Nach Kontrolle auf Bluttrockenheit wurde der Darm in den Bauchraum zurückgelagert und die Bauchdecke schichtweise mittels Fasziennaht und Hautnaht mit 2.0-SH-Vicryl verschlossen. Die Narkosezufuhr wurde gegen Ende der Operation langsam reduziert und schließlich ganz beendet. Alle Tiere wurden postoperativ in einen Einzelkäfig unter milder Wärmelampe gebracht. Dem Trinkwasser ist in den folgenden Tagen $1,3 \mathrm{mg} / \mathrm{ml}$ Novaminsulfon hinzugefügt worden. Zusätzlich erhielten die Tiere bis zum 3. postoperativen Tag $0,1 \mathrm{mg} / \mathrm{kg}$ KG Temgesic ${ }^{\circledR}$ zweimal täglich und 300 IE Heparin subkutan einmal täglich. Der Gesundheitszustand der Tiere unterlag täglichen klinischen Kontrollen. Die Aortenimplantate blieben 8, 16 oder 26 Wochen im Empfängertier und wurden danach zur weiteren Verarbeitung und Untersuchung explantiert (s. Abbildung 3).

\subsubsection{Explantation der Aortenpräparate aus Empfänger}

Nach jeweils 8, 16 oder 26 Wochen folgte die Explantation der zuvor implantierten Aortensegmente aus Empfängertieren (s. Abbildung 3). Der Eingriff erfolgte ebenfalls unter Isofluran-Narkose und Gabe von $0,1 \mathrm{mg} / \mathrm{kg}$ KG Temgesic ${ }^{\circledR}$. Die Haare im Bereich der Bauchwunde wurden trocken rasiert und mit einer nassen Kompresse entfernt. Nach Desinfektion der Bauchregion mit Octenisept ${ }^{\circledR}$ wurde die Bauchdecke mit einer scharfen Schere median eröffnet. Der Darm wurde nach außen gelagert und die Aorta vorsichtig stumpf freipräpariert. Durch Abklemmen der Aorta proximal oberhalb und distal unterhalb der Anastomosennähte konnte das Aortentransplantat mit einer scharfen Schere exzidiert werden. Direkt nach Explantation erfolgte die Teilung des Aortenstückes in 3 Teile. Das proximale und distale Stück wurde zur HE-Färbung und immunhistochemischen Untersuchung verwendet. Das mittlere Stück nutzten wir zur Funktionsmessung, die direkt nach Explantation stattfand. Die Tiere wurden durch Durchtrennung der zentralen Gefäße unter tiefer Narkose getötet. 


\subsection{Funktionsmessung}

\subsubsection{Versuchsapparatur}

In einem Organbad (mit Krebs-Henseleit-Puffer) wurde das Kontraktions- und Dilatationsverhalten der Aortenringe gemessen (s. Abbildung 4). Die Versuchsapparatur bestand aus zwei Teilen. Ein $10 \mathrm{ml}$ fassendes Organbad mit zwei seitlich angebrachten Haken war an einem doppelwandigen Glasbehälter angeschlossen. Dieser Glasbehälter enthielt 50 $\mathrm{ml}$ KH-Puffer und wurde mit einem Thermostat auf $37{ }^{\circ} \mathrm{C}$ aufgewärmt. Jeweils ein Aortenring wurde zwischen den gegenüber befindlichen Haken im Organbad eingespannt und von Krebs-Henseleit-Puffer aus dem Glasbehälter umspült. Eine Pumpe hielt den kontinuierlichen Fluss bzw. den Kreislauf aufrecht, indem die Flüssigkeit mit einer Absaugvorrichtung abgesaugt und in den Glasbehälter zurückgeführt wurde. Die Flüssigkeit innerhalb des Glasbehälters umspülten wir mit Carbogen (95 \% Sauerstoff, $5 \%$ Kohlendioxid). Der linke Haken konnte mit einer Drehschraube auseinander bewegt werden. Auf dieser Weise war es möglich, an den Ringen eine beliebige Spannung zu erzeugen. Z. B. je weiter die beiden Haken und somit auch der eingespannte Aortenring auseinander bewegt wurden, desto größer war die entwickelte Kraft/Spannung. Der rechte Haken war mit einem Kraftaufnehmer/Transducer verbunden. Das abgeleitete elektrische Signal konnte mit dem Programm (LabView $\left.{ }^{\circledR}\right)$ auf einem Rechner als Grafik dargestellt und gespeichert werden. Parallel konnten zwei Aortenringe gleichzeitig in isolierten Organbädern untersucht werden (s. Abbildung 4). 


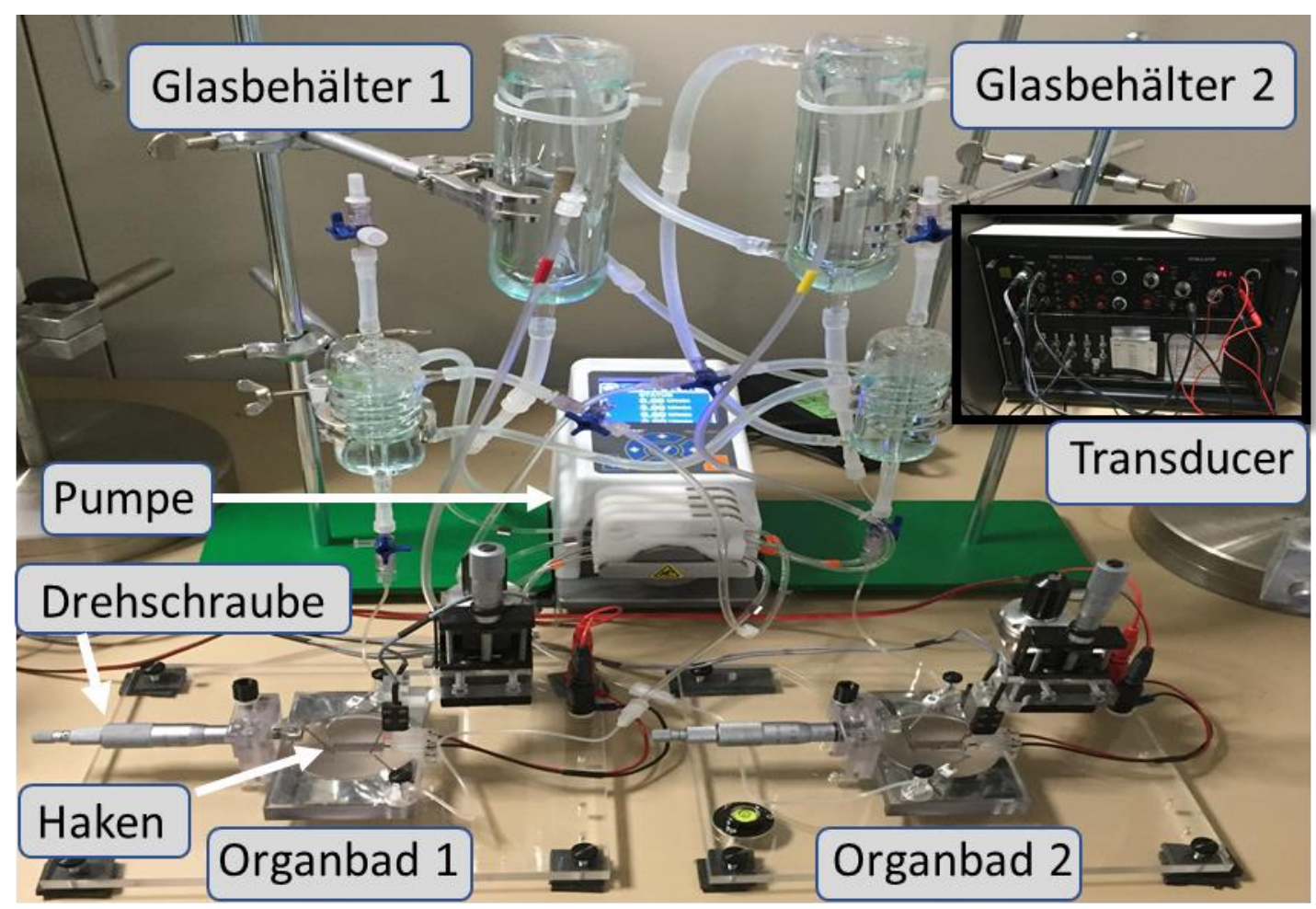

Abbildung 4: Versuchsapparatur zur Messung des Kontraktions- und Dilatationsverhaltens der Aortentransplantate. Im Bildausschnitt rechts ist der Transducer dargestellt.

\subsubsection{Vorbereitung}

Nach 8, 16 und 26 Wochen wurden die Aortentransplantate aus den Versuchstieren entnommen und der Funktionsmessung zugeführt. Zusätzlich erfolgten Messungen an „gesunden“ Kontroll-Aortenringen. Alle Aortenpräparate hatten eine Breite von 1-2mm. Somit sollten Messfehler und falsch abgeleitete Spannungswerte möglichst vermieden werden. Jeweils zwei Aortenringe konnten parallel in den beiden isolierten Organbädern untersucht werden. Die Ringe wurden an den Haken im Organbad angebracht und vor jeder Messung der Nullpunkt kalibriert. Es wurde zunächst eine Ruhespannung von $0 \mathrm{mN}$ eingestellt. Die Ringe und auch die beiden Haken befanden sich also in Ruheposition. Nach einer Eingewöhnungsphase von 30 min wurden die Aortenringe durch Auseinanderbewegen der Haken schrittweise auf eine Spannung von $15 \mathrm{mN} \pm 0,5 \mathrm{mN}$ vorgedehnt. Die Prozedur dauerte $30 \mathrm{~min}$, gefolgt von 30-minütiger Äquilibrierung. Es sollte eine möglichst stabile Spannung von $15 \mathrm{mN}$ erreicht werden. Die weiteren Arbeitsschritte der Untersuchung sind im Folgenden aufgelistet. 


\subsubsection{Ablauf}

Zur Beurteilung des Kontraktions- und Dilatationsverhaltens der Aortenringe nach einer langen Kaltlagerung von zwei Wochen in der jeweiligen Konservierungslösung wurden diese 8, 16 oder 26 Wochen nach Implantation einer Funktionsmessung zugeführt. Untersucht wurde dabei die

\subsubsection{Rezeptorunabhängige Kontraktion mit Kaliumchlorid}

2.3.5 Rezeptorabhängige Kontraktion mit Phenylephrin

2.3.6 Endothelabhängige Dilatation mit Acetylcholin

2.3.7 Endothelunabhängige Dilatation mit Nitroprussid

Die Baseline- Präparate wurden ohne vorausgehende Konservierung getestet und dienten der Vergleichbarkeit als Idealwerte.

\subsubsection{Rezeptorunabhängige Kontraktion mit Kaliumchlorid $(\mathrm{KCl})$}

Zunächst wurde in das Organbad mit eingespannten Aortenringen $60 \mathrm{mM} \mathrm{KCl} \mathrm{hinzugegeben.}$ Anschließend konnte durch schrittweise Zugabe von jeweils $20 \mathrm{mM} \mathrm{KCl}$ die Endkonzentrationen von 80, 100 und $120 \mathrm{mM}$ erreicht werden. Die jeweilige maximale Kraftentwicklung in $\mathrm{mN}$ ist nach Erreichen eines konstanten Kraftniveaus aufgezeichnet worden. Die Untersuchung mit $\mathrm{KCl}$ hatte dabei eine deutliche Aussagekraft über das zu erwartende Kontraktions- und Dilatationsverhalten der Aortenringe. Die Erzeugung einer Kontraktion von über $3 \mathrm{mN}$ wies auf eine gute Gefäßqualität hin. Über Natrium/KaliumTransporter gelangen $\mathrm{K}^{+}$-Ionen in die Zelle und führen gleichzeitig zum Einstrom von Kalzium-Ionen (Perez und Sanderson 2005). Dies verursacht eine schnelle Aktivierung des kontraktilen Apparates der Mediamuskulatur und somit eine Gefäßkontraktion. Der übliche Mechanismus (beta-adrenerge Rezeptoren, Aktivierung der cGMP- Kaskade und KalziumEinstrom) wird damit übersprungen. Mit diesem Schritt konnte also getestet werden, ob der Kontraktionsapparat der jeweiligen Aortenringe intakt ist. Nach Beendigung der Messung folgte eine mehrfache Spülung des Organbades und somit der Aortenringe mit KrebsHenseleit-Lösung, bis die Ruhespannung von $15 \pm 0,5 \mathrm{mN}$ erreicht war. 


\subsubsection{Rezeptorabhängige Kontraktion mit Phenylephrin (PE)}

Phenylephrin bindet über die Alpha-adrenerge Rezeptoren an die Zelloberfläche und führt zu einer Kalziumfreisetzung und Kontraktion der glatten Muskelzellen in der Media (Tung et al. 1987; Nigro und Scivoletto 1983). Es wurde eine Dosis-Wirkungs-Kurve in ansteigender Kontraktion erstellt. Die Endkonzentration im Organbad betrug dabei zwischen $1 \times 10^{-9}$ und $1 \times 10^{-5} \mathrm{~mol} / \mathrm{L}$. Die maximal erzeugte Spannung wurde in die Wertung genommen. Nach Abschluss der Messung erfolgte auch hier eine mehrfache Spülung der Aortenringe im Organbad mit KH-Lösung bis zum Erreichen einer Ruhespannung von 15 $\pm 0,5 \mathrm{mN}$.

\subsubsection{Endothelunabhängige Dilatation mit Sodium- Nitroprussid (SNP)}

Um das Dilatationsverhalten der Aortensegmente beurteilen zu können, sind diese zunächst mit Phenylephrin (PE) versetzt worden und zwar mit einer submaximalen Konzentration von $90 \%$. Dabei sollte vermieden werden, dass durch die vorausgehende 100\%ige Gefäßkontraktion die Dilatationsfähigkeit der Gefäße aufgehoben bzw. negativ beeinflusst wird. Es wurde also $3 \times 10^{-6} \mathrm{~mol} / 1 \mathrm{PE}$ hinzugegeben, um anschließend die DosisWirkungskurve mit Nitroprussid zu erfassen. Nitroprussid ist ein Stickstoffmonoxid-Donor und führt über zyklische Guanosinmonophosphat-Freisetzung zu einer Vasodilatation (IbarraAlvarado et al. 2002). Dieser Schritt ist endothelunabhängig, da dieser keine endothelständige NO-Synthase benötigt. Da NO- Verfügbarkeit gewährleistet ist, testet man mit Nitroprussid die Relaxation der Media-Zellen.

\subsubsection{Endothelabhängige Dilatation mit Acetylcholin (Ach)}

Auch hier wurde zunächst die submaximale Kontraktion mit Pheylephrin bestimmt. Acetylcholin bindet an die muskarinergen Rezeptoren, die sich an der EndothelzellOberfläche befinden (Furchgott und Zawadzki 1980). Dies führt zum Kalziumeinstrom in die Endothelzellen. Kalzium bindet an Calmudulin und bewirkt damit die Aktivierung von Stickstoffmonoxid-Synthase (NO-Synthase) (Berra et al. 2005). Die NO-Synthase bildet Stickstoffmonoxid (NO) bei der Konversion von L-Arginin in L-Citrullin (Förstermann und Sessa 2012). NO diffundiert in die Gefäßmuskelzellen und induziert die Freisetzung von zyklischem Guanosin-Monophosphat (cGMP) (Rapoport et al. 1983; Förstermann et al. 
1986). cGMP aktiviert die Proteinkinase G, was wiederum die Kalziumkanäle schließt. Es kommt schließlich zu einer Vasodilatation durch Kalziummangel.

\subsubsection{Messung im Organbad mit Krebs-Henseleit-Puffer}

Der frisch aus der Ratte entnommene Aortenring wurde im Krebs-Henseleit-Puffer (KHS) gespült. Die Aortensegmente waren 1-2 mm dick. Anschließend konnte der Ring unter dem Lichtmikroskop mit zwei feinen Dumont-Pinzetten an die Haken im Organbad angebracht werden. Das Organbad wurde mit $37^{\circ} \mathrm{C}$ warmer KHS gefüllt und mit Carbogen (Sauerstoff $95 \%$, Kohlendioxid $5 \%$ ) angereichert. Das Gesamtvolumen im Organbad betrug 50ml. Die eingespannten Aortenringe wurden für 30 min. equilibriert. Die Ruhespannung wurde auf 0 eingestellt. Schrittweise über 20 min wurden die Aortenringe auf eine Ruhespannung von 15 $\mathrm{mN}$ vorgedehnt.Nach dem Erreichen von $15 \mathrm{mN}$ folgte eine erneute Equilibrierung von 20min. Es wurde $5 \mu \mathrm{l}$ einer 0,01 molaren Indomethacin- Lösung zu den $50 \mathrm{ml}$ KHS hinzugefügt und $5 \mathrm{~min}$ abgewartet. Auch $3 \mathrm{ml}$ einer 1 molaren Kaliumchlorid- Lösung wurden zu den $50 \mathrm{ml} \mathrm{KHS} /$ Indomethacin $(\mathrm{KCl}$ Endkonzentration $60 \mathrm{mM}$ ) zugesetzt und 5 min inkubiert. In 3 Schritten wurden jeweils $333 \mu \mathrm{KCl}$ hinzugegeben, um eine Endkonzentration $80 \mathrm{mM}, 100 \mathrm{mM}$ und $120 \mathrm{mM}$ zu erreichen. Anschließend wurde die KHS/Indo/KCl- Lösung mehrfach mit frischer KHS- Lösung ausgewaschen bis eine Ruhespannung von $15 \mathrm{mN}$ erreicht war. Nun wurde eine Dosis-Wirkungs-Kurve mit Phenylephrin herstellt. Die Verdünnungsreihe Phenylephrin mit den Konzentrationen $1 \times 10^{-2}$ bis $1 \times 10^{-6}$ wurde zuvor hergestellt. Nach Zugabe der einzelnen Konzentrationen in das Organbad wurde die Gleichgewichtseinstellung abgewartet. Die entsprechenden Messwerte wurden dokumentiert. Die Aortenringe wurden nun mehrfach mit KHS für mindestens 30 min lang ausgewaschen bis die Vorspannung von $15 \mathrm{mN}$ erreicht war. Es wurden $5 \mu$ einer 0,01 molaren Indomethacin-Lösung zu den $50 \mathrm{ml}$ KHS hinzugefügt und 5 min abgewartet. Nun wurde die submaximale Kontraktion (90 \%) der Ringe mit Phenylephrin (PE) bestimmt; eine Kontraktion mit PE war notwendig, um anschließend das Dilatationsverhalten der Aortenringe mit Acetylcholin $\mathrm{zu}$ messen. Die Verdünnungsreihe Acetylcholin mit den Konzentrationen $1 \times 10^{-1}$ bis $1 \times 10^{-7}$ wurde zuvor hergestellt. Nach Zugabe der einzelnen Konzentrationen in das Organbad wurde die Gleichgewichtseinstellung abgewartet. Die entsprechenden Messwerte wurden dokumentiert. Zwischen den Schritten wurde 10 min Einwirkzeit eingehalten. Die Aortenringe wurden nun mehrfach mit KHS für mindestens 30 
min ausgewaschen bis die Vorspannung von $15 \mathrm{mN}$ erreicht war. Es wurde $5 \mu$ l einer 0,01 molaren Indomethacin-Lösung zu den 50ml KHS hinzugefügt und 5 min inkubiert. Nun wurde erneut die submaximale Kontraktion (90\%) der Ringe mit PE bestimmt; eine Kontraktion mit PE war notwendig, um anschließend das Dilatationsverhalten der Aortenringe mit Nitroprussid zu messen. Die Natrium-Nitroprussid (SNP)-Verdünnungsreihe mit den Konzentrationen $1 \times 10^{-2}$ bis $1 \times 10^{-7}$ wurde zuvor hergestellt. Nach Zugabe von einzelnen Konzentrationen in das Organbad wurde die Gleichgewichtseinstellung (steady state) abgewartet. Die entsprechenden Messwerte wurden dokumentiert.Die Aortenringe wurden anschließend mit KHS gespült und in Formalin zur weiteren Untersuchung konserviert.

\subsection{Histopathologische Untersuchungen}

Neben der Funktionsmessung erfolgte auch eine histomorphologische Untersuchung der Aortenpräparate nach Explantation aus Empfängertieren. Zu diesem Zwecke wurden die Präparate zunächst in Formalin gelagert. Anschließend sind diese einerseits einer Hämatoxilin-Eosin-Färbung und andererseits der immunhistologischen Färbung der glatten Muskelzellen zugeführt worden. Unter dem Lichtmikroskop wurden dann die morphologischen Veränderungen an der Gefäßwand begutachtet und hiervon Aufnahmen erstellt. Mit dem Auswertungsprogramm Analysis 3.2 (Soft Imaging System ${ }^{\circledR}$ ) konnten diese anschließend am Rechner genauer betrachtet und die Endothelproliferation ausgemessen werden.

\subsubsection{Histologische Untersuchung}

Als eine Standardfärbung in der Histologie ermöglicht die HE-Färbung, die Struktur des Gewebes darzustellen. Die Hämatoxylinlösung (Hämalaun) färbt im ersten Schritt die Kerne blau oder dunkelviolett, indem positiv geladene Aluminium-Hämatein-Komplexe an die negativ geladenen Phosphatreste der Zellkern-DNA binden (Merck, Darmstadt). Die Eosinlösung im zweiten Schritt dagegen lässt das Zytoplasma, das Kollagen und das Keratin durch Bindung an Proteine rot erscheinen. Nach Explantation der Aortentransplantate aus Empfängertieren wurden diese 1-2 mm große Stücke geteilt und anschließend für 24-48 h in 4,5 \% - $10 \%$ Phosphat- gepuffertes Formalin fixiert. Die Präparate wurden etwa 3-4 Stunden 
je nach Fixierungs-Dauer rehydriert. Anschließend wurden sie im Einbettautomat je 1,5 h in 50\%igem, 70\%igem, 80\%igem, 2x 96\%igem und 2x 100\%igem Ethanol, 2x in Chloroform und $3 \mathrm{x}$ in Parafin eingebettet. Nun konnten die Präparate zu Blöcken gegossen werden, woraufhin sie auf $-20^{\circ} \mathrm{C}$ auf einer Kühlplatte gekühlt wurden. Gekühlte Blöcke konnten mit dem Schlittenmikrotom auf $1 \mu \mathrm{m}$ geschnitten werden. Diese Schnitte wurden im $45{ }^{\circ} \mathrm{C}$ warmen Wasser gestreckt und auf gereinigte Objektträger aufgezogen und über Nacht bei Raumtemperatur getrocknet. Anschließend folgte die Hämatoxylin-Eosin-Färbung (HEFärbung) der vorbereiteten histologischen Präparate wie unten beschrieben. Die Schnitte/Proben wurden über 4 Minuten 3x mit Xylol gespült. Es folgte eine 2-fache Spülung mit 100\%igem Ethanol, ebenfalls für 4 Minuten. Die Präparate wurden 4 Minuten lang in einer absteigenden Alkohol-Reihe, nämlich $96 \%, 70 \%, 50 \%, 30 \%$ und anschließend mit Aqua bidestillata versetzt. Es wurde 3x mit Hämalaun über 80 Sekunden gefärbt. Hydratisiert wurde für 7 Minuten im lauwarmen Wasser, woraufhin eine Spülung mit Aqua bidestillata für 2 min folgte. Nun wurde 2x mit 1\%igem Eosin über 1min gefärbt. Gespült wurde für 30 Sekunden in Aqua bidest. Die Präparate sind 2x kurz mit 96\%igem Ethanol, 2x mit 100\%igem Ethanol über 3 Miuten und 3x mit Xylol über 3 Minuten versetzt worden. Eingedeckt wurden die Objektträger mit Entellan

\subsubsection{Endothelproliferationsmessung}

Um den Einfluss der langen Konservierung auf die Endothelzellen zu beurteilen, wurde das Endothel nach HE-Färbung mikroskopisch(BH 2 Olympus, Tokio, Japan)untersucht. Es erfolgte zunächst eine Qualitätsbeurteilung der Präparate unter 10-facher und 40-facher Vergrößerung. Unter 25-facher Vergrößerung wurden Aufnahmen der Präparate erstellt und diese am Rechner begutachtet. Zur Quantifizierung der Endothelproliferation wurde die neu entstandene Fläche mit dem Programm Analysis 3.2 (Soft Imaging System ${ }^{\circledR}$ Emsis, Münster, Deutschland) gemessen.

\subsubsection{Immunhistochemische Untersuchung}

Zusätzlich zu den Funktions- und Endothelproliferationsuntersuchungen war es auch von Bedeutung, die glatten Muskelzellen zu identifizieren. Zu diesem Zwecke wurde der Antikörper anti-alpha smooth muscle actin eingesetzt. Dieser monoklonale Antikörper ist 
spezifisch für den alpha smooth muscle actin (a-SMA)(Skalli et al. 1986) von nicht nur Ratten, sondern auch weiteren Nagetieren und Menschen. Vorteilhaft ist auch, dass der Antikörper lediglich $\alpha$-SMA und keine weiteren Aktin-Isoforme erkennt. Somit erlaubt es eine klare Differenzierung der glatten Muskelzellen von anderen Zellarten. Die Vorgehensweise zur Markierung von a-SMA, Myofibroblasten und Myoepithelzellen entsprechend dem Protokoll DakoCytomation (Dako, Glostrup, Denmark) ist im Folgenden beschrieben. Die Objektträger mit den Präparaten wurden $3 x$ mit Xylol je 3 min entparrafiniert. Die Rehydrierung mit Alkohol wurde in absteigender Reihenfolge für jeweils 3 Minuten durchgeführt: 2x $100 \%, 96 \%, 70 \%, 50 \%, 30 \%$ und Aqua bidest. Anschließend folgte die Antigen-Demaskierung:

Die Proben wurden mit Proteinase K (c $250 \mu \mathrm{g} / \mathrm{ml}$ ) für 6 min bei Raumtemperatur versetzt. Anschließend sind diese 5x jeweils 3 min lang in 10\%igem Citrat-Puffer mit dem pH-Wert 6,0 in der Mikrowelle bei 800 Watt gelagert worden. Für 30-40 min wurden die Proben in 10\%igem Citrat-Puffer mit einem pH-Wert von 6,0 im Dampfgarer erhitzt. Für 30 min folgte eine Inkubation im Dampfgarer in 10\%igem Citrat-Puffer mit einem pH-Wert von 8,0 mit EDTA. Nun konnten die Objektträger für 20 min mit Target Retrieval Solution pH 9 im Dampfgarer versetzt werden. Anschließend wurden sie 20-30 min lang abgekühlt. Proteinase $\mathrm{K}$ wurde 1:50 mit 0,05 Tris/ $\mathrm{HCl} \mathrm{pH} \mathrm{7,6}$ verdünnt und $5 \mathrm{~min}$ bei $37{ }^{\circ} \mathrm{C}$ belassen. Zuletzt wurden die Proben im 10\%igen Citrat-Puffer über Nacht bei $56{ }^{\circ} \mathrm{C}$ belassen. Die Objektträger wurden am folgenden Tag 5x über $2 \mathrm{~min}$ in 0,05 M Tris- Puffer mit pH-Wert 7,6 gewaschen. Das Blocken der endogenen Peroxidase wurde mit 3\%igem Wasserstoffperoxid für $15 \mathrm{~min}$ in der feuchten Kammer durchgeführt. Die Objektträger wurden erneut 5x über 2 min in 0,05 M Tris-Puffer mit pH-Wert 7,6 gewaschen. Die Proben wurden nun mit Antikörper-Diluent für $30 \mathrm{~min}$ (feuchte Kammer) bei Raumtemperatur inkubiert. Die Primär-Antikörper wurden über Nacht im Kühlschrank (feuchte Kammer) inkubiert. Am folgenden Tag wurden die Objektträger gewaschen und mit dem SekundärAntikörper oder Verstärker für 30 min versetzt. Die Objektträger wurden erneut gewaschen. Cromogen wurde angesetzt und unter Sicht die Signalgebung kontrolliert. Gestoppt wurde in Aqua bidest., wobei diese 1x für 5 min gewechselt wurde. Die Gegenfärbung wurde in Hämalaun für 2 min durchgeführt. Die Differenzierung fand im lauwarmen Leitungswasser für 7 min statt. Das Dehydrieren folgte für 2x 3 min zunächst in 96\%igem Ethanol und 2x 3 min in 100\%igem Ethanol. Nach 4x 3minütigem Einbringen in Xylol wurden die Objektträger mit Enthellan eingedeckt. 


\subsection{Statistik}

Die erfassten Daten wurden im Rechner gespeichert und zusätzlich handschriftlich protokolliert. Anschließend sind Excel-Tabellen erstellt worden. Die Auswertung der Daten erfolgte mit dem Programm GraphPad Prism ${ }^{\circledR}$ in der Version 7. Die Daten werden als Mittelwert \pm Standardabweichung angegeben. Der Shapiro-Wilk-Test wurde benutzt, um zu testen, ob die Daten eine Normalverteilung aufweisen. Das Überleben der Empfängertiere wurde mittels der Kaplan-Meier-Methode berechnet. Zur Testung der Signifikanz wurden der Students-t-Test, der exakte Fisher-Test und der Mann-Whitney-Test verwendet. Bei Vergleich von mehreren unabhängigen Datenreihen wurde der ANOVA-Test herangezogen. Als statistisch signifikant wurde ein p-Wert kleiner als 0,05 erachtet. 


\section{Ergebnisse}

\section{1 Überleben, operative und demographische Daten der Tiere}

Als Versuchstiere kamen ausschließlich männliche Wistar Raten mit vergleichbarem Alter und Gewicht zum Einsatz (s. Tabelle 5). Ein statistischer Vergleich der Gewichte der Spender- und Empfängertiere zwischen den jeweiligen Gruppen zeigte keinen signifikanten Unterschied. Die Narkose und Anastomosen-Zeiten waren in der NaCl-Gruppe signifikant länger als in den beiden anderen Gruppen. Der Grund dafür liegt hauptsächlich in der Qualität der Aortentransplantate, die nach 2 Wochen Lagerung in $\mathrm{NaCl}$ makroskopisch schlechter war im Vergleich zu den anderen Gruppen. Dies erschwerte den operativen Umgang und verlängerte so die Anastomosenzeit. Während in der TiProtec ${ }^{\circledR}$-Gruppe alle Tiere die Prozedur überlebten, musste in den beiden anderen Gruppen jeweils ein Tier in den ersten $24 \mathrm{~h}$ aufgrund einer totalen Ischämie der unteren Extremitäten getötet werden. 
Tabelle 5: Gruppeneinteilung, operative Daten und Überleben der Versuchstiere. Das Gewicht sowie die Zeiten sind als Mittelwert (mean) und Standardabweichung (SD) angegeben. Als statistische Tests kamen der ANOVA-Test (a) und der Log-Rank-Test (b) zum Einsatz.

\begin{tabular}{|c|c|c|c|c|c|}
\hline Lösung & & $\mathrm{NaCl}$ & HTK & TiP & $\mathbf{P}$ \\
\hline \multirow[t]{4}{*}{ Gruppen } & n, 8 Wo & 8 & 8 & 10 & \\
\hline & n, 16 Wo & 5 & 8 & 5 & \\
\hline & n, 26 Wo & 6 & 6 & 6 & \\
\hline & n, tot & 1 & 1 & 0 & \\
\hline Gesamt & & 20 & 23 & 21 & \\
\hline \multirow[t]{2}{*}{$\begin{array}{l}\text { Gewicht, g, } \\
\text { mean, (SD) }\end{array}$} & Spender & $336(25)$ & $332(30)$ & $344(25)$ & $0,21^{\mathrm{a}}$ \\
\hline & Empfänger & $346(31)$ & $348(37)$ & $350(20)$ & $0,93^{\mathrm{a}}$ \\
\hline \multirow[t]{2}{*}{$\begin{array}{l}\text { Zeiten, min, } \\
\text { mean (SD) }\end{array}$} & Narkose & $45(6)$ & $40(5)$ & $41(3)$ & $0,0004^{\mathrm{a}}$ \\
\hline & Anastomose & $20(3)$ & $18(3)$ & $18(2)$ & $0,04^{\mathrm{a}}$ \\
\hline \multirow[t]{2}{*}{ Überleben } & $\mathbf{N}$ & 19 & 22 & 21 & $0,6^{\mathrm{b}}$ \\
\hline & $\%$ & 95 & 96 & 100 & \\
\hline
\end{tabular}

\subsection{Funktionsmessung}

Das Kontraktions- und Dilatationsverhalten der explantierten Aortensegmente wurde in einem Organbad getestet. Es wurde zunächst die rezeptorunabhängige Vasokonstriktion mit $\mathrm{KCl}$ und Phenylephrin mit aufsteigender Konzentration getestet. Anschließend wurde das endothelabhängige und endothelunabhängige Dilatationsverhalten unter Acetylcholin und Nitroprussid untersucht. Als Kontrollgruppe dienten Aortensegmente gesunder Ratten des entsprechenden Alters (Baseline, BL). Im Folgenden werden die Ergebnisse nach den unterschiedlichen Untersuchungszeitpunkten (8, 16 und 26 Wochen nach Implantation) zusammengefasst wiedergegeben. 


\subsubsection{Vasoreagibilität 8 Wochen nach Implantation}

\section{Rezeptorunabhängige und -abhängige Vasokonstriktion}

Die Untersuchung des rezeptorunabhängigen Kontraktionsverhaltens der Aortensegmente 8 Wochen nach Implantation erfolgte mit Hilfe einer aufsteigenden KCl-Konzentrationsreihe. Hierbei zeigte die Kontrollgruppe eine maximale Kraft von $20,8 \pm 0,5 \mathrm{mN} / \mathrm{mm}$ bei einer $\mathrm{KCl}$ Konzentration von $120 \mathrm{mM}$ (s. Tabelle 6 und Abbildung 5A). Unter den Untersuchungsgruppen zeigten die Ringe der TiProtec ${ }^{\circledR}-$ Gruppe lediglich eine leichte Kraftentwicklung mit 16,8 $\pm 1,8 \mathrm{mN} / \mathrm{mm}$ unter einer KCl-Konzentration von $100 \mathrm{mM}$. Dieser Unterschied war nur im Vergleich zu HTK statistisch signifikant. Die rezeptorabhängige Vasokonstriktion wurde mit Phenylephrin getestet. Dabei zeigten die Kontrollringe eine steigende Kraftentwicklung unter der aufsteigenden Konzentrationsreihe bis 19,4 $\pm 0,2 \mathrm{mN} / \mathrm{mm}$ bei einer PE-Konzentration von $1 \times 10^{-5} \mathrm{mM}$ (Tabelle 7 und Abbildung 5B). Alle Ringe, die in den untersuchten Lösungen $(\mathrm{NaCl}$, TiP und HTK) gelagert waren, zeigten hingegen keine konstriktive Reaktion unter Phenylephrin.

Tabelle 6: Rezeptorunabhängige Vasokonstriktion unter $\mathrm{KCl}$. Vergleich der verschiedenen Konservierungslösungen sowie der Kontrollgruppe (BL) nach 8 Wochen. ${ }^{*} p<0,05$ versus TiP / HTK / NaCl; ${ }^{\mathrm{T}} \mathrm{p}<0,05$ versus HTK

\begin{tabular}{|c|c|c|c|c|c|c|c|c|}
\hline Lösung & \multicolumn{2}{|c|}{$\mathrm{NaCl}$} & \multicolumn{2}{c|}{ HTK } & \multicolumn{2}{c|}{ TiP } & \multicolumn{2}{c|}{ BL } \\
\hline Aortenringe (n) & \multicolumn{2}{|c|}{4} & \multicolumn{2}{c|}{5} & \multicolumn{2}{c|}{5} & \multicolumn{2}{c|}{4} \\
\hline \multirow{2}{*}{ C (KCl) mM } & \multicolumn{7}{|c|}{ Gefäßtonus mN/mm } \\
\cline { 2 - 11 } & Mean & SD & Mean & SD & Mean & SD & Mean & SD \\
\hline KHS+Indo & 15,3 & 0,1 & 15,2 & 0,1 & 15,3 & 0,1 & 15,3 & 0,0 \\
\hline 60 & 15,4 & 0,1 & 15,2 & 0,1 & 16,1 & 1,6 & $19,2^{*}$ & 0,8 \\
\hline 80 & 15,6 & 0,2 & 15,3 & 0,1 & $16,3^{\mathrm{I}}$ & 1,7 & $19,9^{*}$ & 0,9 \\
\hline 100 & 15,6 & 0,1 & 15,3 & 0,2 & $16,6^{\mathrm{I}}$ & 1,8 & $20,3^{*}$ & 0,7 \\
\hline 120 & 15,6 & 0,2 & 15,3 & 0,2 & $16,3^{\mathrm{I}}$ & 1,8 & $20,8^{*}$ & 0,5 \\
\hline
\end{tabular}


Tabelle 7: Rezeptorabhängige Vasokonstriktion unter PE. Vergleich der verschiedenen Konservierungslösungen sowie der Kontrollgruppe (BL) nach 8 Wochen. ${ }^{\dagger} p<0,05$ versus TiP / $\mathrm{HTK} / \mathrm{NaCl}$

\begin{tabular}{|c|c|c|c|c|c|c|c|c|}
\hline Lösung & \multicolumn{2}{|c|}{$\mathrm{NaCl}$} & \multicolumn{2}{|c|}{ HTK } & \multicolumn{2}{|c|}{ TiP } & \multicolumn{2}{|c|}{$\mathrm{BL}$} \\
\hline Aortenringe (n) & \multicolumn{2}{|c|}{4} & \multicolumn{2}{|c|}{5} & \multicolumn{2}{|c|}{5} & \multicolumn{2}{|c|}{3} \\
\hline \multirow{2}{*}{$\mathrm{C}(\mathrm{PE}) \mathrm{mM}$} & \multicolumn{8}{|c|}{ Gefäßtonus mN/mm } \\
\hline & Mean & SD & Mean & SD & Mean & SD & Mean & SD \\
\hline $1 \times 10^{-9}$ & 15,1 & 0,1 & 15,1 & 0,1 & 15,2 & 0,1 & $15,8^{\dagger}$ & 0,5 \\
\hline $3 \times 10^{-9}$ & 15,1 & 0,1 & 15,1 & 0,1 & 15,2 & 0,1 & $15,7^{\dagger}$ & 0,5 \\
\hline $1 \times 10^{-8}$ & 15,0 & 0,1 & 15,1 & 0,1 & 15,2 & 0,2 & $15,8^{\dagger}$ & 0,5 \\
\hline $3 \times 10^{-8}$ & 15,0 & 0,1 & 15,1 & 0,2 & 15,2 & 0,2 & $16,3^{\dagger}$ & 0,0 \\
\hline $1 \times 10^{-7}$ & 15,1 & 0,1 & 15,1 & 0,1 & 15,3 & 0,5 & $16,4^{\dagger}$ & 0,0 \\
\hline $3 \times 10^{-7}$ & 15,1 & 0,1 & 15,1 & 0,1 & 15,4 & 0,6 & $16,8^{\dagger}$ & 0,2 \\
\hline $1 \times 10^{-6}$ & 15,1 & 0,1 & 15,2 & 0,1 & 15,5 & 0,7 & $17,1^{\dagger}$ & 0,1 \\
\hline $3 \times 10^{-6}$ & 15,1 & 0,1 & 15,1 & 0,1 & 15,5 & 0,6 & $18,6^{\dagger}$ & 0,5 \\
\hline $1 \times 10^{-5}$ & 15,1 & 0,1 & 15,1 & 0,1 & 15,3 & 0,4 & $19,4^{\dagger}$ & 0,2 \\
\hline
\end{tabular}




\section{Rezeptorunabhängige und -abhängige Vasodilatation}

Die Relaxationsfähigkeit der Aortensegmente wurde unter der Zugabe von Nitroprussid und Acetylcholin getestet. Hierzu wurden die Ringe zunächst mit der submaximalen Konzentration an PE zur Vasokonstriktion gebracht. Die Kontrollringe zeigten sowohl unter Nitroprussid als auch unter Acetylcholin eine adäquate Vasodilatation, die mit steigender Konzentration zunahm (s. Tabelle 8, Tabelle 9 und Abbildung 5C-D). Bei den Aortenringen der Untersuchungsgruppen zeigte hingegen weiterhin keine Vasokonstriktion unter Phenylephrin und somit auch keine endothelabhängige oder - unabhängige Vasodilatation.

Tabelle 8: Rezeptorunabhängige Vasodilatation unter SNP. Vergleich der verschiedenen Konservierungslösungen sowie der Kontrollgruppe (BL) nach 8 Wochen. ${ }^{\ddagger} p<0,05$ versus TiP / $\mathrm{HTK} / \mathrm{NaCl} ;{ }^{\S} \mathrm{p}<0,05$ versus $\mathrm{HTK} / \mathrm{NaCl}$

\begin{tabular}{|c|c|c|c|c|c|c|c|c|c|}
\hline Lösung & \multicolumn{2}{|c|}{$\mathrm{NaCl}$} & \multicolumn{2}{c|}{ HTK } & \multicolumn{2}{c|}{ TiP } & \multicolumn{2}{c|}{ BL } \\
\hline Aortenringe (n) & \multicolumn{2}{|c|}{4} & \multicolumn{2}{c|}{5} & \multicolumn{2}{c|}{5} & \multicolumn{2}{c|}{3} \\
\hline \multirow{2}{*}{ C (SNP) mM } & \multicolumn{7}{|c|}{ Gefäßtonus mN/mm } \\
\cline { 2 - 10 } & Mean & SD & Mean & SD & Mean & SD & Mean & SD \\
\hline $1 \times 10^{-10}$ & 15,2 & 0,1 & 15,2 & 0,0 & 15,3 & 0,1 & $18,9^{\ddagger}$ & 0,6 \\
\hline $1 \times 10^{-9}$ & 15,2 & 0,1 & 15,2 & 0,0 & 15,3 & 0,1 & $16,5^{\ddagger}$ & 0,4 \\
\hline $1 \times 10^{-8}$ & 15,2 & 0,1 & 15,1 & 0,1 & 15,3 & 0,1 & $15,8^{\ddagger}$ & 0,0 \\
\hline $1 \times 10^{-7}$ & 15,2 & 0,1 & 15,0 & 0,1 & 15,3 & 0,1 & $15,6^{\ddagger}$ & 0,1 \\
\hline $1 \times 10^{-6}$ & 15,2 & 0,2 & 15,0 & 0,1 & 15,3 & 0,1 & $15,5^{\S}$ & 0,1 \\
\hline
\end{tabular}


Tabelle 9: Rezeptorabhängige Vasodilatation unter Ach. Vergleich der verschiedenen Konservierungslösungen sowie der Kontrollgruppe $(B L)$ nach 8 Wochen. ${ }^{\ddagger} p<0,05$ versus TiP / $\mathrm{HTK} / \mathrm{NaCl}$

\begin{tabular}{|c|c|c|c|c|c|c|c|c|c|}
\hline \multirow{2}{*}{ Lösung } & \multicolumn{2}{|c|}{$\mathrm{NaCl}$} & \multicolumn{2}{c|}{ HTK } & \multicolumn{2}{c|}{ TiP } & \multicolumn{2}{c|}{ BL } \\
\hline Aortenringe (n) & \multicolumn{2}{|c|}{4} & \multicolumn{2}{c|}{5} & \multicolumn{2}{c|}{5} & \multicolumn{2}{c|}{3} \\
\hline \multirow{2}{*}{ C (Ach) mM } & \multicolumn{7}{|c|}{ Gefäßtonus mN/mm } \\
\cline { 2 - 10 } & Mean & SD & Mean & SD & Mean & SD & Mean & SD \\
\hline $1 \times 10^{-9}$ & 15,1 & 0,0 & 15,2 & 0,1 & 15,3 & 0,2 & $18,1^{¥}$ & 1,0 \\
\hline $1 \times 10^{-8}$ & 15,1 & 0,1 & 15,2 & 0,1 & 15,2 & 0,2 & $18,1^{¥}$ & 0,9 \\
\hline $1 \times 10^{-7}$ & 15,1 & 0,1 & 15,2 & 0,1 & 15,2 & 0,2 & $17,8^{¥}$ & 0,7 \\
\hline $1 \times 10^{-6}$ & 15,1 & 0,1 & 15,1 & 0,1 & 15,2 & 0,3 & $17,5^{¥}$ & 0,5 \\
\hline $1 \times 10^{-5}$ & 15,1 & 0,1 & 15,1 & 0,1 & 15,1 & 0,3 & $17,3^{¥}$ & 0,7 \\
\hline $3 \times 10^{-5}$ & 15,17 & 0,00 & 15,1 & 0,1 & 14,9 & 0,4 & $16,6^{\ddagger}$ & 0,7 \\
\hline
\end{tabular}


A

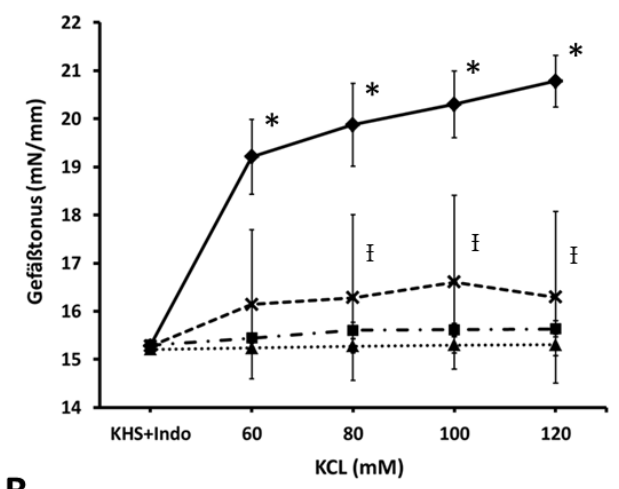

B

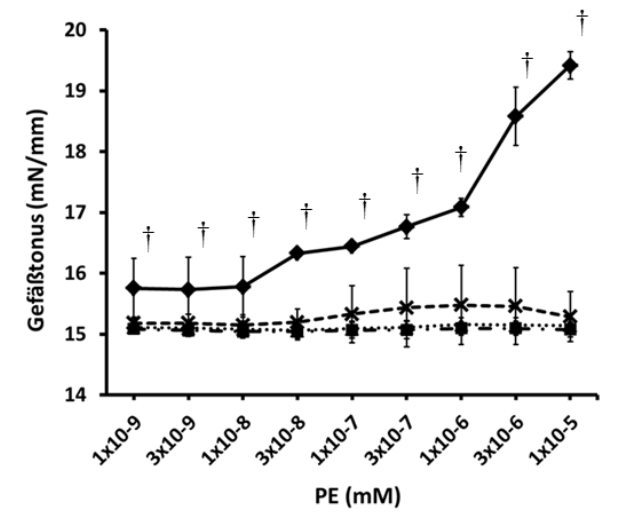

C

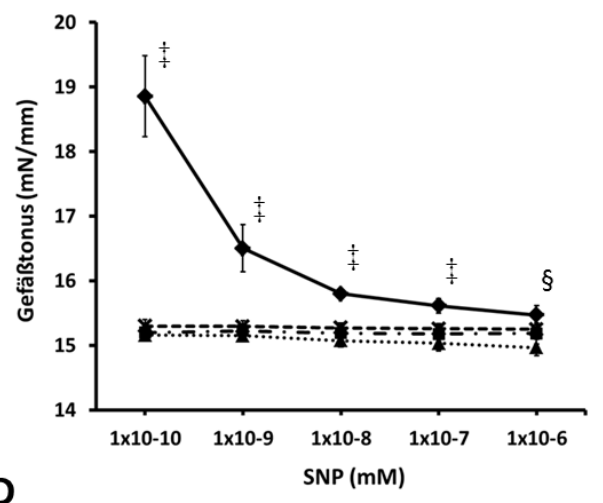

$\rightarrow B \mathrm{BL}$

$\rightarrow \mathrm{NaCL}$ $\cdot \cdot$ A. HtK

$-x-$ TiP

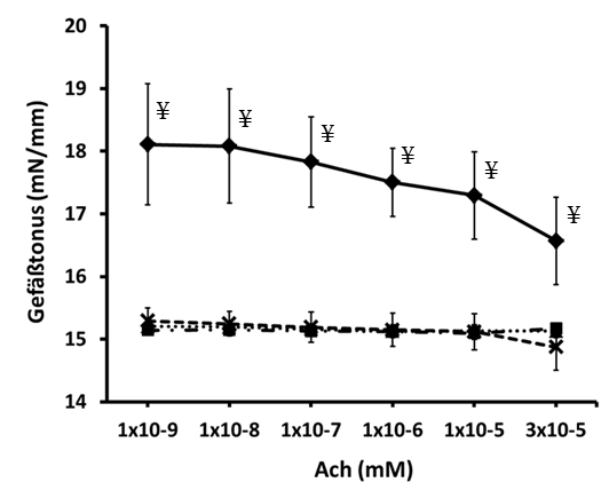

Abbildung 5: Vasoreagibilität der Aortenringe 8 Wochen nach Implantation. Die rezeptorunabhängige und -abhängige Vasokonstriktion wurde mit Kaliumchlorid $(\mathrm{KCl})$ bzw. mit Phenylephrin (PE) getestet $(A-B)$. Die rezeptorunabhängige und -abhängige Vasodilatation wurde mit Sodium-Nitroprussid (SNP) bzw. mit Acetylcholin (Ach) getestet (CD). BL, Baseline (Kontrollgruppe). ${ }^{*} \mathrm{p}<0,05$ versus TiP / HTK / NaCl; ${ }^{\dagger} \mathrm{p}<0,05$ versus HTK; ${ }^{\dagger} p$ $<0,05$ versus TiP / HTK / NaCl; ${ }^{\star} \mathrm{p}<0,05$ versus TiP / HTK / NaCl; ${ }^{\S} \mathrm{p}<0,05$ versus HTK / $\mathrm{NaCl} ;{ }^{¥} \mathrm{p}<0,05$ versus TiP / $\mathrm{HTK} / \mathrm{NaCl}$

\subsubsection{Vasoreagibilität 16 Wochen nach Implantation}

\section{Rezeptorunabhängige und -abhängige Vasokonstriktion}

Die Untersuchung des rezeptorunabhängigen Kontraktionsverhaltens der Aortensegmente 16 Wochen nach Implantation erfolgte mit Hilfe einer aufsteigenden KCl-Konzentrationsreihe. Hierbei dienten Aortenringe von gesunden Ratten entsprechenden Alters als Kontrolle. Diese zeigten eine maximale Kraft von 19,07 $\pm 2,51 \mathrm{mN} / \mathrm{mm}$ bei einer KCl-Konzentration von 120 
$\mathrm{mM}$ (s. Tabelle 10 und Abbildung 6A). Unter den Untersuchungsgruppen reagierten die Ringe nicht auf eine rezeptorunabhängige Stimulation mit $\mathrm{KCl}$. Auch bei der rezeptorabhängigen Vasokonstriktion mit Phenylephrin zeigten nur die Aortenringe der Kontrollringe eine adäquate Dosis-Wirkungs-Kurve, während bei den Ringen der übrigen Gruppen keine Reaktion detektiert werden konnte (s. Tabelle 11 und Abbildung 6B).

Tabelle 10: Rezeptorunabhängige Vasokonstriktion unter $\mathrm{KCl}$. Vergleich der verschiedenen Konservierungslösungen sowie der Kontrollgruppe (BL) nach 16 Wochen. ${ }^{*} p<0,05$ versus TiP / HTK / NaCl

\begin{tabular}{|c|c|c|c|c|c|c|c|c|c|}
\hline Lösung & \multicolumn{2}{|c|}{$\mathrm{NaCl}$} & \multicolumn{2}{c|}{ HTK } & \multicolumn{2}{c|}{ TiP } & \multicolumn{2}{c|}{ BL } \\
\hline Aortenringe (n) & \multicolumn{2}{|c|}{5} & \multicolumn{2}{c|}{5} & \multicolumn{2}{c|}{5} & \multicolumn{2}{c|}{4} \\
\hline \multirow{2}{*}{ C (KCl) mM } & \multicolumn{7}{|c|}{ Gefäßtonus mN/mm } \\
\cline { 2 - 12 } & Mean & SD & Mean & SD & Mean & SD & Mean & SD \\
\hline KHS+Indo & 15,29 & 0,09 & 15,14 & 0,12 & 15,11 & 0,11 & 15,27 & 0,10 \\
\hline 60 & 15,35 & 0,05 & 15,21 & 0,27 & 15,00 & 0,15 & $17,61^{*}$ & 2,09 \\
\hline 80 & 15,29 & 0,13 & 15,20 & 0,27 & 14,92 & 0,20 & $18,17^{*}$ & 2,67 \\
\hline 100 & 15,30 & 0,13 & 15,18 & 0,27 & 15,29 & 0 & $17,89^{*}$ & 0,58 \\
\hline 120 & 15,42 & 0,19 & 15,11 & 0,31 & 14,86 & 0,28 & $19,07^{*}$ & 2,51 \\
\hline
\end{tabular}


Tabelle 11: Rezeptorabhängige Vasokonstriktion unter PE. Vergleich der verschiedenen Konservierungslösungen sowie der Kontrollgruppe (BL) nach 16 Wochen. ${ }^{\dagger} p<0,05$ versus TiP / HTK / NaCl

\begin{tabular}{|c|c|c|c|c|c|c|c|c|c|}
\hline Lösung & \multicolumn{2}{|c|}{$\mathrm{NaCl}$} & \multicolumn{2}{c|}{ HTK } & \multicolumn{2}{c|}{ TiP } & \multicolumn{2}{c|}{ BL } \\
\hline Aortenringe (n) & \multicolumn{2}{|c|}{4} & \multicolumn{2}{c|}{5} & \multicolumn{2}{c|}{5} & \multicolumn{2}{c|}{3} \\
\hline \multirow{2}{*}{ C (PE) mM } & \multicolumn{7}{|c|}{ Gefäßtonus mN/mm } \\
\cline { 2 - 10 } & Mean & SD & Mean & SD & Mean & SD & Mean & SD \\
\hline $1 \times 10^{-9}$ & 15,16 & 0,12 & 15,05 & 0,10 & 14,90 & 0,13 & $15,56^{\dagger}$ & 0,21 \\
\hline $3 \times 10^{-9}$ & 15,11 & 0,14 & 15,03 & 0,08 & 14,88 & 0,17 & $15,57^{\dagger}$ & 0,22 \\
\hline $1 \times 10^{-8}$ & 15,10 & 0,13 & 14,99 & 0,11 & 14,80 & 0,19 & $15,76^{\dagger}$ & 0,29 \\
\hline $3 \times 10^{-8}$ & 15,15 & 0,18 & 14,99 & 0,11 & 14,77 & 0,21 & $15,84^{\dagger}$ & 0,21 \\
\hline $1 \times 10^{-7}$ & 15,18 & 0,17 & 14,97 & 0,15 & 14,76 & 0,22 & $16,23^{\dagger}$ & 0,33 \\
\hline $3 \times 10^{-7}$ & 15,17 & 0,19 & 14,97 & 0,19 & 14,72 & 0,24 & $16,80^{\dagger}$ & 0,65 \\
\hline $1 \times 10^{-6}$ & 15,18 & 0,17 & 14,79 & 0,37 & 14,74 & 0,25 & $18,15^{\dagger}$ & 1,58 \\
\hline $3 \times 10^{-6}$ & 15,18 & 0,18 & 14,80 & 0,36 & 14,75 & 0,27 & $19,02^{\dagger}$ & 2,04 \\
\hline & 15,16 & 0,18 & 14,78 & 0,36 & 14,73 & 0,24 & $20,00^{\dagger}$ & 2,57 \\
\hline
\end{tabular}

\section{Rezeptorunabhängige und -abhängige Vasodilatation}

Eine aufsteigende Konzentrationsreihe von jeweils Nitroprussid und Acetylcholin wurde eingesetzt, um die endothelunabhängige und -abhängige Vasodilatation der Aortensegmente zu testen. Hierzu wurden die Ringe zunächst mit der submaximalen Konzentration an PE zur submaximalen Spannung gebracht. Während die Kontrollringe sowohl unter Nitroprussid als auch unter Acetylcholin eine adäquate Relaxation zeigten, die mit steigender Konzentration zunahm (s. Tabelle 12, Tabelle 13 und Abbildung 6C-D), konnte bei den Aortenringen der Untersuchungsgruppen hingegen weiterhin keine Vasokonstriktion unter Phenylephrin aufgebaut und somit auch keine endothelabhängige und -unabhängige Vasodilatation gesehen werden. 
Tabelle 12: Rezeptorunabhängige Vasodilatation unter SNP. Vergleich der verschiedenen Konservierungslösungen sowie der Kontrollgruppe (BL) nach 16 Wochen. ${ }^{\ddagger} p<0,05$ versus TiP / HTK / NaCl; ${ }^{\S} \mathrm{p}<0,05$ versus HTK / TiP

\begin{tabular}{|c|c|c|c|c|c|c|c|c|}
\hline Lösung & \multicolumn{2}{|c|}{$\mathrm{NaCl}$} & \multicolumn{2}{c|}{ HTK } & \multicolumn{2}{c|}{ TiP } & \multicolumn{2}{c|}{ BL } \\
\hline Aortenringe (n) & \multicolumn{2}{|c|}{4} & \multicolumn{2}{c|}{5} & \multicolumn{2}{c|}{5} & \multicolumn{2}{c|}{3} \\
\hline \multirow{2}{*}{ C (SNP) mM } & \multicolumn{7}{|c|}{ Gefäßtonus mN/mm } \\
\cline { 2 - 10 } & Mean & SD & Mean & SD & Mean & SD & Mean & SD \\
\hline $1 \times 10^{-10}$ & 15,46 & 0,23 & 15,29 & 0,16 & 15,29 & 0,24 & $17,67^{\ddagger}$ & 1,41 \\
\hline $1 \times 10^{-9}$ & 15,45 & 0,29 & 15,27 & 0,15 & 15,29 & 0,24 & $16,68^{\ddagger}$ & 0,64 \\
\hline $1 \times 10^{-8}$ & 15,43 & 0,31 & 15,26 & 0,18 & 15,24 & 0,23 & $15,80^{\S}$ & 0,30 \\
\hline $1 \times 10^{-7}$ & 15,41 & 0,34 & 15,27 & 0,21 & 15,22 & 0,24 & 15,37 & 0,23 \\
\hline $1 \times 10^{-6}$ & 15,38 & 0,34 & 15,24 & 0,19 & 15,19 & 0,27 & 15,04 & 0,30 \\
\hline
\end{tabular}

Tabelle 13: Rezeptorabhängige Vasodilatation unter Ach. Vergleich der verschiedenen Konservierungslösungen sowie der Kontrollgruppe $(B L)$ nach 16 Wochen. ${ }^{\ddagger} p<0,05$ versus $\mathrm{TiP} / \mathrm{HTK} / \mathrm{NaCl}$

\begin{tabular}{|c|c|c|c|c|c|c|c|c|}
\hline Lösung & \multicolumn{2}{|c|}{$\mathrm{NaCl}$} & \multicolumn{2}{|c|}{ HTK } & \multicolumn{2}{|c|}{ TiP } & \multicolumn{2}{|c|}{$\mathrm{BL}$} \\
\hline Aortenringe (n) & \multicolumn{2}{|c|}{4} & \multicolumn{2}{|c|}{5} & \multicolumn{2}{|c|}{5} & \multicolumn{2}{|c|}{3} \\
\hline \multirow{2}{*}{$\mathrm{C}$ (Ach) $\mathrm{mM}$} & \multicolumn{8}{|c|}{ Gefäßtonus mN/mm } \\
\hline & Mean & $\mathrm{SD}$ & Mean & $\mathrm{SD}$ & Mean & $\mathrm{SD}$ & Mean & SD \\
\hline $1 \times 10^{-9}$ & 15,14 & 0,04 & 15,21 & 0,06 & 15,29 & 0,21 & $18,11^{¥}$ & 0,97 \\
\hline $1 \times 10^{-8}$ & 15,15 & 0,05 & 15,19 & 0,08 & 15,25 & 0,20 & $18,08^{¥}$ & 0,91 \\
\hline $1 \times 10^{-7}$ & 15,13 & 0,07 & 15,16 & 0,08 & 15,19 & 0,24 & $17,83^{¥}$ & 0,72 \\
\hline $1 \times 10^{-6}$ & 15,12 & 0,09 & 15,13 & 0,10 & 15,15 & 0,26 & $17,51^{¥}$ & 0,55 \\
\hline $1 \times 10^{-5}$ & 15,10 & 0,10 & 15,13 & 0,10 & 15,12 & 0,29 & $17,30^{¥}$ & 0,69 \\
\hline $3 \times 10^{-5}$ & 15,17 & 0,00 & 15,13 & 0,10 & 14,88 & 0,38 & $17,28^{¥}$ & 0,71 \\
\hline
\end{tabular}




\section{Vasoreagibilität nach 16 Wochen}

A

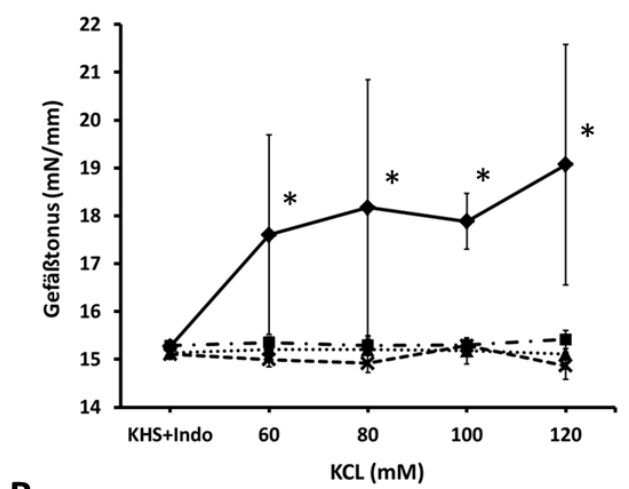

B

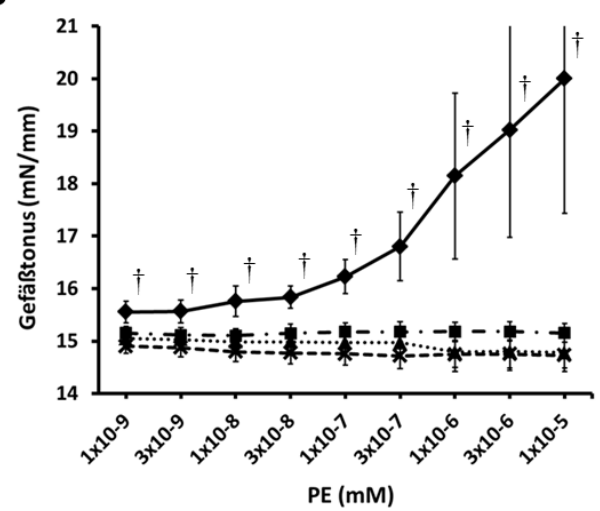

C
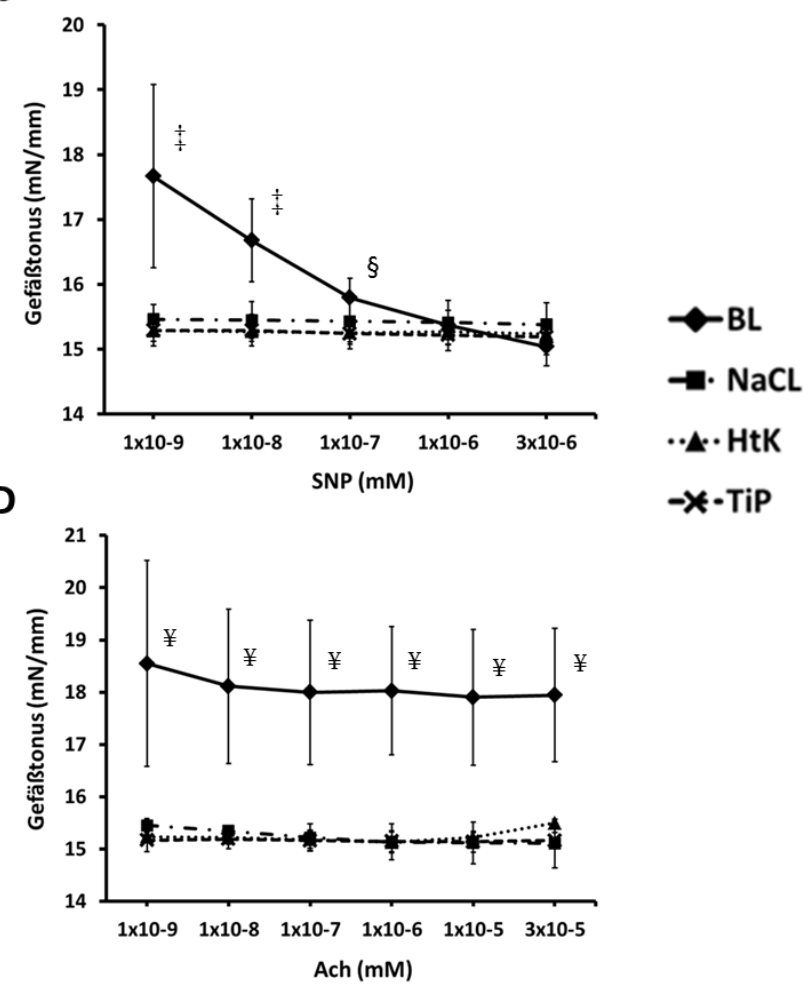

Abbildung 6: Vasoreagibilität der Aortenringe 16 Wochen nach Implantation. Die rezeptorunabhängige und -abhängige Vasokonstriktion wurde mit Kaliumchlorid $(\mathrm{KCl})$ bzw. mit Phenylephrin ( $P E)$ getestet $(A-B)$. Die rezeptorunabhängige und -abhängige Vasodilatation wurde mit Sodium-Nitroprussid (SNP) bzw. mit Acetylcholin (Ach) getestet (CD). BL: Baseline (Kontrollgruppe). ${ }^{*} p<0,05$ versus TiP / HTK / NaCl; ${ }^{\dagger} \mathrm{p}<0,05$ versus TiP / HTK / NaCl; ${ }^{\ddagger} \mathrm{p}<0,05$ versus TiP / HTK / NaCl; ${ }^{\S} \mathrm{p}<0,05$ versus HTK / TiP; ${ }^{\ddagger} \mathrm{p}<0,05$ versus $\mathrm{TiP} / \mathrm{HTK} / \mathrm{NaCl}$

\subsubsection{Vasoreagibilität 26 Wochen nach Implantation}

\section{Rezeptorunabhängige und -abhängige Vasokonstriktion}

Um die Langzeitwirkung der verschiedenen Lagerungslösungen auf die Aorteninterponate in vivo untersuchen zu können, wurden implantierte Aortensegmente erst 26 Wochen nach Implantation explantiert und der Vasofunktionsmessung unterzogen. Hierbei dienten Aortenringe von gesunden Ratten entsprechenden Alters als Kontrolle. Diese konnten eine maximale Spannung von 21,48 $\pm 2,08 \mathrm{mN} / \mathrm{mm}$ bei einer KCl-Konzentration von $120 \mathrm{mM}$ aufbauen (s. Tabelle 14 und Abbildung 7A). Unter den Aortenringen der übrigen Untersuchungsgruppen zeigten die Ringe der TiProtec ${ }^{\circledR}-G r u p p e$ eine leichte 
Vasokonstriktion mit einer maximalen Spannung von 16,51 $\pm 0,57$ unter einer KClKonzentration von $100 \mathrm{mM}$. Die übrigen Gruppen wiesen keine wesentliche Reaktion auf eine rezeptorunabhängige Stimulation mit $\mathrm{KCl}$ auf. Bei der rezeptorabhängigen Vasokonstriktion mit Phenylephrin hingegen zeigten nur die Aortenringe der Kontrollringe eine adäquate Dosis-Wirkungs-Kurve, während bei den Ringen der übrigen Gruppen keine nennenswerte Spannung detektiert werden konnte (s. Abbildung 7B).

Tabelle 14: Rezeptorunabhängige Vasokonstriktion unter $\mathrm{KCl}$. Vergleich der verschiedenen Konservierungslösungen sowie der Kontrollgruppe (BL) nach 26 Wochen. ${ }^{*} p<0,05$ versus $\mathrm{TiP} / \mathrm{HTK} / \mathrm{NaCl}$

\begin{tabular}{|c|c|c|c|c|c|c|c|c|}
\hline Lösung & \multicolumn{2}{|c|}{$\mathrm{NaCl}$} & \multicolumn{2}{|c|}{ HTK } & \multicolumn{2}{|c|}{ TiP } & \multicolumn{2}{|c|}{$\mathrm{BL}$} \\
\hline Aortenringe (n) & \multicolumn{2}{|c|}{5} & \multicolumn{2}{|c|}{5} & \multicolumn{2}{|c|}{5} & \multicolumn{2}{|c|}{4} \\
\hline \multirow{2}{*}{$\mathrm{C}(\mathrm{KCl}) \mathrm{mM}$} & \multicolumn{8}{|c|}{ Gefäßtonus mN/mm } \\
\hline & Mean & $\mathrm{SD}$ & Mean & $\mathrm{SD}$ & Mean & $\mathrm{SD}$ & Mean & $\mathrm{SD}$ \\
\hline KHS+Indo & 15,32 & 0,12 & 15,31 & 0,10 & 15,35 & 0,12 & 15,34 & 0,21 \\
\hline 60 & 15,37 & 0,11 & 15,55 & 0,28 & 15,67 & 0,79 & $19,38^{*}$ & 2,24 \\
\hline 80 & 15,36 & 0,12 & 15,78 & 0,51 & 15,75 & 0,83 & $20,77^{*}$ & 1,83 \\
\hline 100 & 15,36 & 0,12 & 16,03 & 0,08 & 16,51 & 0,57 & $21,13^{*}$ & 1,93 \\
\hline 120 & 15,38 & 0,12 & 15,64 & 0,49 & 15,80 & 0,89 & $21,48^{*}$ & 2,08 \\
\hline
\end{tabular}


Tabelle 15: Rezeptorunabhängige Vasokonstriktion unter PE. Vergleich der verschiedenen Konservierungslösungen sowie der Kontrollgruppe (BL) nach 26 Wochen. ${ }^{\mathrm{I}} \mathrm{p}<0,05$ versus $\mathrm{NaCl} ;{ }^{\dagger} \mathrm{p}<0,05$ versus TiP / $\mathrm{HTK} / \mathrm{NaCl}$;

\begin{tabular}{|c|c|c|c|c|c|c|c|c|c|c|}
\hline Lösung & \multicolumn{2}{|c|}{$\mathrm{NaCl}$} & \multicolumn{2}{c|}{ HTK } & \multicolumn{2}{c|}{ TiP } & \multicolumn{2}{c|}{ BL } \\
\hline Aortenringe (n) & \multicolumn{2}{|c|}{4} & \multicolumn{2}{|c|}{5} & \multicolumn{2}{c|}{5} & \multicolumn{2}{c|}{3} \\
\hline \multirow{2}{*}{ C (PE) mM } & \multicolumn{7}{|c|}{ Gefäßtonus mN/mm } \\
\cline { 2 - 10 } & Mean & SD & Mean & SD & Mean & SD & Mean & SD \\
\hline $1 \times 10^{-9}$ & 15,10 & 0,07 & 15,22 & 0,13 & 15,25 & 0,14 & 15,33 & 0,20 \\
\hline $3 \times 10^{-9}$ & 15,11 & 0,07 & 15,20 & 0,15 & 15,21 & 0,14 & 15,29 & 0,12 \\
\hline $1 \times 10^{-8}$ & 15,05 & 0,05 & 15,18 & 0,14 & 15,21 & 0,13 & $16,05^{\dagger}$ & 1,07 \\
\hline $3 \times 10^{-8}$ & 15,09 & 0,06 & 15,26 & 0,09 & 15,21 & 0,13 & $16,46^{\dagger}$ & 1,17 \\
\hline $1 \times 10^{-7}$ & 15,07 & 0,08 & 15,19 & 0,08 & 15,25 & 0,14 & $17,17^{\dagger}$ & 0,92 \\
\hline $3 \times 10^{-7}$ & 15,09 & 0,09 & 15,19 & 0,10 & 15,29 & 0,22 & $17,94^{\dagger}$ & 0,39 \\
\hline $1 \times 10^{-6}$ & 15,07 & 0,09 & 15,16 & 0,09 & 15,33 & 0,29 & $18,58^{\dagger}$ & 0,64 \\
\hline $3 \times 10^{-6}$ & 15,08 & 0,09 & 15,11 & 0,08 & 15,35 & 0,33 & $19,52^{\dagger}$ & 1,10 \\
\hline $1 \times 10^{-5}$ & 15,08 & 0,08 & 15,06 & 0,10 & 15,31 & 0,38 & $20,62^{\dagger}$ & 1,48 \\
\hline & & & & & & & & & &
\end{tabular}

\section{Rezeptorunabhängige und -abhängige Vasodilatation}

Für die Testung der endothelunabhängigen und -abhängigen Realaxationsfähigkeit der Aortenringe wurden diese zunächst mit der submaximalen Konzentration an PE zur submaximalen Spannung gebracht. Die Kontrollringe zeigten sowohl unter Nitroprussid als auch unter Acetylcholin eine adäquate dosisabhängige Relaxation (s. Tabelle 16, Tabelle 17 und Abbildung 7C-D). Bei den Aortenringen der Untersuchungsgruppen hingegen weiterhin keine Vasokonstriktion unter Phenylephrin aufgebaut und somit auch keine endothelabhängige und -unabhängige Vasodilatation gesehen werden. 
Tabelle 16: Rezeptorunabhängige Vasodilatation unter SNP. Vergleich der verschiedenen Konservierungslösungen sowie der Kontrollgruppe (BL) nach 26 Wochen. ${ }^{\star} p<0,05$ versus TiP / HTK / NaCl

\begin{tabular}{|c|c|c|c|c|c|c|c|c|c|}
\hline Lösung & \multicolumn{2}{|c|}{$\mathrm{NaCl}$} & \multicolumn{2}{c|}{ HTK } & \multicolumn{2}{c|}{ TiP } & \multicolumn{2}{c|}{ BL } \\
\hline Aortenringe (n) & \multicolumn{2}{|c|}{4} & \multicolumn{2}{c|}{5} & \multicolumn{2}{c|}{5} & \multicolumn{2}{c|}{3} \\
\hline \multirow{2}{*}{ C (SNP) mM } & \multicolumn{7}{|c|}{ Gefäßtonus mN/mm } \\
\cline { 2 - 10 } & Mean & SD & Mean & SD & Mean & SD & Mean & SD \\
\hline $1 \times 10^{-10}$ & 15,27 & 0,22 & 15,28 & 0,15 & 15,43 & 0,23 & $18,44^{\ddagger}$ & 1,12 \\
\hline $1 \times 10^{-9}$ & 15,28 & 0,24 & 15,28 & 0,12 & 15,43 & 0,23 & $16,07^{\ddagger}$ & 0,16 \\
\hline $1 \times 10^{-8}$ & 15,26 & 0,22 & 15,24 & 0,12 & 15,42 & 0,20 & 15,32 & 0,16 \\
\hline $1 \times 10^{-7}$ & 15,25 & 0,22 & 15,21 & 0,12 & 15,42 & 0,25 & 15,13 & 0,17 \\
\hline $1 \times 10^{-6}$ & 15,23 & 0,22 & 15,21 & 0,11 & 15,41 & 0,25 & 15,04 & 0,19 \\
\hline
\end{tabular}

Tabelle 17: Rezeptorabhängige Vasodilatation unter Ach. Vergleich der verschiedenen Konservierungslösungen sowie der Kontrollgruppe (BL) nach 26 Wochen. ${ }^{\ddagger} p<0,05$ versus $\mathrm{TiP} / \mathrm{HTK} / \mathrm{NaCl}$

\begin{tabular}{|c|c|c|c|c|c|c|c|c|c|}
\hline Lösung & \multicolumn{2}{|c|}{$\mathrm{NaCl}$} & \multicolumn{2}{c|}{ HTK } & \multicolumn{2}{c|}{ TiP } & \multicolumn{2}{c|}{ BL } \\
\hline Aortenringe (n) & \multicolumn{2}{|c|}{4} & \multicolumn{2}{c|}{5} & \multicolumn{2}{c|}{5} & \multicolumn{2}{c|}{3} \\
\hline \multirow{2}{*}{ C (Ach) mM } & \multicolumn{7}{|c|}{ Gefäßtonus mN/mm } \\
\cline { 2 - 9 } & Mean & SD & Mean & SD & Mean & SD & Mean & SD \\
\hline $1 \times 10^{-9}$ & 15,19 & 0,14 & 15,24 & 0,12 & 15,51 & 0,12 & $19,72^{\ddagger}$ & 1,93 \\
\hline $1 \times 10^{-8}$ & 15,17 & 0,15 & 15,25 & 0,13 & 15,46 & 0,13 & $19,73^{¥}$ & 1,97 \\
\hline $1 \times 10^{-7}$ & 15,16 & 0,16 & 15,23 & 0,12 & 15,45 & 0,12 & $19,68^{¥}$ & 1,98 \\
\hline $1 \times 10^{-6}$ & 15,15 & 0,18 & 15,22 & 0,16 & 15,42 & 0,12 & $19,67^{¥}$ & 2,04 \\
\hline $1 \times 10^{-5}$ & 15,16 & 0,19 & 15,19 & 0,14 & 15,41 & 0,14 & $19,08^{\ddagger}$ & 1,05 \\
\hline $3 \times 10^{-5}$ & 15,17 & 0,12 & 15,26 & 0,10 & 15,42 & 0,14 & $18,41^{\ddagger}$ & 1,52 \\
\hline
\end{tabular}




\section{Vasoreagibilität nach 26 Wochen}

A

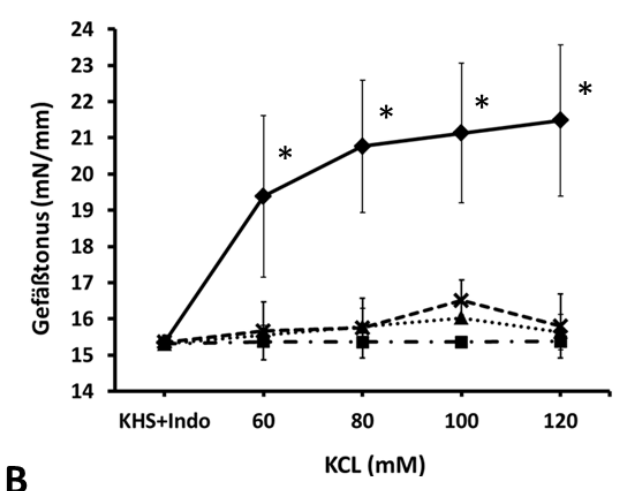

B

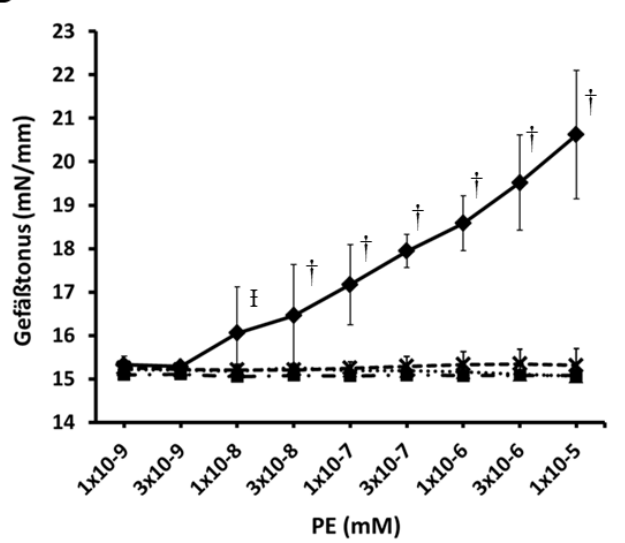

C
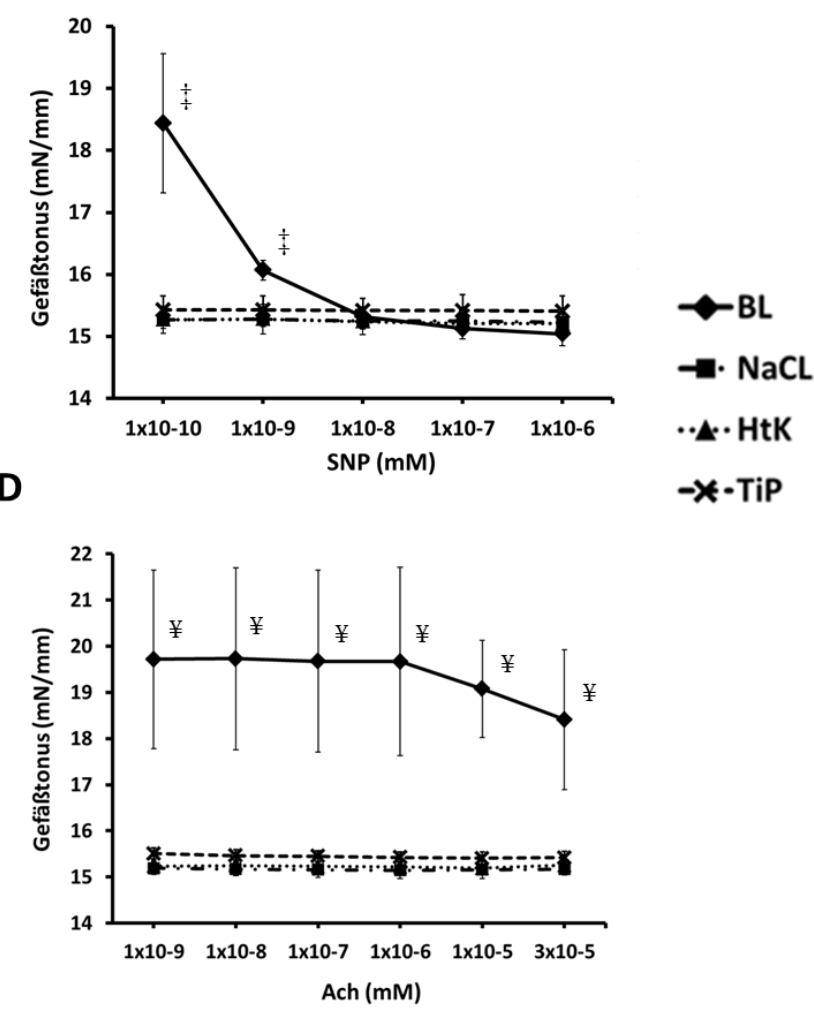

Abbildung 7: Vasoreagibilität der Aortenringe 26 Wochen nach Implantation. Die rezeptorunabhängige und -abhängige Vasokonstriktion wurde mit Kaliumchlorid ( $\mathrm{KCl}$ ) bzw. mit Phenylephrin (PE) getestet (A-B). Die rezeptorunabhängige und -abhängige Vasodilatation wurde mit Sodium-Nitroprussid (SNP) bzw. mit Acetylcholin (Ach) getestet (CD). BL, Baseline (Kontrollgruppe). ${ }^{*} \mathrm{p}<0,05$ versus TiP / HTK / NaCl; ${ }^{\mathrm{H}} \mathrm{p}<0,05$ versus $\mathrm{NaCl} ;{ }^{\dagger}$ $\mathrm{p}<0,05$ versus TiP / HTK / NaCl; $p<0,05$ versus TiP / HTK / NaCl; ${ }^{\ddagger} p<0,05$ versus TiP / HTK $/ \mathrm{NaCl}$

\subsection{Histomorphologische Auswertung der Aortensegmente}

Nach 8, 16 oder 26 Wochen wurden die Aortentransplantate aus den Empfängertieren explantiert. Anschließend erfolgte eine Hämatoxylin-Eosin-Färbung, um die Morphologie der Gefäße beurteilen zu können. Hierbei wurde insbesondere das Ausmaß der Neointimabildung analysiert und planimetrisch quantifiziert. Die immunhistochemische Färbung des a-SMA sollte Aufschluss über den Typ der beteiligten Zellart geben. 


\subsubsection{Hämatoxylin-Eosin-Färbung}

Die routinehistologische Färbung mit Hämatoxylin und Eosin erfolgte bei allen Explantaten als Querschnitt der Aorta. So konnten alle Wandschichten und das Lumen am besten beurteilt werden. Als Kontrolle dienten HE-Färbungen der Querschnitte von Rattenaorten der Kontrolltiere.

\section{NaCl-Gruppe}

Abbildung 8 zeigt repräsentative Bilder der HE-Färbung der Aortenexplantate nach Lagerung in physiologischere Kochsalzlösung. Übersichtsbilder der Aorta von Kontrolltieren zeigen die normale Histologie der infrarenalen Rattenaorta als Vergleich (s. Abbildung 8, A-C). Nach 8 Wochen zeichnet sich eine mäßige Intimahyperplasie ab, die zirkulär die gesamte Intima betrifft. Dabei ist die Neointima dicht von Zellen besetzt, die keine strukturierte Anordnung aufweisen. Darunter zeigt sich eine erheblich geschrumpfte Mediaschicht, die ausschließlich aus elastischen Fasern und der Extrazellulärmatrix besteht. Glatte Muskelzellen lassen sich hier nicht mehr nachweisen. Die Adventitia ist verdickt und zeigt zahlreiche Fibroblasten eingebettet in einer breiten Schicht aus extrazellulärer Matrix, wobei die Zelldichte in Richtung der Membrana elastica externa zunimmt. Nach 16 Wochen sind die oben beschrieben Veränderungen in allen Wandschichten weiterhin präsent, wobei die Zelldichte in der Neointima und in der Adventitia geringer erscheint (s. Abbildung 8, G-I). 26 Wochen nach Implantation zeigen die Aortentransplantate eine erhebliche Zunahme der Intimahyperplasie. Die Neointima ist dabei dicht von Zellen besetzt, die Lumen-nah eine zirkuläre Anordnung und Media-nah eine longitudinale Anordnung aufweisen (s. Abbildung 8, J-L). Das Ausmaß der Intimahyperplasie ist unregelmäßig verteilt. 


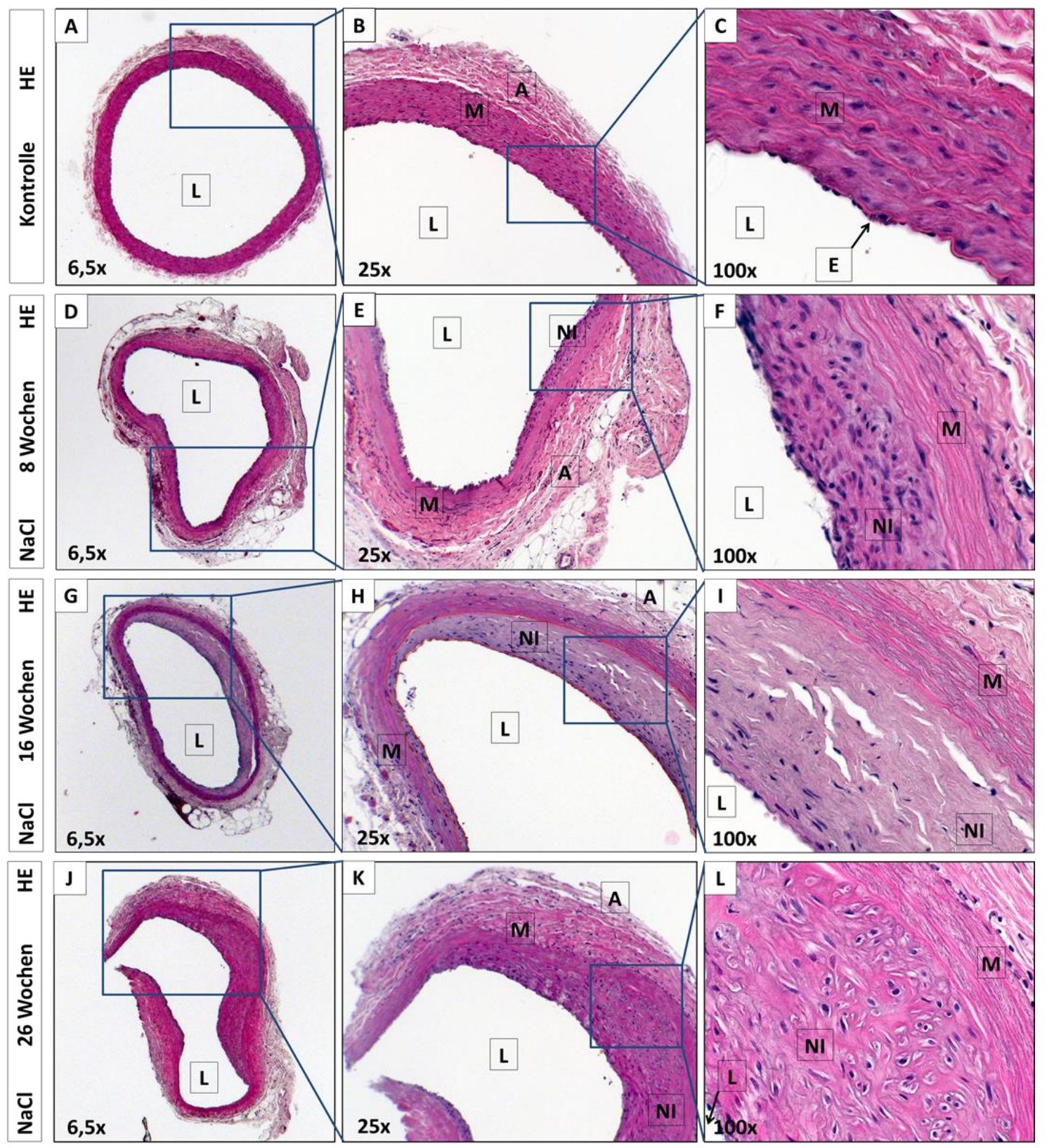

Abbildung 8: HE-Färbung der Aortenringe der NaCl-Gruppe 8, 16 und 26 Wochen nach Implantation (D-L) sowie der Kontrollgruppe (A-C). Bereits 8 Wochen nach Implantation zeigt sich die Bildung einer Neointima (NI), die exzentrisch ausgebildet ist. Die Tunica media (M) ist deutlich verjüngt und besteht nur noch aus elastischen Fasern sowie extrazellulärer Matrix, zeigt jedoch keine Zellen (D-F). Diese Veränderungen an den Gefäßschichten zeigen sich ebenfalls nach 16 und 26 Wochen (G-L), wobei die Intimahyperplasie nach 26 Wochen besonders ausgeprägt ist. L: Lumen, A: Adventitia, M: Media, NI: Neointima, E: Endothel. Vergrößerung: 6,5x, 25x und 100x

\section{HTK Gruppe}

In der HTK-Gruppe zeigten sich 8 Wochen nach Transplantation die Aortenexplantate mit einer erheblichen exzentrischen Intimahyperplasie (s. Abbildung 9). Dabei war die 
Mediaschicht stark geschrumpft und zeigte nur elstische Fasern ohne Zellen. Diese Veränderungen waren nach 16 Wochen geringer, nach 26 Wochen jedoch besonders stark ausgeprägt.

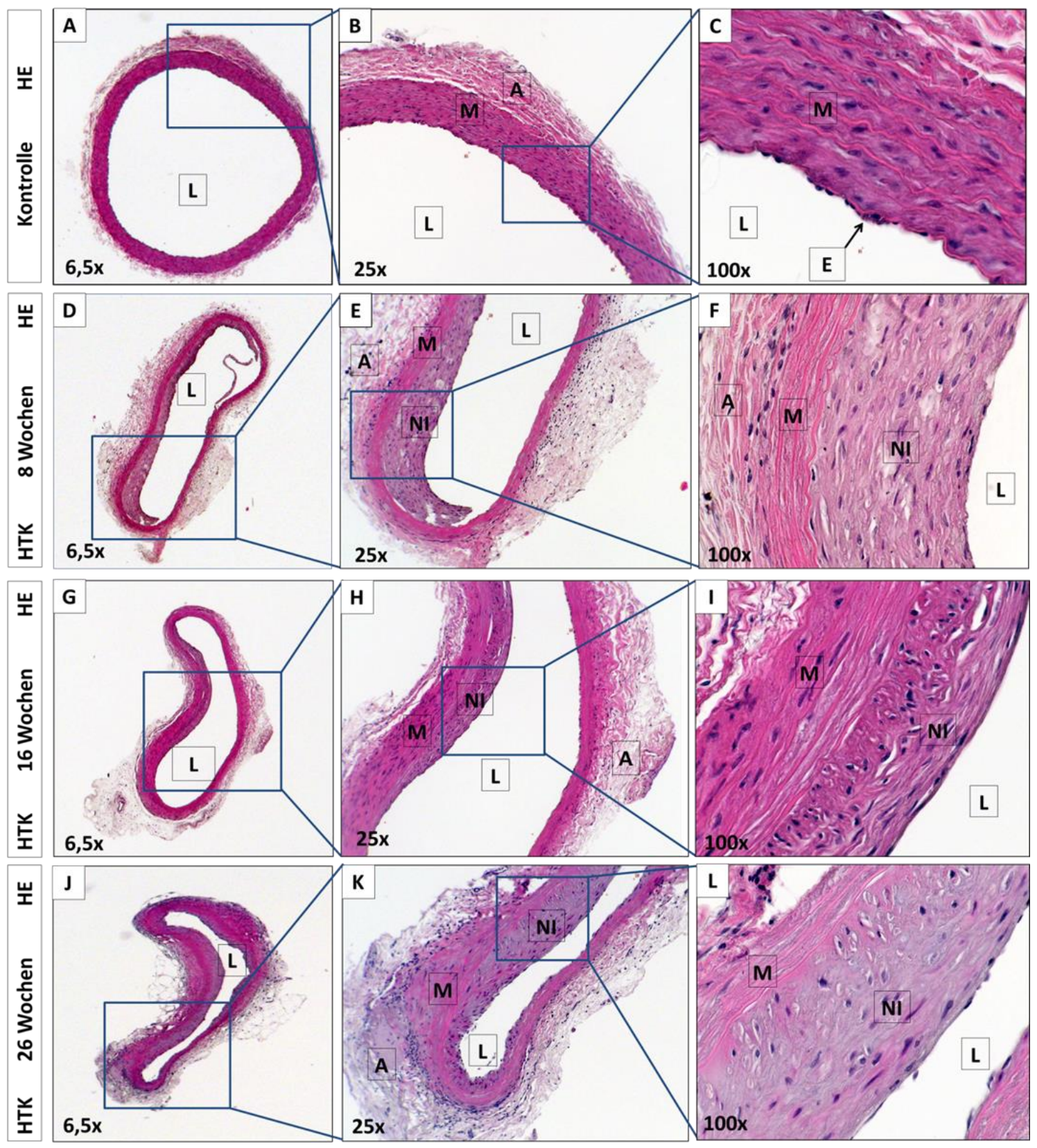

Abbildung 9: HE-Färbung der Aortenringe der HTK-Gruppe 8, 16 und 26 Wochen nach Implantation (D-L) sowie der Kontrollgruppe (A-C). Bereits 8 Wochen nach Implantation zeigt sich die Bildung einer Neointima (NI), die exzentrisch ausgebildet ist. Die Tunica media (M) ist deutlich verjüngt und besteht nur noch aus elastischen Fasern sowie extrazellulärer Matrix, zeigt jedoch keine Zellen (D-F). Diese Veränderungen an den Gefäßschichten zeigen sich ebenfalls nach 16 und 26 Wochen (G-L), wobei die Intimahyperplasie nach 26 Wochen besonders ausgeprägt ist. L: Lumen, A: Adventitia, M: Media, NI: Neointima, E: Endothel. Vergrößerung: 6,5x, 25x und 100x 


\section{TiProtec ${ }^{\circledR}$-Gruppe}

Die Gefäße, die in TiProtec ${ }^{\circledR}$ gelagert waren, zeigten 8 und 26 Wochen nach Transplantation eine geringe Intimahyperplasie, wobei nach 16 Wochen eine leichte Zunahme der Intimahyperplasie beobachtet werden konnte (Abbildung 10). Die Media zeigte sich auch bei diesen Gefäßen stark verjüngt und ohne Nachweis von Zellen. Sie bestand lediglich aus elastischen Fasern und extrazellulärem Matrix. 

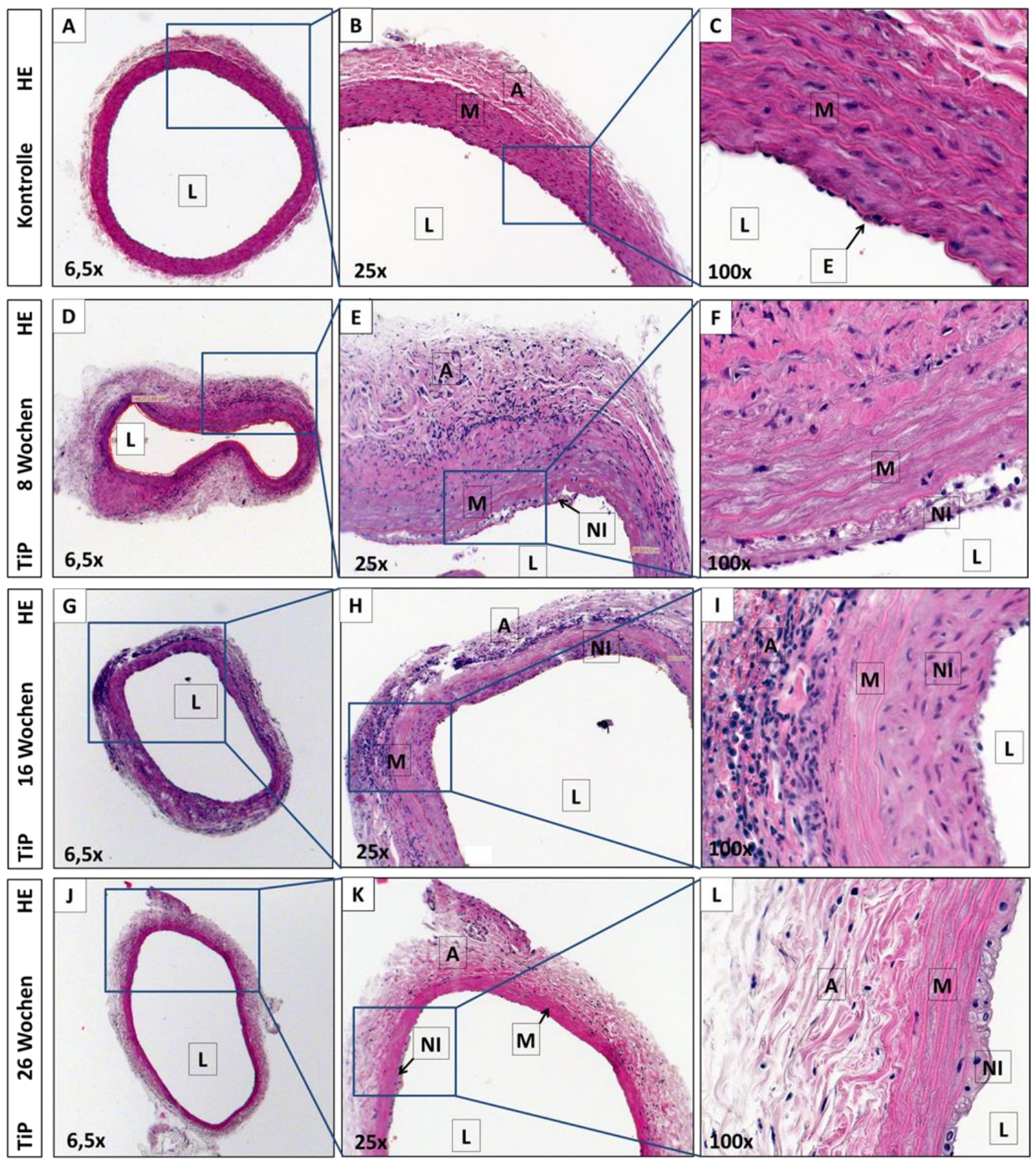

Abbildung 10: HE-Färbung der Aortenringe der TiP-Gruppe 8, 16 und 26 Wochen nach Implantation (D-L) sowie der Kontrollgruppe (A-C). 8 Wochen nach Implantation zeigt sich eine mäßige Neointima-Bildung (NI), die exzentrisch ausgebildet ist. Die Tunica media (M) ist deutlich verjüngt und besteht nur noch aus elastischen Fasern sowie extrazellulärer Matrix, zeigt jedoch keine Zellen (D-F). Diese Veränderungen an den Gefäßschichten zeigen sich ebenfalls nach 16 und 26 Wochen (G-L), wobei die Intimahyperplasie nach 26 Wochen sehr gering ausgeprägt ist. L: Lumen, A: Adventitia, M: Media, NI: Neointima, E: Endothel. Vergrößerung: 6,5x, 25x und 100x 


\subsubsection{Intimahyperplasie}

In den histologischen Präparaten der Aortenquerschnitte konnte in allen Gruppen nach den untersuchten Zeiträumen eine Intimahyperplasie nachgewiesen werden. Diese war jedoch, abhängig von der Gruppe und dem untersuchten Zeitraum, unterschiedlich ausgeprägt. Um das Ausmaß genauer untersuchen zu können, führten wir eine planimetrische Analyse der Intimahyperplasie in den Aortenquerschnitten anhand der HE-gefärbten Präparate. Hierbei zeigte sich 8 Wochen nach Implantation eine höhere Neointimabildung in den Aortengefäßen, die in $\mathrm{NaCl}$ gelagert waren, im Vergleich zu den Gefäßen, die in HTK oder TiProtec ${ }^{\circledR}$ konserviert wurden (s. Abbildung 11). Dieser Unterschied war zu TiProtec ${ }^{\circledR}$ statistisch signifikant $(p<0,05)$. Nach 16 Wochen zeigte sich für alle Gruppen eine Reduktion der Intimahyperplasie im Vergleich zu 8 Wochen nach Transplantation. Die Unterschiede innerhalb der Gruppen waren sehr gering und statistisch nicht signifikant. Nach 26 Wochen postoperativ zeigten die Gefäße in $\mathrm{NaCl}$ und HTK einen deutlichen Anstieg der Neointimabildung, während in den Gefäßen, die in TiProtec ${ }^{\circledR}$ gelagert waren, diese weiter abnahm. Dadurch ergab sich für TiProtec ${ }^{\circledR}$ ein statistisch signifikanter Unterschied in der Intimahyperplasie im Vergleich zu den Gruppen $\mathrm{NaCl}$ und HTK $(\mathrm{p}<0,05)$. 


\section{Intimahyperplasie}

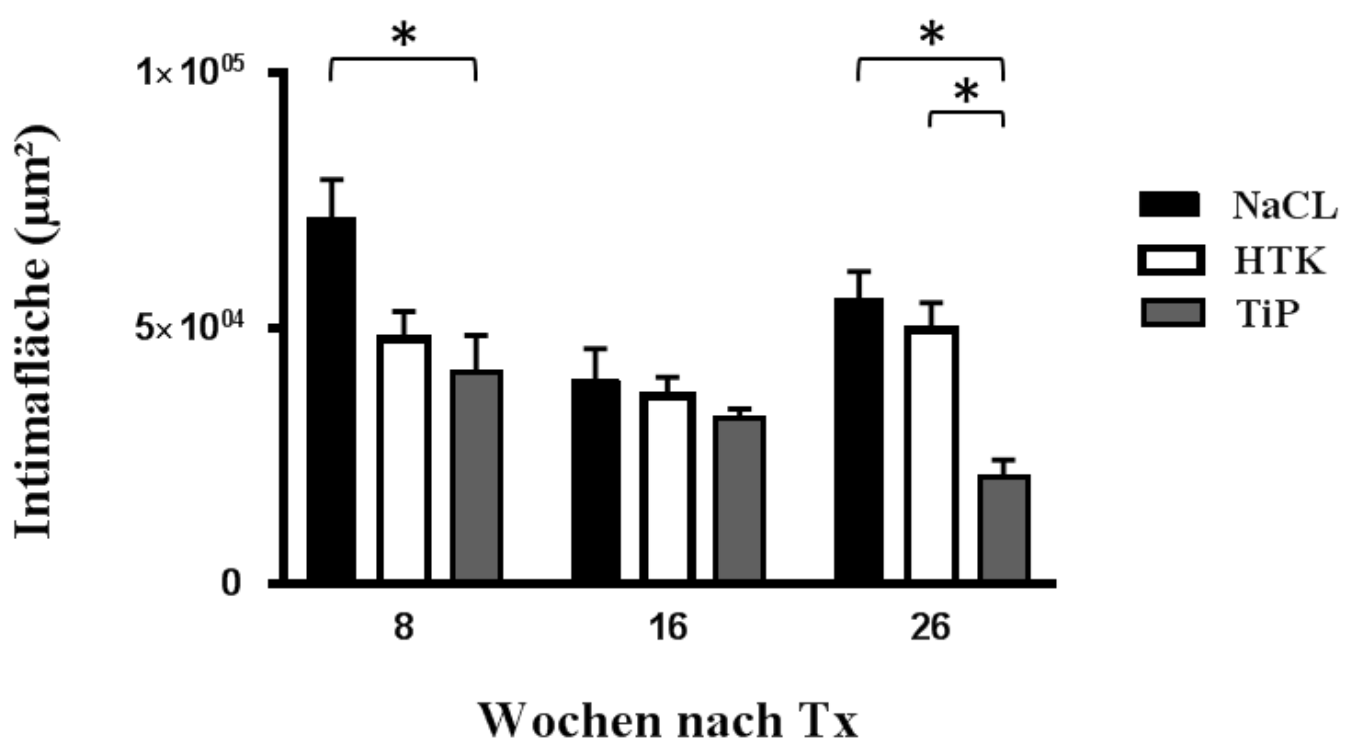

Abbildung 11: Ausmaß der Intimahyperplasie in den Gruppen NaCL, HTK und TiP 8, 16 und 26 Wochen nach Transplantation. Zur Quantifizierung der Intimahyperplasie erfolgte eine planimetrische Messung der Intima der Aortenquerschnitte. Die statistische Auswertung erfogte mit one-way ANOVA, * $p<0,05$, Tx:Transplantation

\subsubsection{Immunhistochemie}

Aus unseren Vasofunktionsversuchen konnten wir entnehmen, dass alle gelagerten Gefäße nach Transplantation die Fähigkeit zur Vasokontriktion verloren haben. Dieser Funktionsverlust war endothelunabhängig, sodass wir von einem Schaden des kontraktilen Apparates der Gefäße selbst ausgehen mussten. Erste Hinweise auf die Ursache zeigten sich in den HE-gefärbten Präparaten. Hier lag ein zum Teil kompletter Zellverlust in der Media in allen Gefäßen vor. Um nachzuweisen, ob noch glatte Muskelzellen in den Gefäßen vorhanden waren, führten wir eine immunhistochemische Färbung der Aortenquerschnitte mit dem Marker für glatte Muskelzellen alpha smooth muscle actin ( $\alpha$-SMA) durch.

\section{NaCl-Gruppe}

Die Untersuchung der Gefäße in der NaCl-Gruppe zeigt, dass nahezu alle Zellen der Neointima (NI) bereits 8 Wochen nach Implantation sich positiv für $\alpha$-SMA färben lassen (s. Abbildung 12, D-F). Nach 16 Wochen allerdings sind in der nach wie vor starken Neointima 
deutlich weniger positive Zellen nachzuweisen. Diese befinden sich endothelnah (s. Abbildung 12, G-I). Nach 26 Wochen zeigt sich die Neointima erneut stark positiv für $\alpha-$ SMA (s. Abbildung 12, J-L). In allen untersuchten Zeitpunkten sind in der Tunica media, die deutlich verjüngt ist, kaum $\alpha$-SMA-positive Zellen nachweisbar.

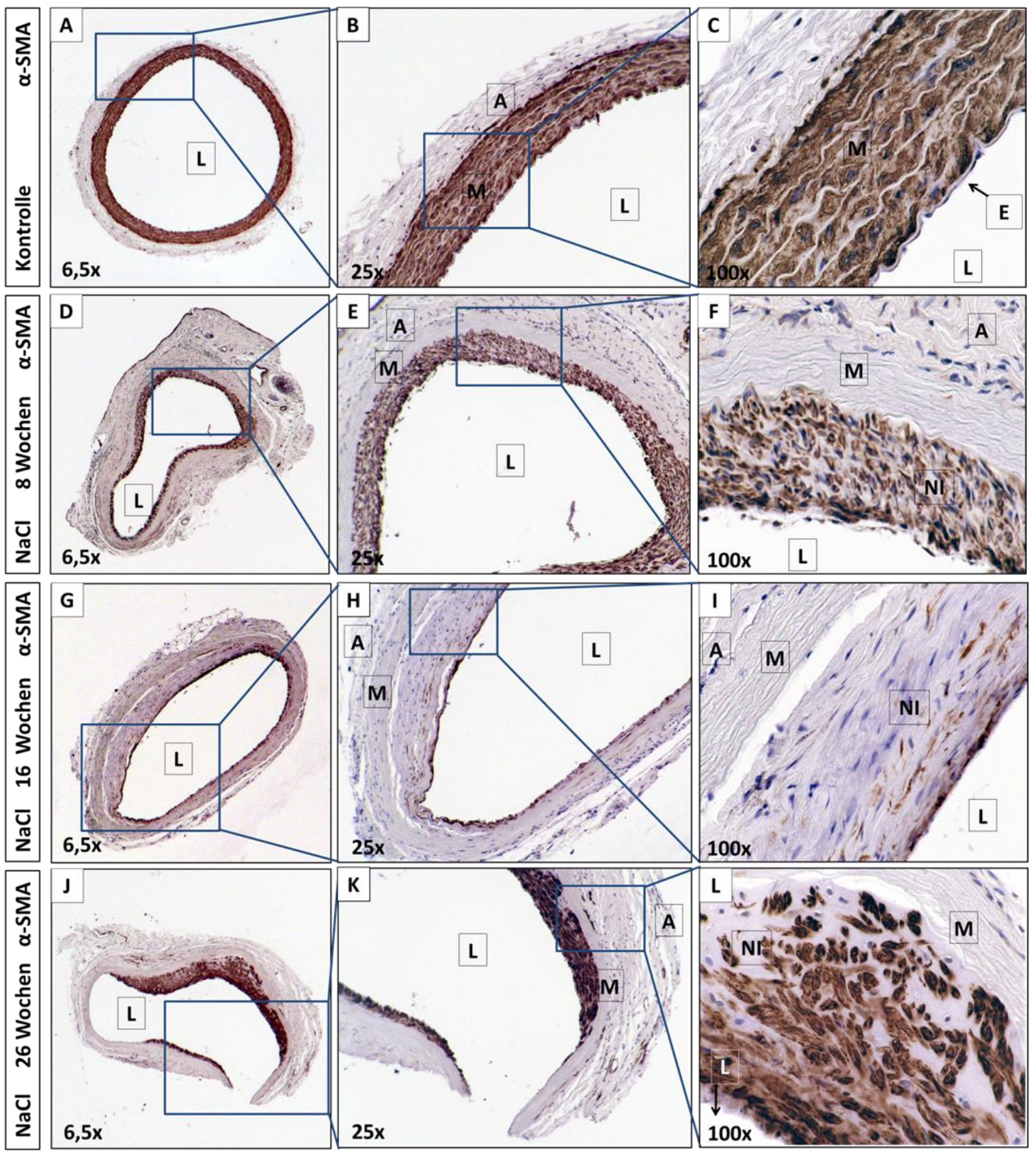

Abbildung 12: Immunhistochemische Färbung der Aortengefäße mit einem Antikörper gegen $\alpha$-SMA. Dargestellt sind Querschnitte der Aortengefäße der Kontrollgruppe (A-C) sowie der $\mathrm{NaCl}-G r u p p e$ 8, 16 und 26 Wochen nach Implantation (D-L). L: Lumen, A: Adventitia, M: Media, NI: Neointima, E: Endothel. Vergrößerung: 6,5x, 25x und 100x 


\section{HTK-Gruppe}

In den Gefäßen, die in HTK gelagert waren, zeigte sich 8 Wochen nach Implantation ein ähnliches Bild. In der Neointima hielten sich hauptsächlich Zellen auf, die für $\alpha$-SMA positiv gefärbt wurden, und in der geschrumpften Media konnten kaum Zellen nachgewiesen werden (Abbildung 13, D-F). 16 und 26 Wochen nach Implantation zeigte sich jedoch ein differentes Bild. Während die Neointima auch hier zahlreiche für $\alpha$-SMA positive Zellen beherbergte und die Media nach wie vor zellarm sich darstellte, waren in der Adventitia verstreut aber hauptsächlich jedoch gürtelförmig an die Media angrenzend angeordnete für $\alpha$-SMA positive Zellen nachweisbar (s. Abbildung 13, G-L). 


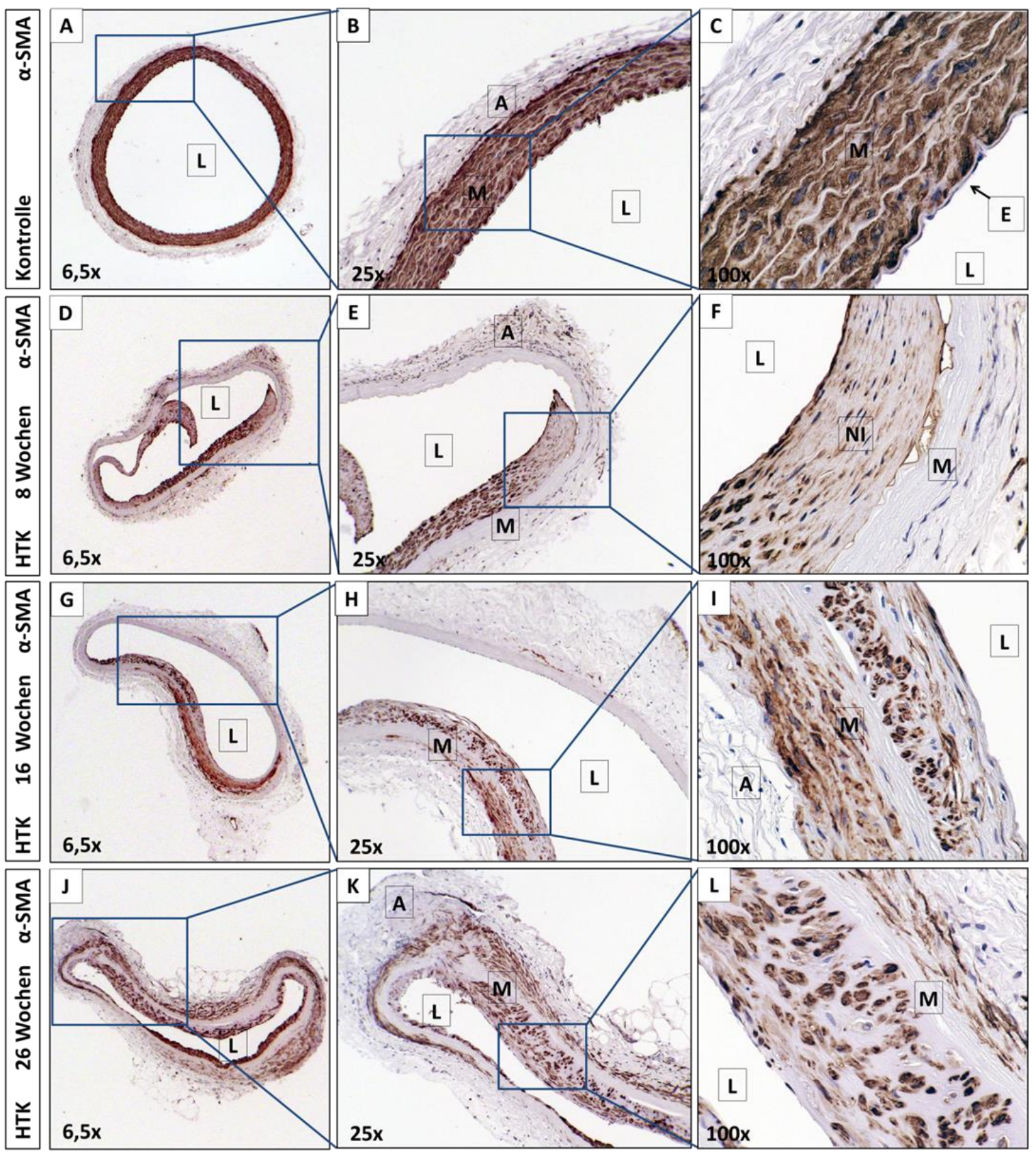

Abbildung 13: Immunhistochemische Färbung der Aortengefäße mit einem Antikörper gegen $\alpha$-SMA. Dargestellt sind Querschnitte der Aortengefäße der Kontrollgruppe (A-C) sowie der HTK-Gruppe 8, 16 und 26 Wochen nach Implantation (D-L). L: Lumen, A: Adventitia, M: Media, NI: Neointima, E: Endothel. Vergrößerung: 6,5x, 25x und 100x 


\section{TiProtec ${ }^{\circledR}$-Gruppe}

Die Gefäßtransplantate, die in TiProtec ${ }^{\circledR}$ gelagert wurden, zeigten 8 Wochen nach Implantation eine ausgeprägte Neointimabildung, die sich exzentrisch darstellte (s. Abbildung 14, D-F). Die Färbung von $\alpha$-SMA zeigte ein positives Ergebnis für die beteiligten Zellen innerhalb der Neointima. Darüber hinaus zeigten sich keine positiven Zellen im Bereich der Media. 16 Wochen nach Implantation war die Neointimabildung geringer. Die Zellen der Neointima ließen sich mit einem spezifischen Antikörper für $\alpha$-SMA positiv färben, wohingegen in der Media und Adventitia keine Zellen sich positiv darstellten (Abbildung 14, G-I). 26 Wochen nach Implantation war die Neointimabildung deutlich reduziert und es konnten wenige Zellen in diesem Bereich positiv gefärbt werden (s. Abbildung 14, J-L). Die Media zeigte sich, wie zuvor auch, ohne Präsenz von Zellen. In der Adventita waren vereinzelt positive Zellen nachweisbar. 


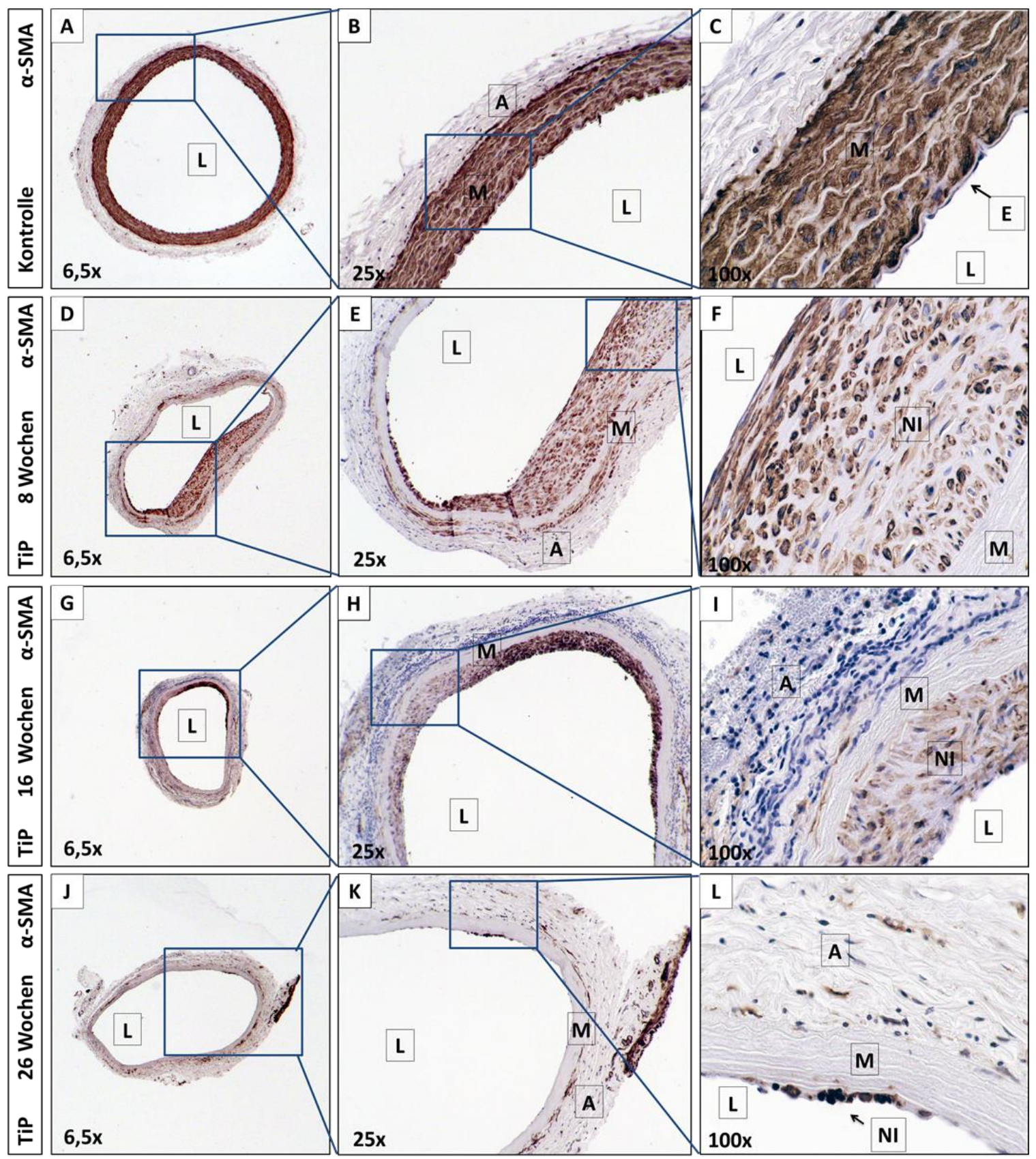

Abbildung 14: Immunhistochemische Färbung der Aortengefäße mit einem Antikörper gegen $\alpha$-SMA. Dargestellt sind Querschnitte der Aortengefäße der Kontrollgruppe (A-C) sowie der TiP-Gruppe 8, 16 und 26 Wochen nach Implantation (D-L). L: Lumen, A: Adventitia, M: Media, NI: Neointima, E: Endothel. Vergrößerung: 6,5x, 25x und 100x 


\subsection{Zusammenfassung der Ergebnisse}

Eine Kaltlagerung von Gefäßen über zwei Wochen führte in unserer Studie zu einem massiven Funktionsverlust. Zwar zeigten die in TiProtec ${ }^{\circledR}$ konservierten Gefäße 8 Wochen nach Implantation eine geringe Fähigkeit zur Kontraktilität im Vergleich zur NaCl- und HTK- Gruppe, diese war jedoch nach 16 und 26 Wochen nicht mehr vorhanden. Das Dilatationsverhalten war in allen Gruppen nicht messbar. Anders sah es aber bei den morphologischen und immunhistochemischen Veränderungen aus. Die in TiProtec $\mathbb{R}$ konservierten Gefäße zeigten die niedrigste Endothelproliferationsrate im Vergleich zu NaCl und HTK. Die an der Neointimabildung beteiligten Zellen konnten mit einem spezifischen Antikörper für $\alpha$-SMA positiv gefärbt werden. Parallel hierzu zeigte sich eine komplette Zellleere im Bereich der Media, wo sich sonst die glatten Muskelzellen sich befinden. Daraus lässt sich ableiten, dass es sich bei diesen Zellen um glatte Gefäßmuskelzellen handelt, die in die Intima eingewandert sind.

Es konnte also gezeigt werden, dass

- $\quad$ eine lange Kaltlagerung von zwei Wochen in TiProtec ${ }^{\circledR}$ die Gefäßfunktion nicht erhalten kann.

- $\quad$ eine nur geringe Endothelproliferation nach TiProtec ${ }^{\circledR}$-Lagerung im Langzeitverlauf vorhanden war.

- die Neointimabildung durch eine Einwanderung von glatten Muskelzellen verursacht wird.

- $\mathrm{NaCl}$ und HTK zur längeren Konservierung von Gefäßen keinen positiven Effekt haben

- $\quad$ TiProtec ${ }^{\circledR}$ als Konservierungslösung bei Langzeitlagerung (2 Wochen) positive Effekte hat. 


\section{Diskussion}

Die periphere arterielle Verschlusskrankheit ist eine der häufigsten atherosklerotischen Erkrankungen des Alters (Diehm et al. 2004b). Auch asymptomatisch ist sie ein signifikanter Prädiktor kardiovaskulärer Morbidität und Mortalität (Criqui et al. 1992; Hooi et al. 2004; Mlacak et al. 2006). Bestehen Ruheschmerzen oder droht eine kritische Ischämie, muss eine chirurgische Revaskularisation erfolgen (Aronow 2004). Eine Bypassanlage wird bei langstreckigen Stenosen oder Verschlüssen der unteren Extremität häufig notwendig. Als Graft der Wahl dabei kommt die Vena saphena magna in Frage. Auch in der Kardiochirurgie werden Arterien und Venen als Bypassmaterial verwendet (Desai et al. 2007). Nicht alle Patienten haben aber geeignete Gefäße, die als Bypass benutzt werden können. Die Venen sind z. B. bei einer aortokoronaren Myokardrevaskularisation bereits entnommen oder als Graft nicht brauchbar. Auch für die existierenden Gefäße sollten bessere Konservierungsbedingungen geschaffen werden, um ein Transplantatversagen und damit eine Reoperation zu vermeiden. Auch nach einer Protheseninfektion werden Ersatzgefäße benötigt. Das Problem verschärft sich durch eine wachsende Zahl der älteren und multimorbiden Patienten. Der Bedarf an Gefäßtransplantaten und Gefäßbanken mit optimalen Konservierungsbedingungen nimmt daher weiter $\mathrm{zu}$.

In dieser Studie wurden $\mathrm{NaCl}$, HTK und die neue Konservierungslösung TiProtec ${ }^{\circledR}$ bezüglich ihrer Gefäßprotektion miteinander verglichen. Segmente von Rattenaorten wurden dabei für zwei Wochen in der jeweiligen Lösung bei $4{ }^{\circ} \mathrm{C}$ kaltgelagert. Anschließend folgte die Implantation in Empfängertiere. Nach 8, 16 oder 26 Wochen wurden die Aortensegmente explantiert und einer Funktionsuntersuchung mit rezeptorabhängigen und -unabhängigen Kontraktion sowie endothelabhängigen und -unabhängigen Dilatation überführt. In der morphologischen Untersuchung wurde die Endothelproliferation analysiert.

Im Rahmen dieser Arbeit konnte erstmalig untersucht werden, ob TiProtec ${ }^{\circledR}$ den Gefäßen nach einer zweiwöchigen Konservierung bei $4{ }^{\circ} \mathrm{C}$ und Reimplantation in einem In-vivoTransplantationsmodell einen ausreichenden Schutz bieten kann. Es konnte gezeigt werden, dass

- $\quad$ TiProtec ${ }^{\circledR}$ die Funktion der glatten Muskelzellen nach langer Kaltlagerung nicht erhalten konnte. 
- der Verlust der Funktion der glatten Muskelzellen am ehesten mit der langen Kaltlagerung von zwei Wochen assoziiert ist.

- die Intimahyperplasie nach 8 und 26 Wochen signifikant niedriger war, wenn die Gefäße in TiProtec $®$ konserviert waren.

- $\mathrm{NaCl}$ und HTK nicht zur längeren Gefäßkonservierung verwendet werden sollten

\subsection{Studienlimitation}

Die Qualität der Aortensegmente hatte natürlich einen entscheidenden Einfluss auf die Funktionalität. Es wurde während der Präparation stets darauf geachtet, die Gefäßproben keinem mechanischen Schaden auszusetzen. Sowohl die Endothelschicht als auch die Muskularis wurden mit äußerster Vorsicht behandelt. Alle Eingriffe und Verarbeitung der Proben wurden vom selben Chirurgen durchgeführt, um einen Operateur abhängigen Einfluss auszuschließen. Auch die Lagerungszeiten zwischen den einzelnen Schritten (ExplantationLagerung-Implantation-Explantation-Funktionsmessung/Einfrieren) wurden möglichst kurz und konstant gehalten. Nachdem jeweils ein Tier aus der NaCl- und TIP-Gruppe ausgeschlossen werden musste, betrug die Anzahl der untersuchten Aortensegmente 25 in der HTK- Gruppe und jeweils 24 in der NaCl-und TiP-Gruppe. Alle Proben unterliefen einer Untersuchung zur Funktionsmessung, Endothelproliferationsmessung und Immunhistochemie. Der Probenumfang war vergleichbar mit weiteren Studien, die sich mit langer Kaltlagerung von Gefäßen befasst haben (Wilbring et al. 2013; Garbe et al. 2011). Während der Funktionsmessung im Organbad könnten vor allem das Anbringen der Aortenringe an den Haken sowie der Prozess der Vordehnung zu einem Gefäßwandschaden führen. Um dies zu vermeiden, wurden die Aortenringe nur an der Adventitia berührt und die Vordehnung sehr vorsichtig und langsam vollzogen. Sauerstoffzufuhr wurde ununterbrochen gewährleistet und Temperaturschwankungen durch häufige Kontrollen ausgeschlossen. Da es sich bei dieser Studie um eine In-vivo-experimentelle Studie handelte, wurde ein Rattenmodell ausgewählt. Grund hierfür war, dass dies nach unseren Recherchen ein häufig untersuchtes Modell darstellte. Die Endothelfunktion von Ratten und humanen Gefäßen hat dabei einen ähnlichen Mechanismus (Hutri-Kähönen et al. 1999). Dennoch sind in Zukunft weitere Studien mit humanen Gefäßen notwendig, um die vorliegenden Ergebnisse auf die Klinik zu übertragen. 


\subsection{Konservierungslösungen}

Die Endothelfunktion der Gefäßtransplantate ist abhängig von der verwendeten Konservierungslösung (Welz et al. 1991). Ziel ist dabei, die Endothelaktivierung, die zu einer chronischen Inflammation und schließlich zu einem Graftverschluss führt, zu verhindern (Schaeffer et al. 1997). Die ersten Organkonservierungslösungen waren zusammengesetzt, um den Ionenaushalt der Zellen aufrechtzuerhalten (Belzer und Southard 1988). Es wurde angenommen, dass Hypothermie zu einer Inhibition der Natrium/Kalium- ATPase und damit Natriumakkumulation in der Zelle führt, gefolgt von Chlorideinstrom und Zellschwellung (Hochachka 1986). Neuere Studien zeigen jedoch, dass dieser Mechanismus keine Rolle bei der Zellschädigung spielt (Gizewski et al. 1997). Die Hypothermie selbst soll vielmehr die Zellfunktion beeinträchtigen (Rauen et al. 2000). Die Gefäßkonservierungslösungen sollen also einen ausreichenden Schutz gegen diese kälteinduzierte Schädigung bieten, um eine bessere Transplantatfunktion zu erzielen. Der Endothelschutz reduziert dabei das Auftreten von Stenosen und Graftokklusionen (Solberg et al. 1992). Zur Erhaltung der Graftfunktion spielt also das Endothel eine zentrale Rolle und sollte daher besonders geschützt werden.

Neben der physiologischen Natriumchloridlösung (Fahner et al. 2006) werden Gefäßtransplantate heute in Organprotektionslösungen wie z. Bsp. HTK gelagert (Abrahamse et al. 2002). Zusätzlich findet aber auch die speziell für die Gefäße entwickelte Lösung

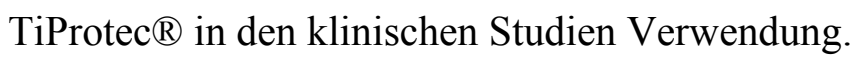

\subsubsection{0,9 \%ige plasmaisotone $\mathrm{NaCl}-\mathrm{Lösung}$}

Es wird angenommen, dass die 0,9\%ige Kochsalzlösung ursprünglich während der CholeraPandemie in Europa in 1831 entstanden ist (Masson 1971). Dennoch ist die Zusammensetzung der heutigen Natriumchloridlösung eine ganz andere als die der damals verwendeten Infusionslösungen, so dass die historische Herkunft dieser Lösung umstritten bleibt (Awad et al. 2008). Weltweit wird $\mathrm{NaCl}$ heute als häufigste Infusionslösung eingesetzt. In der kardiovaskulären Chirurgie wird sie aber auch zur kurzen Lagerung von Blutgefäßen gebraucht (Veres et al. 2015). Während einige Studien keinen Nachteil durch NaClKonservierung für die Gefäßfunktion zeigen konnten (Cartier et al. 1995; Tsakok et al. 2012), reicht nach Walbring et al. bereits eine kurze Lagerungsphase von humanem VSM in $\mathrm{NaCl}$ zur Beeinträchtigung der Endothelfunktion (Wilbring et al. 2011). Eine zweistündige 
Konservierung von VSM in Kochsalzlösung führte zu einer verminderten Kontraktion nach Kaliumchlorid- und Phenylephrinegabe (Wise et al. 2015). Zusätzlich konnte Cavallari et al. zeigen, dass es nach $\mathrm{NaCl}$-Lagerung zu einer signifikanten Intimahyperplasie kommen kann (Cavallari et al. 1997). Veres kam 2014 in einer tierexperimentellen Studie mit Aortensegmenten von Ratten zu einem ähnlichem Ergebnis. Eine Kaltlagerung von zwei Stunden in $\mathrm{NaCl}$ führte $\mathrm{zu}$ einem ausgeprägten Endothelschaden (Veres et al. 2015). Unbestritten bleibt auch, dass die Wahl der perioperativen Konservierungslösung die Transplantatreaktion beeinflussen kann (Chester et al. 1993).

Im Rahmen unserer Studie konnten vergleichbare Daten erhoben werden. Sowohl die Endothelfunktion als auch Endothelproliferation war nach $\mathrm{NaCl}$ - Konservierung deutlich negativ beeinflusst. Bemerkenswert war auch, dass im Vergleich zu HTK und TiProtec ${ }^{\circledR}$ kaum bis keinerlei Reaktion auf Kaliumchlorid, Phenylephrine, Acetylcholin oder Nitroprussid eruierbar war. Die Intimahyperplasie war in dieser Gruppe deutlich erhöht und darin die Proliferation der glatten Muskelzellen in hohem Maße nachweisbar. Die komplett aufgehobene Endothelfunktion hängt am ehesten mit der langen Konservierungszeit zusammen. Vor allem aber wird verdeutlicht, dass Natriumchlorid keinerlei Schutzmöglichkeiten für Blutgefäße bieten kann. $\mathrm{NaCl}$ sollte daher zur langen Konservierung von Blutgefäßen nicht verwendet werden.

\subsubsection{Histidin-Tryptophan-Ketoglutarat (HTK/Custodiol®/Bretschneider’s)}

Custodiol ist eine kristalloide Kardioplegielösung mit intrazellulärer Zusammensetzung (Köhler Chemie 1999). Sie wird in der Herzchirurgie vor allem bei Klappenoperationen und komplexen Eingriffen verwendet (Liu et al. 2008). Aber auch in der Transplantationschirurgie findet sie bei der Organkonservierung Verwendung (Gubernatis et al. 1990). Vorteilhaft in der Kardiochirurgie ist dabei, dass eine einzige Gabe von HTK einen Myokardschutz von über zwei Stunden gewährleisten kann (Gebhard et al. 1984). Dadurch könnten Unterbrechungen während der Operation vermieden werden (Braathen et al. 2011). HTK war erstmalig von Bretschneider in den 1970er Jahren beschrieben (Bretschneider et al. 1975). Sie hat eine niedrige Natrium- und Kalziumkonzentration. Natriummangel im Extrazellularraum führt zur Hyperpolarisation der Myozyten-Plasmamembran. Die während der Ischämie angesammelten sauren Metabolite werden durch Histidin gepuffert. Ketoglutarate sorgen für die ATP-Produktion bei der Reperfusion, und Tryptophan 
stabilisiert die Zellmembran. Mannitol reduziert das Zellödem und dient zum Neutralisieren von freien Radikalen (Bretschneider 1980). Gubernatis et al. beschreiben, dass HTK die Funktion der humanen Lebertransplantate auch nach über $12 \mathrm{~h}$ Kaltlagerung gut erhalten konnte (Gubernatis et al. 1990). In einer weiteren Studie untersuchten Widemann et al. HTK und $\mathrm{NaCl}$ bezüglich ihrer Wirkung auf die mitochondriale Funktion. Dabei wurden Schweineherzen und -blutgefäße nach Kaltlagerung von $14 \mathrm{~h}$ (Myokard) oder $24 \mathrm{~h}$ (Segmente der Aorta ascendens, A. mammaria, VSM) einer Respirometrie zugeführt. Custodiol zeichnete sich dabei durch hohe Protektion der myokardialen Mitochondrien aus und konnte demnach als Konservierungslösung in der Organtransplantation verwendet werden (Wiedemann et al. 2013). Eine Überlegenheit gegenüber $\mathrm{NaCl}$ bei der Gefäßkonservierung in dieser Studie konnte jedoch nicht nachgewiesen werden. Custodiol ${ }^{\circledR}$ wurde auch in einigen weiteren Arbeiten zur Lagerung von Gefäßtransplantaten eingesetzt. Schaeffer et al. untersuchten in einer Studie humane VSM und bovine Arteria und Vena mammaria, die zuvor in $\mathrm{HTK}, \mathrm{NaCl}$, heparinisiertem $\mathrm{NaCl}$, Ringer-Lactat-Lösung oder heparinisiertem Blut für zwei Stunden gelagert waren. Die Endothelschicht wurde daraufhin auf Zellschaden überprüft. HTK war dabei den anderen Lagerungslösungen deutlich überlegen (Schaeffer et al. 1997). Eine weitere Studie zeigte, dass HTK die kontraktile Gefäßfunktion für 36 h fast komplett erhalten konnte (Grohs et al. 1996). Bas et al. beschrieb jedoch 2016, dass die Endothelfunktion und die Funktion der glatten MuskelzellenFunktion von humanen VSM nach 48 h HTK-Lagerung deutlich beeinträchtigt war (Bas et al. 2016). In den letzten Jahren wurde auch eine modifizierte HTK-Lösung (Custodiol-N®) mit weiteren Bestandteilen (Eisenchelatoren, N-Acetyl-Histidin, hohe Kalium- und Chloridkonzentration) hergestellt. Zahlreiche tierexperimentelle Versuche zeigen, dass der Konservierungs- und Reperfusionsschaden durch Verwendung von Custodiol-N® deutlich verringert werden kann (Bahde et al. 2008; Stegemann et al. 2009; Wu et al. 2009). In unserer Studie konnte Custodiol-N® nach zweiwöchiger Kaltlagerung die Endothelfunktion nicht erhalten. Zu keinem Untersuchungszeitpunkt konnte eine messbare Kontraktilität durch eine Stimulation mit KCl- oder Norepinephrin erzielt werden. Die Vasodilatation war auch nach allen Transplantationszeiten nicht messbar. Die Endothelproliferation konnte durch HTK nicht verhindert werden und war mit der in der NaCl-Gruppe vergleichbar. HTK verfügt über weniger Eisenchelatoren, wie Desferan und LK 614. Daher konnte am ehesten die kälteinduzierte und eisenabhängige Schädigung des Endothels nicht verhindert werden. Wille et al beschreibt, dass diese Schädigung durch Kaltlagerung zeitabhängig ist und während der 
Reperfusion verstärkt wird (Wille et al. 2008). Auch HTK scheint also zur langen Kaltlagerung von zwei Wochen nicht geeignet zu sein.

\subsubsection{TiProtec ${ }^{\circledR}$}

Entsprechend der neueren Erkenntnisse zur Gefäßprotektion wurde aus der Custodiol®Lösung über Custodiol-N $₫$ eine neue Lösung TiProtec $\AA$ entwickelt (Wille et al. 2008). Diese Lösung soll die Gefäßendothelzellen vor kälteinduzierte Schädigung schützen, die durch reaktive Sauerstoffradikale verursacht wird und eisenabhängig ist (Rauen und de Groot 2004; Rauen et al. 2000; Salahudeen et al. 2000). Die intrazellulären Eisenionen bilden nach Kälteexposition hochreaktive Sauerstoffradikale, die vor allem die Mitochondrien über Membranporenbildung und damit Membranpotenzialverlust schädigen (Rauen et al. 2000). Auch die Endothelzellen werden während der Kaltlagerung zeitabhängig geschädigt, wobei die Schädigung bei der Reperfusion weiter zunimmt (Wille et al. 2008). Die Gruppe um Frau Rauen entwickelte basierend auf diesen Erkenntnissen aus Custodiol-N® durch Anpassung von Bestandteilen und Konzentration die TiProtec ${ }^{\circledR}$-Lösung. Bei kleineren Gewebeproben wie Gefäße war eine hohe Konzentrationen an Puffer nicht notwendig, so dass diese reduziert und die entstandene osmotische Ionendifferenz vor allem durch Chlorid ersetzt wurde (Wille et al. 2008). Chlorid wirkte sich dabei positiv auf die Vitalität der Endothelzellen. Der positive Effekt von Chlorid wurde auch in einem Herztranplantationsmodell der Mäuse gezeigt (Wu et al. 2011). Als Puffer diente N-Acetylhistidin in einer geringeren Menge statt Histidin, da unter Histidin selbst eisenabhängig Sauerstoffradikale entstehen (Rauen et al. 2007). N- Acetylhistidin dagegen scheint redoxaktives Eisen stärker zu binden. Des Weiteren zeigte sich eine kaliumreiche Lösung endothelschützend im Vergleich $\mathrm{zu}$ einer natriumreichen Lösung (Wille et al. 2008; Zatschler et al. 2009). Am ehesten kommt es durch die hohe Kaliumkonzentration zu keinem Kaliumaustritt aus den Gefäßendothelzellen und somit wird die Apoptose verhindert (Lang et al. 2005). Ein leicht saures Milieu mit einem pH-Wert von 7,0 wirkte sich positiv auf die Zellfunktion und auf das Membranpotenzial von Mitochondrien (Wille et al. 2008; Nishimura et al. 1998). Die Aminosäure Alanin soll verhindern, dass bei Hypoxie während der Kaltlagerung zur Porenbildung an der Zellwand und darüber zu einem Natriumeinstrom kommt (Rauen und de Groot 2004; Bahde et al. 2008) Glycin wirkt ebenfalls membranstabilisierend, vermutlich über membranständige Rezeptoren (Weinberg et al. 1990). Auch Tryptophan aus Custodiol-N® wurde in der selben Konzentration zugesetzt (Wu et al. 2009). Die Substrate des Zitratzyklus, Aspartat und a- 
Ketoglutarat, wurden ebenfalls von der Custodiol-N® Lösung beibehalten (Wille et al. 2008). Da Endothelzellen eine hohe glykolytische Aktivität aufweisen, ist der neuen Lösung Glukose hinzugefügt worden (Mertens et al. 1990). Schließlich kam zum hydrophilen Eisenchelator Deferoxamin der lipophile Eisenchelator LK 614 (Wille et al. 2008). Die lipophile Eigenschaft hat den Vorteil, dass der LK 614 schnell und bereits zu Beginn der Kaltlagerung durch die Zellmembran passieren und in die Zellinnere gelangen kann, um dort redoxaktives Eisen zu binden und zu neutralisieren. Die Konzentration der Eisenchelatoren mussten dabei genau angepasst werden, da in höheren Mengen eine toxische Wirkung bestand (Koch et al. 2010). Die Optimierung der Basislösung Custodiol-N®, wie oben beschrieben, erfolgte in einem Schweineaortenmodell. Dabei wurden $2 \mathrm{~cm}$ lange Aortensegmente in HTK, Perfadex oder der neuen optimierten TiProtec ${ }^{\circledR}$-Lösung bei $4{ }^{\circ} \mathrm{C}$ für maximal 21 Tage konserviert. Die Endothelzellvitalität wurde anschließend über eine Propidiumjodid-Färbung, die die Kerne nekrotischer und apoptotischer Zellen markiert, bestimmt. Zusätzlich folgten Untersuchungen zur Thrombozytenadhäsion und zum mitochondrialen Membranpotenzial. Die Endothelzellvitalität und das mitochondriale Membranpotenzial waren unter TiProtec ${ }^{\circledR}$ im Vergleich zur HTK und Perfadex deutlich besser erhalten (Wille et al. 2008). Auch eine verminderte Thrombozytenadhäsion an das Endothel konnte nachgewiesen werden. Die Überlegenheit der TiProtec-Lösung konnte auch in weiteren Untersuchungen bestätigt werden. Zatschler et al. untersuchten Segmente der Aorta und Arteria mesenterica superior der Ratte nach 4 Tagen Kaltlagerung. Bestimmt wurden unter anderem die Endothelstruktur, die Tonusentwicklung nach KCL-Gabe, die endothelabhängige und endothelunabhängige Relaxation und die Expression der endothelialen NO-Synthase. Verglichen mit der physiologischen Kochsalzlösung und HTK zeigte die neue Gefäßprotektionslösung eine komplette Erhaltung der Endothelstruktur, der Endothelfunktion und der Funktion der glatten Muskelzellen (Zatschler et al. 2009). In einer weiteren Studie wurden humane Arteria mammaria Segmente untersucht (Garbe et al. 2011). Die im Rahmen der aortokoronaren Bypassoperationen entnommenen Gefäßproben wurden für maximal 25 Tage bei $4{ }^{\circ} \mathrm{C}$ in HTK, 0,9\%iger NaCL oder TiProtec ${ }^{\circledR}$ gelagert. Bestimmt wurde unter anderem die Vasokonstriktion mit $\mathrm{KCl}$ sowie endothelabhängige und endothelunabhängige Vasodilatation mit Acetylcholin und Nitroprussid. Die Ergebnisse der physiologischen Kochsalzlösung waren hierbei ernüchternd, indem bereits nach 10stündiger Lagerungszeit der Gefäßtonus komplett aufgehoben war. Die HTK- Gruppe zeigte zwar nach $4 \mathrm{~h}$ Konservierung einen guten Funktionserhalt, nach 4 Tagen jedoch kam es zu einem 
deutlichen Funktionsverlust der Gefäßsegmente. Die TiProtec $®$-Gruppe brachte auch hier die besten Ergebnisse. Nach 4 Tagen war die Endothel- und die glatte Muskelzellfunktion vollkommen erhalten. Nach 10 Tagen betrug die endothelabhängige Relaxation $50 \%$ bei komplett erhaltener Funktion der glatten Muskelzellen. Tiprotec ${ }^{\circledR}$ wurde auch zur Konservierung von Muskelgewebe verwendet. Rattendiaphragma konnte nach 2,5h Kaltlagerung eine bessere Kraftentwicklung gegenüber NaCl-konservierte Proben aufweisen (Wille et al. 2011). Wilbring et al. zeigten in einer Studie mit humanen VSM-Segmenten, die $24 \mathrm{~h}$ und $96 \mathrm{~h}$ kaltgelagert waren, dass TiProtec ${ }^{\circledR}$ die Endothelfunktion gegenüber $\mathrm{NaCl}$ deutlich schützen konnte (Wilbring et al. 2013). In $\mathrm{NaCl}$ gelagerte Venen dagegen verloren ihr Vermögen an Vasokonstrikion, endothelzell- und glatte Muskelzell- abhängige Dilatation nach 96 h nahezu komplett. Veres et al. verglichen in einer bislang einzigen In-vivo-Studie im Rattenmodell die physiologische Kochsalzlösung, HTK und TiProtec ${ }^{\circledR}$ im Hinblick auf Endothelerhaltung. Nach zweistündiger Kaltlagerung in der jeweiligen Lösung wurden Aortensegmente in Aorta abdominalis transplantiert. Nach 2 h, 24 h und einer Woche folgte die Explantation und Untersuchung der Gefäße. Die endothelabhängige und endothelunabhängie Vasodilatation war in der TiProtec $®-G r u p p e$ gegenüber Kochsalzlösung und HTK deutlich überlegen (Veres et al. 2016). Auch unsere Studie zeigte zwar eine bessere Endothelschichtmorphologie nach TiProtec ${ }^{\circledR}-$ Konservierung, der Erhalt der Endothelfunktion konnte durch TiProtec $\AA$ nicht gewährleistet werden. Das Dilatationsvermögen war nach 14 Tagen Kaltlagerung in allen Gruppen (TiProtec ${ }^{\circledR}$, HTK und $\mathrm{NaCl}$ ) aufgehoben. Dieses Ergebnis ist vergleichbar mit den Daten von Garbe et al., wo nach 10-tägiger Konservierung lediglich $50 \%$ der endothelabhängigen Dilatation messbar war (Garbe et al. 2011). Die Vasokonstriktion war auch in dieser Arbeit der NaCl- und HTKGruppe überlegen, dennoch blieb eine komplette Erhaltung der glatten Muskelzellfunktion aus. Erwähnenswert ist dabei, dass es sich bei allen oben beschriebenen Studien bis auf die Studie von Veres et al. um in Vitro-Untersuchungen handelte. Auch diese Studie ist mit einer 2-stündigen Kaltlagerung und maximaler Transplantationszeit von einer Woche (gegenüber maximal 26 Wochen in unserer Studie) nur bedingt mit unserer Arbeit vergleichbar. Es ist weiterhin $\mathrm{zu}$ berücksichtigen, dass bei In-vivo-Studien auch weitere Faktoren, wie chirurgisches Trauma und Wirtsreaktion, eine Rolle in der Endothelfunktion spielen. Zu beobachten ist aber, dass die Endothelproliferation, die für die Transplantatfunktion von enormer Bedeutung ist, in der TiProtec ${ }^{\circledR}-$ Gruppe im Vergleich $\mathrm{zu} \mathrm{NaCl}$ und HTK am geringsten ausgeprägt war. 


\subsection{Funktionsmessung}

\subsubsection{Rezeptorunabhängige Kontraktion mit $\mathrm{KCl}$}

$\mathrm{KCl}$ führt über Zellmembrandepolarisation $\mathrm{zu}$ einem Kalziumeinstrom durch spannungsabhängige Kalziumkanäle (Karaki et al. 1988a). Es kommt zu einem Anstieg der cytosolischen Kalziumkonzentration und zur Aktivierung der Kalzium-Calmodulinabhängigen MyosinleicHTKetten- Kinase. MLC- Kinase wiederum phosphoryliert MLC, fördert die Aktin-Myosin-Interaktion, und es kommt zu einer Kontraktion (Dillon et al. 1981; Ratz et al. 2005; Silver 1986). Die rezeptorabhängige, G-Protein-gekoppelte Kontraktion wird damit umgangen. Die frisch entnommenen Rattenaortensegmente wurden zunächst im Organbad $\mathrm{KCl}$ ausgesetzt und zeigten auch ihre maximale Kontraktion unter Kaliumchlorid (Kontrollgruppe). Blieb die Reaktion auf Kalium gering oder sogar aus, konnte im Laufe der Versuchsreihen davon ausgegangen werden, dass der Kontraktionsapparat geschädigt und keine Reaktion auf weitere Substanzen zu erwarten war. Insgesamt bestand auch eine enge Korrelation zwischen den morphologischen Veränderungen an den Aortenringen und Reaktion auf Kaliumchlorid. Besonders in der NaCl-Gruppe kam es zur geringsten Reaktion auf Kalium nach 8 Wochen Transplantationszeit, die nach 16 und 26 Wochen komplett ausblieb. $\mathrm{Zu}$ einem vergleichbaren Ergebnis kam auch Garbe et al. In einem in VitroVersuch, wobei bereits nach 10 Stunden NaCl-Konservierung keine Tonusentwicklung an humanen Arterien messbar war (Garbe et al. 2011). Auch Wise et al. zeigten, dass eine Kaltlagerung von 2 Stunden in Kochsalzlösung $\mathrm{zu}$ einer deutlichen Kontraktionseinschränkung geführt hat (Wise et al. 2015).

Die in HTK gelagerten Aortensegmente zeigten bereits nach 8 Wochen TransplantationsPeriode deutliche Kontraktionseinschränkung, die auch nach 16 und 26 Wochen erhalten blieb. Zu einer ähnlichen Erkenntnis kamen Abrahamse und Kollegen bei einer in VitroUntersuchung von Schweinecarotiden (Abrahamse et al. 2002). Nach Kaltlagerung von 2 Wochen in $\mathrm{NaCl}$ und $\mathrm{HTK}$ blieb nahezu jede Reaktion auf Kontrationsstimulus aus. Die TiProtec ${ }^{\circledR}-$ Gruppe in unserer Studie zeigte lediglich nach 8 Wochen Transplantationszeit noch eine Kontraktilität nach $\mathrm{KCl}-\mathrm{Gabe}$, die im Vergleich zur $\mathrm{NaCl}$ und $\mathrm{HTK}$ signifikant war. Diese Kontraktilitätsfähigkeit konnte jedoch nach 16 und 26 Wochen Transplantationszeit nicht mehr detektiert werden. In einem in Vitro Rattenmodell konnte eine nahezu komplett erhaltene Funktion der glatten Muskelzellen der 
Mesenterialartieriensegmente nach 4 Tagen Konservierung in TiProtec $\AA$ nachgewiesen werden (Zatschler et al. 2009). Die Erklärung liegt am ehesten an der langen Kaltlagerung von 14 Tage und der dadurch bedingten Schädigung der gletten Muskelzellen. Keine der untersuchten Lösungen konnte also die Funktion der glatten Muskelzellen nach 14 Tagen Kaltlagerung vollständig erhalten.

\subsubsection{Rezeptorabhängige Kontraktion mit Phenylephrin}

Im Gegensatz $\mathrm{zu} \quad \mathrm{KCl}$ wirkt Phenylephrin (PE) als ein $\alpha$-adrenerges, direktes Sympathomimetikum über einen G-Protein gekoppelten Alpha-1- Rezeptor (Drew und Whiting 1979). Je nach PE-Konzentration bindet es entweder nur Alpha- 1- Rezeptoren, oder auch deren Subtypen (Benevolensky et al. 1987; Errasti et al. 1999; Yamamoto et al. 1984; Kenny et al. 1996) oder gar myokardiale Alpha- und Beta-1-Adrenorezeptoren (Srivastava et al. 1977). Durch Bindung von PE an die Alpharezeptoren wird eine G- Protein-gekoppelte Kaskade ausgelöst. Die Phosphatidylinosit-spezifische Phospholipase C spaltet Phosphatidylinosit-4,5-bisphosphat zu Diacylglycerin und Inosit-1,4,5-trisphosphat (IP3) (Ueda et al. 1986; Wolf et al. 1987). IP3 bindet an IP3- Rezeptoren des sarkoplasmatischen Retikulums. Es kommt zu einem Kalziumausstrom aus dem sarkoplasmatischen Retikulum unter Energieverbrauch und folglich zu erhöhter Kalzuimkonzentration im Zytoplasma. Durch Interaktion von Aktin und Myosin kommt es zu einer Kontraktion (Saida et al. 1988; Saida und van Breemen 1987). Eine fehlende Antwort auf PE könnte multifaktorielle Ursachen haben. Eine lagerungsbedingte Zerstörung der Rezeptoren oder des kontraktilen Apparates oder fehlende Substrate können einige dieser Ursachen sein. Insgesamt konnte in der vorliegenden Studie keine nennenswerte Reaktion auf PE festgestellt werden. Die in allen drei Lösungen ( $\mathrm{NaCl}, \mathrm{HTK}$, TiProtec $\left.{ }^{\circledR}\right)$ konservierten Aortenringe zeigten nach 2 Wochen Kaltlagerung und Transplantation für 8, 16 und 26 Wochen eine fehlende kontraktile Reaktion. Zatschler und Kollegen konnten in einer In-vitro-Studie, in der Rattenarterien nach 4 Tagen Kaltlagerung in Kochsalzlösung, HTK oder TiProtec ${ }^{\circledR}$ gelagert wurden, in den ersten beiden Gruppen eine signifikante Endothelschädigung sowie komplett aufgehobene Tonusentwicklung nachweisen (Zatschler et al. 2009). Nur die TiProtec ${ }^{\circledR}-L o ̈ s u n g ~ k o n n t e$ einen ausreichenden Schutz gegen die kälteinduzierte Schädigung mit gut erhaltener Endothelschicht und -funktion bieten. Die Ergebnisse einer weiteren In-vitro-Studie mit humanen Gefäßen zeigten bereits nach $10 \mathrm{~h} \mathrm{NaCl-Konservierung} \mathrm{einen} \mathrm{vollkommenen}$ 
Tonusverlust nach Norepinephrin-Stimulation (Garbe et al. 2011). Nach 4 Tagen HTKKaltlagerung war das Kontraktions- und Dilatationsvermögen genauso geschädigt. Lediglich TiProtec ${ }^{\circledR}$ war den beiden anderen Lösungen überlegen. Betreffend $\mathrm{NaCl}$ und $\mathrm{HTK}$ zeigten die oben beschriebenen Studien vergleichbare Ergebnisse. Dass in unserer Studie TiProtec ${ }^{\circledR}$ die rezeptorabhängige Kontraktilität der Gefäße vor allem im Langzeitverlauf nicht erhalten konnte, hängt am ehesten mit der längeren Kaltlagerung von 14 Tagen und der dadurch bedingten Schädigung der glatten Muskelzellen zusammen.

\subsubsection{Endothelunabhängige Dilatation mit Nitroprussid}

Nitroprussid ist ein potenter Vasodilatator, der vom Hämoglobin in Cyanid gespalten wird (Tinker und Michenfelder 1976). Als NO-Donor führt es cGMP-abhängig zu einer Aktivierung der Proteinkinase. Über Proteinphosphorylierung wird der PhosphatidylinositolZyklus inhibiert (Walter et al. 1988). Die endothelständige NO-Synthase wird also nicht benötigt. In niedrigen Konzentrationen hemmt Nitroprussid den Kalziumeinstrom in die Zelle, in höheren Dosen setzt es die Kalzium-Sensitivität des kontraktilen Apparates herab (Karaki et al. 1988b). Nach Inhibition von NO-Synthase untersuchten Garbe und Kollegen humane Arteria mammaria bezüglich endothelunabhängiger Vasodilatation (Garbe et al.

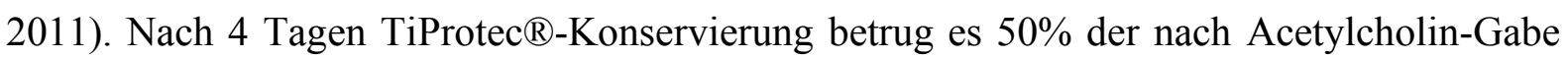
gemessenen Dilatation. HTK- und Kochsalz-Gruppen zeigten dagegen eine deutlich eingeschränkte bzw. aufgehobene Funktion.

Alle untersuchten Aortensegmente in unserer In-vivo-Studie zeigten unabhängig von der verwendeten Konservierungslösung eine fehlende Reaktion auf Nitroprussid. Auch hier scheint die lange Kaltlagerung von 2 Wochen den Muskelapparat deutlich geschädigt zu haben. Hier ist die wahrscheinlichste Erklärung das Fehlen von glatten Muskelzellen innerhalb der Media in den Aortensegmenten, welches keine Relaxation mehr ermöglicht. 


\subsubsection{Endothelabhängige Dilatation mit Acetylcholin}

Acetylcholin führt an den Gefäßendothelzellen über die muskarinerge Rezeptoren zur Ausschüttung von endothelium-derived relaxing factors (EDRF) und damit $\mathrm{zu}$ einer Gefäßrelaxation (Furchgott 1993). Die dilatative Wirkung von Acetylcholin (Ach) kommt aber nur dann zum Tragen, wenn Endothel vorhanden und dieses auch unversehrt ist (Furchgott und Zawadzki 1980). Andernfalls bewirkt Ach eine Vasokonstriktion. Beim EDRF handelt es sich dabei unter anderem um Stickstoffmonoxid (NO), Prostaglandine und endothelium-derived hyperpolariznig factor (EDHF) (Furchgott und Vanhoutte 1989). Es werden aber auch vasokostriktorische Substanzen wie Endothelin ausgeschüttet. Das Endothel setzt unter normalen Bedingungen auch durchgehend NO frei (Vane und Botting 1992). Zusätzlich kommt es durch Ach-Freisetzung an den Gefäßen über EDHF-Freisetzung zur Hyperpolarisation der glatten Muskelzellen und Vasorelaxation (Nagao und Vanhoutte 1992; Chen et al. 1988). Das NO wird von NO-Synthase aus L- Arginin abgespalten und aktiviert die Guanylatzyklase an der glatten Muskelzelle (Furchgott und Vanhoutte 1989). Es wird vermehrt zyklisches Guanosinmonophosphat (cGMP) gebildet, dieses aktiviert die cGMP-abhängige Proteinkinase, die verschiedene Proteine der Signalkaskade phosphoryliert (Rapoport und Murad 1983). Schließlich kommt es durch die Dephosphorylierung der Myosinleichtketten zur Vasorelaxation (Rapoport et al. 1983). Die Endothelfunktion hängt vor allem mit der NO-Freisetzung und -Aktivität zusammen (Lefer und Ma 1993). Leukozytenadhäsion, Emigration an das Endothelium und folglich eine akute Inflammation und Neointimabildung wären einige Folgen einer unzureichenden NO- Freisetzung (Kubes et al. 1991; Cayatte et al. 1994). Zusätzlich führt die Kaltlagerung zu vermehrter Expression des von-Willebrand-Faktors und darunter zur Thrombozytenadhäsion (Upadhya und Strasberg 2002). Der Schutz des Endothels ist daher von enormer Bedeutung (Zatschler et al. 2009). Lagerungs- und Verfahrensbedingte Endothelschäden im Rahmen von kardiovaskulären Eingriffen sollten möglichst vermieden werden. In der vorliegenden Arbeit war die Reaktion auf Ach-Gabe komplett aufgehoben. Nach zwei Wochen Kaltlagerung und 8, 16 und 26 Wochen Transplantation konnte in keiner der untersuchten Gruppen ein messbares Dilatationsvermögen festgestellt werden. Die Gruppen $\mathrm{NaCl}$ und HTK betreffend gibt es vergleichbare Ergebnisse aus In-vitro-Studien. Bereits $2 \mathrm{~h}$ Konservierung in HTK führte zu enormen Endothelveränderungen (Zatschler et al. 2009). Nach 4 Tagen war keine Dilatation mehr messbar. Auch Garbe und Kollegen konnten nach 4 Tagen HTK-Konservierung der 
humanen Arteria mammaria massive Funktionseinschränkungen des Gefäßendothels feststellen, in der NaCl-Gruppe war bereits nach über $10 \mathrm{~h}$ Kaltlagerung keine Tonusentwicklung vor der Dilatationstestung möglich (Garbe et al. 2011). Lediglich TiProtec $\mathbb{R}$ konnte das Endothel auch nach 10 Tagen gut erhalten, wobei die endothelabhängige Dilatation mit Ach 50\% betrug. Wille und Kollegen beschreiben ebenfalls ein gut erhaltenes Endothel in Schweineaorta nach einer Kaltlagerungszeit von über 3 Wochen (Wille et al. 2008). Durch die lange Kaltlagerung von 14 Tagen in TiProtec $®$ war in unserer Arbeit 8, 16 und 26 Wochen nach Transplantation keine Dilatation messbar, da das Endothel und der kontraktile Apparat nicht erhalten werden konnten.

\subsection{Morphologie}

\subsubsection{Endothelproliferation}

Mit der Hämatoxylin-Eosin-Färbung sollten die strukturellen Veränderungen des Endothels quantitativ anhand von Flächenmessung bestimmt werden. Die vorliegende Studie zeigt dabei, dass es im Rahmen der langen Kaltlagerung von insgesamt zwei Wochen nicht nur zu massiven funktionellen, sondern auch strukturellen Endothelschäden gekommen war. Auch eine Beeinträchtigung des glatten Gefäßmuskelapparates konnte festgestellt werden. Besonders ausgeprägt waren die Endothelveränderungen in Form von Endothelproliferation in der NaCl- und HTK-Gruppe. Diese auch als Intimahyperplasie bezeichnete Veränderung führt $\mathrm{zu}$ einer Lumenverkleinerung und somit zu einer Stenose. Lediglich die in der TiProtec ${ }^{\circledR}$ konservierten Aortensegmente zeigten eine signifikant geringere Proliferationstendenz. Durch Endothelschaden kommt es zur Migration der glatten Muskelzellen in die Intima, wo sie proliferieren und so zu einer Intimaverdickung führen (Dilley et al. 1992). Die Endothelproliferation ist also als Folge von Endothelschaden zu sehen. Diese Endothelschädigung ist vor allem durch Kaltlagerung verursacht und entsteht durch eisenabhängige reaktive Sauerstoffspezies (ROS), wobei der größere Schaden während der Reperfusion entsteht (Wille et al. 2008). Die Endothelschicht von Schweineaorten, die 14 Tage in TiProtec gelagert waren, zeigten im Vergleich zur Lagerung in Kochsalzlösung, HTK, University of Wisconsin (UW) und Perfadex eine besser erhaltene Zellstruktur und deutlich weniger nekrotische Zellen. Mesenterialarterien der Ratten zeigten in einer weiteren in Vitro-Studie bereits nach $2 \mathrm{~h}$ HTK-Kaltlagerung einen ausgeprägten Endothelzellschaden. Noch gravierender war die Endothelzellstruktur nach 96h Kochsalzlagerung (Zatschler et al. 
2009). Lediglich die Protektionslösung mit Eisenchelatoren (TiProtec $\AA$ ) konnte die Endothelstruktur erhalten. Vereinbar mit diesen Studien ist die in unserer Studie ermittelte niedrige Endothelproliferation als Zeichen geringer Endothelzellschädigung mit der besseren Protektion durch TiProtec $\AA^{\circledR}$ zu erklären. Die speziell zur Gefäßkonservierung entwickelte Lösung scheint vor allem durch den Zusatz von Eisenchelatoren zum Erhalt der Zellvitalität und -struktur beizutragen. Die Ergebnisse der Funktionsmessung sind in der vorliegenden Studie insofern mit den morphologischen Veränderungen vereinbar.

\subsubsection{Glatte Muskelzellen}

Gefäßeingriffe sind auch mit Gefäßverletzungen assoziiert. Einerseits kommt es zu einer mechanischen Schädigung des Nativgefäßes durch die Naht, Endarteriektomie, Thrombektomie und perkutane transluminale Angioplastie. Andererseits verursacht die Implantation von autologen oder prothetischen Grafts oder Stents zu einer Gefäßverletzung. Arterien und Venen antworten auf solche Verletzung mit einer Neointimabildung (Allaire und Clowes 1997). Infolge von Endothelzellschädigung kommt es zur Migration von glatten Muskelzellen in die Intima und schließlich zur Intimahyperplasie. Diese eingewanderten Zellen stammen entweder aus dem Blutkreislauf oder aber aus den angrenzenden Gefäßrändern (Kouchi et al. 1998; Clowes et al. 1983). Zusätzlich wird die Synthese von Extrazellularmatrix initiert bestehend aus Kollagen, Elastin und Proteoglycan (Sottiurai et al. 1983; Snow et al. 1990). Das Endothel scheint dabei auch nicht nur die Funktion und Migration, sondern auch das Wachstum und den Untergang der glatten Muskelzellen zu beeinflussen (Ross 1993; Davies und Hagen 1993; Nakahashi et al. 1995). Die Intimahyperplasie ist durch zwei verschiedene Veränderungen an den glatten Muskellzellen gekennzeichnet. Einerseits bilden die glatten Muskelzellen eine Media-Fibroplasie durch Myofibroblasten, andererseits degenerieren die Muskelzellen und führen damit zur Medianekrose (Sottiurai et al. 1983). In günstigeren Fällen erreicht die Zellantwort ein steady state mit ausreichend erhaltenem Lumen oder aber die Intimahyperplasie führt zu einer Lumenobstruktion und einem Gefäßverschluss (Loop et al. 1983; FitzGibbon et al. 1986; Campeau et al. 1983). In einem Hasenmodell beschreibt Zwolak den zeitlichen Ablauf der Intimahyperplasie (Zwolak et al. 1987). Dabei wurden Vena jugularis externa Segmente in die Carotis implantiert. Die Thrombozyten, Leukozyten und Mikrothromben lagerten sich an den Anastomosenbereich an, wo kein Endothel vorhanden war. Diese vom Endothel 
freiliegende Oberfläche wurde nach zwei Wochen mit neuen Endothelzellen bedeckt. Zu diesem Zeitpunkt beginnt auch die Intimahyperplasie. In den ersten 4 Wochen kommt es durch die Proliferation der glatten Muskelzellen und Anhäufung zu einer Gefäßwandverdickung. Nach Proliferationsende führt die Zunahme der extrazellulären Matrix zu einer weiteren Intimaverdickung, wobei das Maximum der Wanddicke nach 12 Wochen erreicht wird (Kohler et al. 1989). Zwei Wachstumsfaktoren, der basic fibroblast growth factor (bFGF) und der platelet-derived growth factor (PDGF) triggern die Proliferation der glatten Muskellzellen in der Media und die Migration dieser in die Intima (Saltis et al. 1995; Huang et al. 2017). bFGF wird dabei von dem geschädigten Endothel und den glatten Muskelzellen freigesetzt und stimuliert in der Media die Proliferation der glatten Gefäßmuskellzellen (Lindner und Reidy 1991). In der vorliegenden Studie kam es im Rahmen der langen Kaltlagerung von zwei Wochen vor allem in der NaCl- und HTK-Gruppe $\mathrm{zu}$ einem Verlust der glatten Muskelzellen in der Medischicht. Diese bestand nur noch aus der Extrazellulärmatrix sowie den internen Lamellen. Die Media war dadurch auch deutlich geschrumpft. Beide Lösungen bieten also keinen Schutz gegen die kälteinduzierte Intimaschädigung. Gleichzeitig waren im Bereich der verdickten Intima in diesen Präparaten alle Zellen für $\alpha$-SMA positiv. Dies ist eine weit verbreitete Methode um glatte Muskelzellen nachzuweisen. Daraus lässt sich ableiten, dass durch die lange Kaltlagerung von 2 Wochen und der anschließenden Reperfusion nach Transplantation der Schaden im Bereich des Endothels zu einer Abwanderung der glatten Muskezellen aus der Media in die Intima geführt hat. Lediglich die in TiProtec ${ }^{\circledR}$ konservierten Aortensegmente zeigten eine signifikant geringere Endothelproliferation im Vergleich zu NaCl und HTK.

\subsection{Ausblick}

Tiprotec ${ }^{\circledR}$ konnte in dieser Arbeit im Vergleich zu HTK und $\mathrm{NaCl}$ die beste Protektion gegen die Endothelschädigung und folglich Intimahyperplasie bieten. Längerfristig könnte dies die Entstehung von Artherosklerose mit Transplantatstenose und Transplantatokklusion verhindern. Die Funkionalität der Gefäße war jedoch in allen untersuchten Gruppen beeinträchtigt. Während die Tonusentwicklung bei allen Gruppen herabgesetzt war, war das Dialatiosverhalteten der untersuchten Gefäße kaum messbar. Einen vollkommenen Schutz nach zwei Wochen Kaltkonservierung bei $4{ }^{\circ} \mathrm{C}$ konnte also keine der Lösungen bieten. Diese lange Konservierungszeit von über einer Woche ist aber für die vorgeschriebene 
Gefäßuntersuchung und -verarbeitung notwendig, bevor die Gefäßtransplantate in Gewebebanken konserviert werden können (Richtlinie (EU) 2015/566 2015). Weitere Untersuchungen sind hier notwendig, um die Protektion hier weiter zu verbessern. Auch eine Post-vivo-Explantation von Leichengefäßspendern mit Konservierung bedingt eine optimale Konservierung der Gefäße. 


\section{Zusammenfassung}

Die Prävalenz der pAVK steigt mit der älter werdenden Population. In fortgeschrittenen Stadien werden auch zunehmend Revaskularisationseingriffe mit Bypassanlage notwendig. Um bessere Langzeitergebnisse durch die Revaskularisation erzielen zu können, ist ein funktionell und morphologisch gut erhaltenes Transplantat von enormer Bedeutung. Die bisher eingesetzten Konservierungslösungen zur Gefäßlagerung konnten bisher keinerlei Schutz gegen die eisenabhängige kälteinduzierte Schädigung bieten. Die neue speziell zur Gefäßprotektionslösung entwickelte TiProtec $\AA$-Lösung sollte diese bestehende Lücke schließen. Einige In-vitro-Studien konnten bisher die Überlegenheit dieser Lösung nach Kaltlagerung über einige Tage nachweisen. Die TiProtec $\AA$-Lösung konnte in der vorliegenden Studie im Vergleich zur HTK- und Kochsalzlösung eine übermäßige Intimahyperplasie verhindern.

Für die bessere klinische Transplantatfunktion ist die geringe Endothelproliferation, die zu einer Stenose und Okklusion führen könnte, von großer Bedeutung. In TiProtec ${ }^{\circledR}$ konservierte Gefäße zeigten vor allem im Langzeitversuch mit 26 Wochen die geringste Endothelproliferation. Dies würde in einem klinischen Setting eine lange BypassOffenheitsrate deutlich begünstigen. Dennoch war in allen untersuchten Gruppen die Funktionsmessung deutlich eingeschränkt. Fehlende Dilatation und geringe Kontraktion sprechen für einen nicht ausreichenden Gefäßschutz nach zwei Wochen Kaltkonservierung. Mit der immunhistochemischen Bestimmung von a-SMA konnte die Migration der glatten Muskelzellen in die Intima und deren Proliferation innerhalb der so gebildeten Neointima nachgewiesen werden. 


\section{Literaturverzeichnis}

Abrahamse ST, Dinant S, Pfaffendorf M, van Gulik TM (2002): In vitro function of porcine carotid arteries preserved in UW, HTK and Celsior solutions. Fundam Clin Pharmacol $\underline{16}, 503-511$

Adcock OT, Adcock GL, Wheeler JR, Gregory RT, Snyder SO, Gayle RG (1984): Optimal techniques for harvesting and preparation of reversed autogenous vein grafts for use as arterial substitutes: a review. Surgery $\underline{96}, 886-894$

Albers M, Battistella VM, Romiti M, Rodrigues AAE, Pereira CAB (2003): Metaanalysis of polytetrafluoroethylene bypass grafts to infrapopliteal arteries. $J$ Vasc Surg 37, 1263-1269

Allaire E, Clowes AW (1997): Endothelial Cell Injury in Cardiovascular Surgery: The Intimal Hyperplastic Response1. Ann Thorac Surg 63, 582-591

Allard L, Cloutier G, Durand LG, Roederer GO, Langlois YE (1994): Limitations of ultrasonic duplex scanning for diagnosing lower limb arterial stenoses in the presence of adjacent segment disease. J Vasc Surg $\underline{19}, 650-657$

Allison MA, Ho E, Denenberg JO, Langer RD, Newman AB, Fabsitz RR, Criqui MH (2007): Ethnic-specific prevalence of peripheral arterial disease in the United States. Am J Prev Med $\underline{32}$, 328-333

Ameli FM, Stein M, Provan JL, Prosser R (1989): The effect of postoperative smoking on femoropopliteal bypass grafts. Ann Vasc Surg $\underline{3}, 20-25$

Archie JP (1994): Femoropopliteal bypass with either adequate ipsilateral reversed saphenous vein or obligatory polytetrafluoroethylene. Ann Vasc Surg $\underline{8}, 475-$ 484

Aronow WS (2004): Management of peripheral arterial disease of the lower extremities in elderly patients. J Gerontol A Biol Sci Med Sci $\underline{59}, 172-177$

Aronow WS, Nayak D, Woodworth S, Ahn C (2003): Effect of simvastatin versus placebo on treadmill exercise time until the onset of intermittent claudication in older patients with peripheral arterial disease at six months and at one year after treatment. Am J Cardiol $\underline{92}, 711-712$

Arvela E, Venermo M, Söderström M, Albäck A, Lepäntalo M (2012): Outcome of infrainguinal single-segment great saphenous vein bypass for critical limb ischemia is superior to alternative autologous vein bypass, especially in patients with high operative risk. Ann Vasc Surg 트, 396-403

Awad S, Allison SP, Lobo DN (2008): The history of $0.9 \%$ saline. Clin Nutr Edinb Scotl $27,179-188$ 
Bahde R, Palmes D, Gemsa O, Minin E, Stratmann U, de Groot H, Rauen U, Spiegel $\mathrm{H}-\mathrm{U}$ (2008): Attenuated cold storage injury of rat livers using a modified HTK solution. J Surg Res $\underline{146}$, 49-56

Bainton D, Sweetnam P, Baker I, Elwood P (1994): Peripheral vascular disease: consequence for survival and association with risk factors in the Speedwell prospective heart disease study. Br Heart J $\underline{72}, 128-132$

Bas M, Luther B, Knopf A, Suvorava T, Kojda G (2016): Preservation of Endothelial and Smooth Muscle Function of Human Saphenous Vein Transplants. Exp Clin Transplant $\underline{14}, 86-92$

Belzer FO, Southard JH (1988): Principles of solid-organ preservation by cold storage. Transplantation $\underline{45}, 673-676$

Benevolensky DS, Menshikova EV, Watras J, Levitsky DO, Ritov VB (1987): Characterization of $\mathrm{Ca} 2+$ release from the sarcoplasmic reticulum of myocardium and vascular smooth muscle. Biomed Biochim Acta $\underline{46}$, S393398

Bergan JJ, Veith FJ, Bernhard VM, Yao JS, Flinn WR, Gupta SK, Scher LA, Samson $\mathrm{RH}$, Towne JB (1982): Randomization of autogenous vein and polytetrafluorethylene grafts in femoral-distal reconstruction. Surgery $\underline{92}, 921-$ 930

Berra A, Ganzinelli S, Saravia M, Borda E, Sterin-Borda L (2005): Inducible nitric oxide synthase subserves cholinergic vasodilation in retina. Vis Neurosci 22 , 371-377

Bisdas T, Bredt M, Pichlmaier M, Aper T, Wilhelmi M, Bisdas S, Haverich A, Teebken OE (2010): Eight-year experience with cryopreserved arterial homografts for the in situ reconstruction of abdominal aortic infections. J Vasc Surg $\underline{52}, 323-330$

Bisdas T, Pichlmaier M, Wilhelmi M, Bisdas S, Haverich A, Teebken OE (2011): Effects of the ABO-mismatch between donor and recipient of cryopreserved arterial homografts. Int Angiol 프, 247-255

Botting R, Vane JR (1989): Vasoactive mediators derived from the endothelium. Arch Mal Coeur Vaiss 82 Spec No 4, 11-14

Braathen B, Jeppsson A, Scherstén H, Hagen OM, Vengen $\varnothing$, Rexius $H$, Lepore $V$, Tønnessen T (2011): One single dose of histidine-tryptophan-ketoglutarate solution gives equally good myocardial protection in elective mitral valve surgery as repetitive cold blood cardioplegia: A prospective randomized study. J Thorac Cardiovasc Surg 141, 995-1001

Bretschneider HJ (1980): Myocardial Protection. Thorac Cardiovasc Surg 28, 295302 
Bretschneider HJ, Hübner G, Knoll D, Lohr B, Nordbeck H, Spieckermann PG (1975): Myocardial resistance and tolerance to ischemia: physiological and biochemical basis. J Cardiovasc Surg (Torino) $\underline{16}$, 241-260

Buckberg GD (1991): Myocardial temperature management during aortic clamping for cardiac surgery. Protection, preoccupation, and perspective. J Thorac Cardiovasc Surg 102, 895-903

Buerger L (2009): Landmark Publication from The American Journal of the Medical Sciences: Thrombo-Angiitis Obliterans: A Study of the Vascular Lesions Leading to Presenile Spontaneous Gangrene1. Am J Med Sci 337, 274-284

Bustamante M, Gomez-Dermit V, García I, Pontón A, Revuelta JM, Gonzalez-Tutor A (2009): Endoluminal repair of a pseudoaneurysm in a patient with cryopreserved arterial allograft of the iliac vessel. Ann Vasc Surg 23, 410.e1720

Cahill PA, Redmond EM (2016): Vascular endothelium - Gatekeeper of vessel health. Atherosclerosis 248, 97-109

Campbell JH, Campbell GR (1989): Biology of the vessel wall and atherosclerosis. Clin Exp Hypertens A $\underline{11}$, 901-913

Campeau L, Enjalbert M, Lespérance J, Vaislic C, Grondin CM, Bourassa MG (1983): Atherosclerosis and late closure of aortocoronary saphenous vein grafts: sequential angiographic studies at 2 weeks, 1 year, 5 to 7 years, and 10 to 12 years after surgery. Circulation $\underline{68}, \| 1-7$

Cartier R, Bouchard D, Latulippe JF, Buluran J (1995): [Effect of solutions of preservation on the vascular reactivity of human saphenous veins]. Ann Chir $\underline{49}, 728-734$

Cavallari N, Abebe W, Mingoli A, Sapienza P, Hunter WJ, Agrawal DK, Cavallaro A, Edwards JD (1997): Short-term preservation of autogenous vein grafts: effectiveness of University of Wisconsin solution. Surgery 121, 64-71

Cayatte AJ, Palacino JJ, Horten K, Cohen RA (1994): Chronic inhibition of nitric oxide production accelerates neointima formation and impairs endothelial function in hypercholesterolemic rabbits. Arterioscler Thromb J Vasc Biol $\underline{14}$, 753-759

Chen G, Suzuki H, Weston AH (1988): Acetylcholine releases endothelium-derived hyperpolarizing factor and EDRF from rat blood vessels. $\mathrm{Br} \mathrm{J}$ Pharmacol $\underline{95}$, 1165-1174

Chester AH, O'Neil GS, Tadjakarimi S, Borland JA, Yacoub MH (1993): Effect of peri-operative storage solution on the vascular reactivity of the human saphenous vein. Eur J Cardio-Thorac Surg Off J Eur Assoc Cardio-Thorac Surg $\underline{7}, 399-404$ 
Clagett GP, Robinowitz M, Youkey JR, Fisher DF, Fry RE, Myers SI, Lee EL, Collins GJ, Virmani R (1986): Morphogenesis and clinicopathologic characteristics of recurrent carotid disease. J Vasc Surg $\underline{3}, 10-23$

Clowes AW, Reidy MA, Clowes MM (1983): Kinetics of cellular proliferation after arterial injury. I. Smooth muscle growth in the absence of endothelium. Lab Investig J Tech Methods Pathol $\underline{49}$, 327-333

Collins GM, Bravo-Shugarman M, Terasaki PI (1969): Kidney Preservation for Transportation. Lancet 294, 1219-1222

Collins R, Cranny G, Burch J, Aguiar-lbáñez R, Craig D, Wright K, Berry E, Gough M, Kleijnen J, Westwood M (2007): A systematic review of duplex ultrasound, magnetic resonance angiography and computed tomography angiography for the diagnosis and assessment of symptomatic, lower limb peripheral arterial disease. Health Technol Assess Winch 11, iii-iv, xi-xiii, 1-184

Crawford F, Welch K, Andras A, Chappell FM (2016): Ankle brachial index for the diagnosis of lower limb peripheral arterial disease. Cochrane Database Syst $\operatorname{Rev} \underline{9}$, CD010680

Criqui MH, Fronek A, Barrett-Connor E, Klauber MR, Gabriel S, Goodman D (1985): The prevalence of peripheral arterial disease in a defined population. Circulation $\underline{71}, 510-515$

Criqui MH, Langer RD, Fronek A, Feigelson HS, Klauber MR, McCann TJ, Browner $D$ (1992): Mortality over a period of 10 years in patients with peripheral arterial disease. N Engl J Med $\underline{326}$, 381-386

Davies MG, Hagen PO (1993): The vascular endothelium. A new horizon. Ann Surg $\underline{218}, 593-609$

Davies MG, Hagen PO (1994): Pathobiology of intimal hyperplasia. Br J Surg $\underline{81}$, 1254-1269

Deb S, Cohen EA, Singh SK, Une D, Laupacis A, Fremes SE, RAPS Investigators (2012): Radial artery and saphenous vein patency more than 5 years after coronary artery bypass surgery: results from RAPS (Radial Artery Patency Study). J Am Coll Cardiol $\underline{60}, 28-35$

Desai ND, Naylor CD, Kiss A, Cohen EA, Feder-Elituv R, Miwa S, Radhakrishnan S, Dubbin J, Schwartz L, Fremes SE, Radial Artery Patency Study Investigators (2007): Impact of patient and target-vessel characteristics on arterial and venous bypass graft patency: insight from a randomized trial. Circulation $\underline{115}$, 684-691

Dhaliwal G, Mukherjee D (2007): Peripheral arterial disease: Epidemiology, natural history, diagnosis and treatment. Int J Angiol 16, 36-44

Diehm C, Kareem S, Lawall H (2004a): Epidemiology of peripheral arterial disease. VASA Z Gefässkrankh $\underline{33}, 183-189$ 
Diehm C, Schuster A, Allenberg JR, Darius H, Haberl R, Lange S, Pittrow D, Stritzky B von, Tepohl G, Trampisch H-J (2004b): High prevalence of peripheral arterial disease and co-morbidity in 6880 primary care patients: crosssectional study. Atherosclerosis $\underline{172}, 95-105$

Diehm C, Lange S, Darius H, Pittrow D, von Stritzky B, Tepohl G, Haberl RL, Allenberg JR, Dasch B, Trampisch HJ (2006): Association of low ankle brachial index with high mortality in primary care. Eur Heart J $\underline{27}, 1743-1749$

Dilley RJ, McGeachie JK, Tennant M (1992): Vein to artery grafts: a morphological and histochemical study of the histogenesis of intimal hyperplasia. Aust $\mathrm{N} Z \mathrm{~J}$ Surg $\underline{62}, 297-303$

Dillon PF, Aksoy MO, Driska SP, Murphy RA (1981): Myosin phosphorylation and the cross-bridge cycle in arterial smooth muscle. Science 211, 495-497

Dirican A, Özsoy M, Barut B, İnce V, Ateş M, Yılmaz S (2014): Retrohepatic inferior vena cava reconstruction with saphenous vein patch in advanced stage cholangiocarcinoma. Ulus Cerrahi Derg $\underline{30}$, 160-164

Dombre V, De Seigneux S, Schiffer E (2016): [Sodium chloride 0.9\%: nephrotoxic crystalloid?]. Rev Med Suisse 12, 270-272, 274

Dormandy J, Heeck L, Vig S (1999): The fate of patients with critical leg ischemia. Semin Vasc Surg 12, 142-147

Drew GM, Whiting SB (1979): Evidence for two distinct types of postsynaptic alphaadrenoceptor in vascular smooth muscle in vivo. Br J Pharmacol $\underline{67}, 207-215$

Drouin A, Noiseux N, Chartrand-Lefebvre C, Soulez G, Mansour S, Tremblay J-A, Basile F, Prieto I, Stevens L-M (2013): Composite versus conventional coronary artery bypass grafting strategy for the anterolateral territory: study protocol for a randomized controlled trial. Trials $\underline{14}, 270$

Ebner A, Zatschler B, Deussen A (2011): Evaluation of cold storage conditions for vessels obtained from donor rats after cardiac death. J Vasc Surg $\underline{54}, 1769$ 1777

Errasti AE, Velo MP, Torres RM, Sardi SP, Rothlin RP (1999): Characterization of alpha1-adrenoceptor subtypes mediating vasoconstriction in human umbilical vein. Br J Pharmacol $\underline{126}$, 437-442

Espinola-Klein C, Savvidis S (2009): Periphere arterielle Verschlusskrankheit Epidemiologie, Klinik und Diagnostik. Internist $\underline{50}, 919$

Espinola-Klein C, Rupprecht H-J, Blankenberg S, Bickel C, Peth S, Kopp H, Victor A, Hafner G, Meyer J (2002): Manifestationen der Atherosklerose in verschiedenen Gefäßregionen Gemeinsamkeiten und Unterschiede hinsichtlich Epidemiologie, Ätiologie und Prognose. Med Klin 97, 221-228 
Faggiotto A, Ross R, Harker L (1984): Studies of hypercholesterolemia in the nonhuman primate. I. Changes that lead to fatty streak formation. Arteriosclerosis $\underline{4}, 323-340$

Fahner PJ, Idu MM, Gulik TM van, Legemate DA (2006): Systematic review of preservation methods and clinical outcome of infrainguinal vascular allografts. J Vasc Surg 44, 518-524

FitzGibbon GM, Leach AJ, Keon WJ, Burton JR, Kafka HP (1986): Coronary bypass graft fate. Angiographic study of 1,179 vein grafts early, one year, and five years after operation. J Thorac Cardiovasc Surg 91, 773-778

Förstermann U, Sessa WC (2012): Nitric oxide synthases: regulation and function. Eur Heart J $\underline{33}, 829-837$

Förstermann U, Mülsch A, Böhme E, Busse R (1986): Stimulation of soluble guanylate cyclase by an acetylcholine-induced endothelium-derived factor from rabbit and canine arteries. Circ Res $\underline{58}, 531-538$

Fowkes FG (1988): Epidemiology of atherosclerotic arterial disease in the lower limbs. Eur J Vasc Surg 2, 283-291

Fowkes FG, Housley E, Cawood EH, Macintyre CC, Ruckley CV, Prescott RJ (1991): Edinburgh Artery Study: prevalence of asymptomatic and symptomatic peripheral arterial disease in the general population. Int $\mathrm{J}$ Epidemiol 20, 384-392

Fowkes FGR, Rudan D, Rudan I, Aboyans V, Denenberg JO, McDermott MM, Norman PE, Sampson UKA, Williams LJ, Mensah GA, Criqui MH (2013): Comparison of global estimates of prevalence and risk factors for peripheral artery disease in 2000 and 2010: a systematic review and analysis. Lancet 382, $1329-1340$

Furchgott RF (1993): Introduction to EDRF research. J Cardiovasc Pharmacol $\underline{22}$ Suppl 7, S1-2

Furchgott RF, Zawadzki JV (1980): The obligatory role of endothelial cells in the relaxation of arterial smooth muscle by acetylcholine. Nature $\underline{288}, 373-376$

Furchgott RF, Vanhoutte PM (1989): Endothelium-derived relaxing and contracting factors. FASEB J $\underline{3}, 2007-2018$

Garbe S, Zatschler B, Müller B, Dieterich P, Ebner A, Rauen U, Matschke K, Deussen $A$ (2011): Preservation of human artery function following prolonged cold storage with a new solution. J Vasc Surg $\underline{53}, 1063-1070$

Geary RL, Kohler TR, Vergel S, Kirkman TR, Clowes AW (1994): Time course of flow-induced smooth muscle cell proliferation and intimal thickening in endothelialized baboon vascular grafts. Circ Res $\underline{74}, 14-23$ 
Gebhard MM, Preusse CJ, Schnabel PA, Bretschneider HJ (1984): Different effects of cardioplegic solution HTK during single or intermittent administration. Thorac Cardiovasc Surg $\underline{32}, 271-276$

Girolami B, Bernardi E, Prins MH, Ten Cate JW, Hettiarachchi R, Prandoni P, Girolami A, Büller HR (1999): Treatment of intermittent claudication with physical training, smoking cessation, pentoxifylline, or nafronyl: a metaanalysis. Arch Intern Med 159, 337-345

Gizewski ER, Rauen U, Kirsch M, Reuters I, Diederichs H, Groot HD (1997): Rapid decrease in cellular sodium and chloride content during cold incubation of cultured liver endothelial cells and hepatocytes. Biochem J 322 ( Pt 3), 693699

Greenblatt DY, Rajamanickam V, Mell MW (2011): Predictors of surgical site infection after open lower extremity revascularization. J Vasc Surg $\underline{54}$, 433439

Greenland P, Jr SCS, Grundy SM (2001): Improving Coronary Heart Disease Risk Assessment in Asymptomatic People: Role of Traditional Risk Factors and Noninvasive Cardiovascular Tests. Circulation 104, 1863-1867

Gris JC, Schved JF, Aguilar-Martinez P, Arnaud A, Sanchez N (1991): [Endothelial mediators regulating vascular tonus]. Presse Medicale Paris Fr 1983 20, 303308

Grohs JG, Kadletz M, Wodratzka M, Wolner E, Raberger G (1996): Contractile function of human veins after long-term storage in different media. $J$ Cardiovasc Pharmacol 28, 89-93

Gryglewski RJ (1995): Interactions between endothelial mediators. Pharmacol Toxicol $\underline{77}, 1-9$

Gubernatis G, Pichlmayr R, Lamesch P, Grosse H, Bornscheuer A, Meyer HJ, Ringe B, Farle M, Bretschneider HJ (1990): HTK-solution (Bretschneider) for human liver transplantation. First clinical experiences. Langenbecks Arch Chir $\underline{375}$, 66-70

Harker LA, Schwartz SM, Ross R (1981): Endothelium and arteriosclerosis. Clin Haematol 10, 283-296

Hayes PD, Allroggen H, Steel S, Thompson MM, London NJ, Bell PR, Naylor AR (2001): Randomized trial of vein versus Dacron patching during carotid endarterectomy: influence of patch type on postoperative embolization. $J$ Vasc Surg 33, 994-1000

Herold G: Innere Medizin. Gerd Herold (Verlag), Köln 2010

Hertzer NR (1991): The natural history of peripheral vascular disease. Implications for its management. Circulation $\underline{83}$, I12-19 
Hiatt WR, Hoag S, Hamman RF (1995): Effect of diagnostic criteria on the prevalence of peripheral arterial disease. The San Luis Valley Diabetes Study. Circulation 91, 1472-1479

Hirsch AT, Criqui MH, Treat-Jacobson D, Regensteiner JG, Creager MA, Olin JW, Krook SH, Hunninghake DB, Comerota AJ, Walsh ME, et al. (2001): Peripheral arterial disease detection, awareness, and treatment in primary care. JAMA 286, 1317-1324

Hirsch AT, Haskal ZJ, Hertzer NR, Bakal CW, Creager MA, Halperin JL, Hiratzka LF, Murphy WRC, Olin JW, Puschett JB, et al. (2006): ACC/AHA 2005 Practice Guidelines for the management of patients with peripheral arterial disease (lower extremity, renal, mesenteric, and abdominal aortic): a collaborative report from the American Association for Vascular Surgery/Society for Vascular Surgery, Society for Cardiovascular Angiography and Interventions, Society for Vascular Medicine and Biology, Society of Interventional Radiology, and the ACC/AHA Task Force on Practice Guidelines (Writing Committee to Develop Guidelines for the Management of Patients With Peripheral Arterial Disease): endorsed by the American Association of Cardiovascular and Pulmonary Rehabilitation; National Heart, Lung, and Blood Institute; Society for Vascular Nursing; TransAtlantic Inter-Society Consensus; and Vascular Disease Foundation. Circulation 113, e463-654

Hochachka PW (1986): Defense strategies against hypoxia and hypothermia. Science 231, 234-241

Hölscher M, Groenewoud AF (1991): Current status of the HTK solution of Bretschneider in organ preservation. Transplant Proc 르, 2334-2337

Hooi JD, Kester ADM, Stoffers HEJH, Rinkens PELM, Knottnerus JA, Ree JW van (2004): Asymptomatic peripheral arterial occlusive disease predicted cardiovascular morbidity and mortality in a 7-year follow-up study. J Clin Epidemiol 57, 294-300

Huang C, Mei H, Zhou M, Zheng X (2017): A novel PDGF receptor inhibitor-eluting stent attenuates in-stent neointima formation in a rabbit carotid model. Mol Med Rep 15, 21-28

Hunink MG, Wong JB, Donaldson MC, Meyerovitz MF, Harrington DP (1994): Patency results of percutaneous and surgical revascularization for femoropopliteal arterial disease. Med Decis Making 14, 71-81

Hutri-Kähönen N, Kähönen M, Jolma P, Wu X, Sand J, Nordback I, Ylitalo P, Arvola P, Pörsti I (1999): Control of mesenteric arterial tone in vitro in humans and rats. Naunyn Schmiedebergs Arch Pharmacol $\underline{359}$, 322-330

Ibarra-Alvarado C, Galle J, Melichar VO, Mameghani A, Schmidt HHHW (2002): Phosphorylation of blood vessel vasodilator-stimulated phosphoprotein at serine 239 as a functional biochemical marker of endothelial nitric oxide/cyclic GMP signaling. Mol Pharmacol $\underline{61}, 312-319$ 
Ip JH, Fuster V, Badimon L, Badimon J, Taubman MB, Chesebro JH (1990): Syndromes of accelerated atherosclerosis: Role of vascular injury and smooth muscle cell proliferation. J Am Coll Cardiol 15, 1667-1687

Jahania MS, Sanchez JA, Narayan P, Lasley RD, Mentzer RM (1999): Heart preservation for transplantation: principles and strategies. Ann Thorac Surg $\underline{68}, 1983-1987$

Jawas A, Abbas AK, Nazzal M, Albader M, Abu-Zidan FM (2013): Management of war-related vascular injuries: experience from the second gulf war. World $\mathrm{J}$ Emerg Surg $\underline{8}, 22$

Jones WS, Schmit KM, Vemulapalli S, Subherwal S, Patel MR, Hasselblad V, Heidenfelder BL, Chobot MM, Posey R, Wing L, et al.: Treatment Strategies for Patients With Peripheral Artery Disease. (AHRQ Comparative Effectiveness Reviews). Agency for Healthcare Research and Quality (US), Rockville (MD) 2013

Jude EB, Eleftheriadou I, Tentolouris N (2010): Peripheral arterial disease in diabetes--a review. Diabet Med 27, 4-14

Kalender M, Taşar M, Karaca OG, Ecevit AN, Darçin OT (2016): Carotid patch and cerebrovascular event relation after carotid endarterectomy procedure. J Cardiovasc Surg (Torino) $\underline{57}$, 888-892

Karaki H, Sato K, Ozaki H (1988a): Different effects of norepinephrine and $\mathrm{KCl}$ on the cytosolic $\mathrm{Ca} 2+$-tension relationship in vascular smooth muscle of rat aorta. Eur J Pharmacol 151, 325-328

Karaki H, Sato K, Ozaki H, Murakami K (1988b): Effects of sodium nitroprusside on cytosolic calcium level in vascular smooth muscle. Eur J Pharmacol 156, 259266

Kawase Y, Ishii Y, Yoshio T, Nishina D, Bessho R, Nitta T (2016): Three Year Follow-Up of a Vein Patch Repair for a Coronary Artery Saccular Aneurysm of the Left Main Bifurcation. Ann Thorac Cardiovasc Surg 23, 104-107

Kenny BA, Miller AM, Williamson IJ, O'Connell J, Chalmers DH, Naylor AM (1996): Evaluation of the pharmacological selectivity profile of alpha 1 adrenoceptor antagonists at prostatic alpha 1 adrenoceptors: binding, functional and in vivo studies. Br J Pharmacol $\underline{118}, 871-878$

Klinkert P, Post PN, Breslau PJ, van Bockel JH (2004): Saphenous vein versus PTFE for above-knee femoropopliteal bypass. A review of the literature. Eur $\mathrm{J}$ Vasc Endovasc Surg 27, 357-362

Koch A, Loganathan S, Radovits T, Sack F-U, Karck M, Szabó GB (2010): Deferoxamine, the newly developed iron chelator LK-614 and N-alpha-acetylhistidine in myocardial protection. Interact Cardiovasc Thorac Surg 10, 181184 
Köhler Chemie (1999): Custodiol® HTK Solution Common/Classification Name: Isolated Kidney Perfusion and Transport System and Accessories, 21 CFR 876.5880, Dr. Franz Kohler Chemie GmbH Postfach 1117 D-64659 AlsbachHahnlein Germany, Contact: E. Schaffner, M.D. Prepared: June 16, $1999 \mid$ [https://www.fda.gov/cdrh/510k/K992209.pdf]

Kohler TR, Kirkman TR, Clowes AW (1989): The effect of rigid external support on vein graft adaptation to the arterial circulation. J Vasc Surg $\underline{9}, 277-285$

Kouchi Y, Onuki Y, Wu MH-D, Shi Q, Ghali R, Wechezak AR, Kaplan S, Walker M, Sauvage LR (1998): Apparent Blood Stream Origin of Endothelial and Smooth Muscle Cells in the Neointima of Long, Impervious Carotid-Femoral Grafts in the Dog. Ann Vasc Surg 12, 46-54

Kreitner K-F, Kalden P, Neufang A, Düber C, Krummenauer F, Küstner E, Laub G, Thelen M (2000): Diabetes and Peripheral Arterial Occlusive Disease. Am J Roentgenol 174, 171-179

Krotkiewski M (2015): [ls physiological saline really physiological? Hyponatreamia treatment--small deviations from the rules of appropriate therapy create serious complications and side effects]. Pol Merkur Lek Organ Pol Tow Lek $\underline{39}, 237-240$

Kubes P, Suzuki M, Granger DN (1991): Nitric oxide: an endogenous modulator of leukocyte adhesion. Proc Natl Acad Sci U S A $\underline{88}, 4651-4655$

Kühnel W: Taschenatlas Histologie. Georg Thieme Verlag, Stuttgart 2014

Lang F, Föller M, Lang KS, Lang PA, Ritter M, Gulbins E, Vereninov A, Huber SM (2005): Ion Channels in Cell Proliferation and Apoptotic Cell Death. ResearchGate 205, 147-57

Lapchinsky AG (1960): Recent results of experimental transplantation of preserved limbs and kidneys and possible use of this technique in clinical practice. Ann N Y Acad Sci 87 , 539-571

Larch E, Minar E, Ahmadi R, Schnürer G, Schneider B, Stümpflen A, Ehringer H (1997): Value of color duplex sonography for evaluation of tibioperoneal arteries in patients with femoropopliteal obstruction: a prospective comparison with anterograde intraarterial digital subtraction angiography. J Vasc Surg 25, 629-636

Lefer AM, Ma XL (1993): Decreased basal nitric oxide release in hypercholesterolemia increases neutrophil adherence to rabbit coronary artery endothelium. Arterioscler Thromb J Vasc Biol 13, 771-776

Leitlinie pAVK(2015): S3-Leitlinie zur Diagnostik, Therapie und Nachsorge der peripheren arteriellen Verschlusskrankheit . Stand 30. Sept. 2015. https://www.awmf.org/uploads/tx_szleitlinien/065-

003I_S3_PAVK_periphere_arterielle_Verschlusskrankheitfinal-2016-04.pdf 
Leng GC, Lee AJ, Fowkes FG, Whiteman M, Dunbar J, Housley E, Ruckley CV (1996a): Incidence, natural history and cardiovascular events in symptomatic and asymptomatic peripheral arterial disease in the general population. Int $\mathrm{J}$ Epidemiol 25, 1172-1181

Leng GC, Fowkes FG, Lee AJ, Dunbar J, Housley E, Ruckley CV (1996b): Use of ankle brachial pressure index to predict cardiovascular events and death: a cohort study. BMJ $\underline{313}, 1440-1444$

Lindner V, Reidy MA (1991): Proliferation of smooth muscle cells after vascular injury is inhibited by an antibody against basic fibroblast growth factor. Proc Natl Acad Sci U S A 88, 3739-3743

Liu J, Feng Z, Zhao J, Li B, Long C (2008): The Myocardial Protection of HTK Cardioplegic Solution on the Long-Term Ischemic Period In Pediatric Heart Surgery. ResearchGate $\underline{54}, 470-3$

Lobo DN, Awad S (2014): Should chloride-rich crystalloids remain the mainstay of fluid resuscitation to prevent „pre-renal“ acute kidney injury? Kidney Int $\underline{86}$, 1096-1105

Loewe C, Schoder M, Rand T, Hoffmann U, Sailer J, Kos T, Lammer J, Thurnher S (2002): Peripheral Vascular Occlusive Disease: Evaluation with ContrastEnhanced Moving-Bed MR Angiography Versus Digital Subtraction Angiography in 106 Patients. Am J Roentgenol 179, 1013-1021

Loop FD, Lytle BW, Gill CC, Golding LA, Cosgrove DM, Taylor PC (1983): Trends in selection and results of coronary artery reoperations. Ann Thorac Surg $\underline{36}$, 380-388

Lüscher TF, Barton M (1997): Biology of the endothelium. Clin Cardiol 20, II-3-10

Malyar NM, Freisinger E, Meyborg M, Lüders F, Gebauer K, Reinecke H, Lawall H (2016): Amputations and mortality in in-hospital treated patients with peripheral artery disease and diabetic foot syndrome. $\mathrm{J}$ Diabetes Complications $\underline{30}, 1117-1122$

Mamode N, Scott RN (2000): Graft type for femoro-popliteal bypass surgery. Cochrane Database Syst Rev CD001487

Masson AHB (1971): Latta-Pioneer in Saline Infusion. Br J Anaesth 느, 681-686

McKenna M, Wolfson S, Kuller L (1991): The ratio of ankle and arm arterial pressure as an independent predictor of mortality. Atherosclerosis $\underline{87}, 119-128$

Meijer WT, Hoes AW, Rutgers D, Bots ML, Hofman A, Grobbee DE (1998): Peripheral Arterial Disease in the Elderly. Arterioscler Thromb Vasc Biol $\underline{18}$, 185-192

Mertens S, Noll T, Spahr R, Krützfeldt A, Piper HM (1990): Energetic response of coronary endothelial cells to hypoxia. Am J Physiol 258, H689-694 
Mihaylova B, Briggs A, Armitage J, Parish S, Gray A, Collins R, Heart Protection Study Collaborative Group (2005): Cost-effectiveness of simvastatin in people at different levels of vascular disease risk: economic analysis of a randomised trial in 20,536 individuals. Lancet $\underline{365}, 1779-1785$

Mlacak B, Blinc A, Pohar M, Stare J (2006): Peripheral arterial disease and anklebrachial pressure index as predictors of mortality in residents of Metlika County, Slovenia. Croat Med J 47, 327-334

Mombouli JV, Vanhoutte PM (1999): Endothelial dysfunction: from physiology to therapy. J Mol Cell Cardiol $\underline{31}, 61-74$

Moore S (1985): Pathogenesis of atherosclerosis. Metabolism 34, 13-16

Mouzas GL (1967): The present status of organ preservation: a review. Postgrad Med J $\underline{43}, 712-715$

Müller-Schweinitzer E (2009): Cryopreservation of vascular tissues. Organogenesis 5, 97-104

Müller-Schweinitzer E, Mihatsch MJ, Schilling M, Haefeli WE (1997): Functional recovery of human mesenteric and coronary arteries after cryopreservation at $-196^{\circ} \mathrm{C}$ in a serum-free medium. J Vasc Surg $\underline{25}, 743-750$

Munro JM, Cotran RS (1988): The pathogenesis of atherosclerosis: atherogenesis and inflammation. Lab Investig J Tech Methods Pathol $\underline{58}, 249-261$

Murabito JM, Evans JC, Nieto K, Larson MG, Levy D, Wilson PW f (2002): Prevalence and clinical correlates of peripheral arterial disease in the Framingham Offspring Study. Am Heart J $\underline{143}$, 961-965

Nagao T, Vanhoutte PM (1992): Hyperpolarization as a mechanism for endotheliumdependent relaxations in the porcine coronary artery. J Physiol $\underline{445}, 355-367$

Nakahashi T, Fukuo K, Inoue T, Morimoto S, Hata S, Yano M, Ogihara T (1995): Endothelin-1 enhances nitric oxide-induced cytotoxicity in vascular smooth muscle. Hypertens Dallas Tex 1979 25, 744-747

Naylor R, Hayes PD, Payne DA, Allroggen H, Steel S, Thompson MM, London NJM, Bell PRF (2004): Randomized trial of vein versus dacron patching during carotid endarterectomy: long-term results. J Vasc Surg 39, 985-993; discussion 993

Neves JP, Gulbenkian S, Ramos T, Martins AP, Caldas MC, Mascarenhas R, Guerreiro M, Matoso-Ferreira A, Santos R, Monteiro C, Melo JQ (1997): Mechanisms underlying degeneration of cryopreserved vascular homografts. J Thorac Cardiovasc Surg 113, 1014-1021

Newby AC, Zaltsman AB (2000): Molecular mechanisms in intimal hyperplasia. J Pathol 190, 300-309 
Newman AB, Siscovick DS, Manolio TA, Polak J, Fried LP, Borhani NO, Wolfson SK (1993): Ankle-arm index as a marker of atherosclerosis in the Cardiovascular Health Study. Cardiovascular Heart Study (CHS) Collaborative Research Group. Circulation 88, 837-845

Nigro D, Scivoletto R (1983): Mechanism of action of phenylephrine on isolated guinea-pig atria rate. Gen Pharmacol 14, 349-354

Nishimura Y, Romer LH, Lemasters JJ (1998): Mitochondrial dysfunction and cytoskeletal disruption during chemical hypoxia to cultured rat hepatic sinusoidal endothelial cells: the $\mathrm{pH}$ paradox and cytoprotection by glucose, acidotic $\mathrm{pH}$, and glycine. Hepatology 27, 1039-1049

Norgren L, Hiatt WR, Dormandy JA, Nehler MR, Harris KA, Fowkes FGR (2007): Inter-Society Consensus for the Management of Peripheral Arterial Disease (TASC II). Eur J Vasc Endovasc Surg 33, S1-S75

Numano F, Kobayashi Y (1999): Takayasu Arteritis -beyond Pulselessness-. Intern Med $\underline{38}, 226-232$

Nutt MP, Fields BL, Sebree LA, Southard JH, Pyzalska D, Pyzalski R, Thomas A, Mentzer RM, Bianco JA (1992): Assessment of function, perfusion, metabolism, and histology in hearts preserved with University of Wisconsin solution. Circulation $\underline{86}$, II333-338

O'Riordain DS, Buckley DJ, O'Donnell JA (1992): Polytetrafluoroethylene in aboveknee arterial bypass surgery for critical ischemia. Am J Surg 뜨, 129-131

Orlić P, Vukas D, Curuvija D, Markić D, Merlak-Prodan Z, Maleta I, Zivcić-Cosić S, Orlić L, Blecich G, Valencić M, et al. (2008): [Pseudoaneurysm after renal transplantation]. Acta Medica Croatica 62 Suppl 1, 86-89

Oser RF, Picus D, Hicks ME, Darcy MD, Hovsepian DM (1995): Accuracy of DSA in the evaluation of patency of infrapopliteal vessels. J Vasc Interv Radiol $\underline{6}$, 589-594

Ostchega Y, Paulose-Ram R, Dillon CF, Gu Q, Hughes JP (2007): Prevalence of peripheral arterial disease and risk factors in persons aged 60 and older: data from the National Health and Nutrition Examination Survey 1999-2004. J Am Geriatr Soc $\underline{55}, 583-589$

Ouriel K (2001): Peripheral arterial disease. Lancet 358, 1257-1264

Ouwendijk R, de Vries M, Pattynama PMT, van Sambeek MRHM, de Haan MW, Stijnen T, van Engelshoven JMA, Hunink MGM (2005): Imaging Peripheral Arterial Disease: A Randomized Controlled Trial Comparing Contrastenhanced MR Angiography and Multi-Detector Row CT Angiography. Radiology 236, 1094-1103

Owen K, Rob CG (1956): Technique for By-pass Operations in Femoral Arterial Disease. Br Med J 2, 273 
Perez JF, Sanderson MJ (2005): The Frequency of Calcium Oscillations Induced by $5-\mathrm{HT}, \mathrm{ACH}$, and $\mathrm{KCl}$ Determine the Contraction of Smooth Muscle Cells of Intrapulmonary Bronchioles. J Gen Physiol 125, 535-553

Qayumi AK, Jamieson WR, Rosado LJ, Tomlinson CW, Schulzer M, McConville B, Gillespie K, Wong A (1991): Preservation techniques for heart transplantation: comparison of hypothermic storage and hypothermic perfusion. J Heart Lung Transplant 10, 518-526

Quick CR, Cotton LT (1982): The measured effect of stopping smoking on intermittent claudication. Br J Surg 69 Suppl, S24-26

Radovits T, Lin L, Zotkina J, Koch A, Rauen U, Köhler G, Karck M, Szabó G (2008): Endothelial dysfunction after long-term cold storage in HTK organ preservation solutions: effects of iron chelators and N-alpha-acetyl-L-histidine. J Heart Lung Transplant 27, 208-216

Ramos TV, Mathew AJ, Thompson ML, Ehrhardt RO (2014): Standardized cryopreservation of human primary cells. $\underline{64}$, A.3I.1-8

Rancić Z, Radak D, Stojanović D (2002): [Early detection of asymptomatic carotid disease in patients with obliterative arteriosclerosis of the lower extremities]. $130,258-264$

Rapoport RM, Murad F (1983): Agonist-induced endothelium-dependent relaxation in rat thoracic aorta may be mediated through cGMP. Circ Res 52, 352-357

Rapoport RM, Draznin MB, Murad F (1983): Endothelium-dependent relaxation in rat aorta may be mediated through cyclic GMP-dependent protein phosphorylation. Nature $\underline{306}, 174-176$

Ratz PH, Berg KM, Urban NH, Miner AS (2005): Regulation of smooth muscle calcium sensitivity: $\mathrm{KCl}$ as a calcium-sensitizing stimulus. Am J Physiol - Cell Physiol 288, C769-C783

Rauen U, de Groot H (2004): New insights into the cellular and molecular mechanisms of cold storage injury. J Investig Med 52, 299-309

Rauen U, Petrat F, Li T, De Groot H (2000): Hypothermia injury/cold-induced apoptosis--evidence of an increase in chelatable iron causing oxidative injury in spite of low O2-/H2O2 formation. FASEB J 14, 1953-1964

Rauen U, Klempt S, de Groot H (2007): Histidine-induced injury to cultured liver cells, effects of histidine derivatives and of iron chelators. Cell Mol Life Sci64, 192-205

Reichenspurner H, Russ C, Uberfuhr P, Nollert G, Schlüter A, Reichart B, Klövekorn WP, Schüler S, Hetzer R, Brett W (1993): Myocardial preservation using HTK solution for heart transplantation. A multicenter study. Eur $\mathrm{J}$ Cardio-Thorac Surg $\underline{7}, 414-419$ 
Rendal-Vázquez ME, San Luis Verdes A, Pombo Otero J, Segura Iglesias R, Domenech García N, Andión Núñez C (2012): Anatomopathological and immunohistochemical study of explanted cryopreserved arteries. Ann Vasc Surg 26, 720-728

Resnick HE, Lindsay RS, McDermott MM, Devereux RB, Jones KL, Fabsitz RR, Howard BV (2004): Relationship of high and low ankle brachial index to allcause and cardiovascular disease mortality: the Strong Heart Study. Circulation 109, 733-739

Richtlinie (EU) 2015/566 (2015): Richtlinie (EU) 2015/566 der Kommission vom 8. April 2015 zur Durchführung der Richtlinie 2004/23/EG hinsichtlich der Verfahren zur Prüfung der Gleichwertigkeit von Qualitäts- und Sicherheitsstandards bei eingeführten Geweben und Zellen. Amtsblatt der Europäischen Union | $\mathrm{L}$ 93/56 [https://eur-lex.europa.eu/legalcontent/DE/TXT/PDF/?uri=celex:32015L0566]

Rofsky NM, Johnson G, Adelman MA, Rosen RJ, Krinsky GA, Weinreb JC (1997): Peripheral vascular disease evaluated with reduced-dose gadoliniumenhanced MR angiography. Radiology 205, 163-169

Ross R (1979): The pathogenesis of atherosclerosis. Mech Ageing Dev $\underline{9}, 435-440$

Ross R (1993): The pathogenesis of atherosclerosis: a perspective for the 1990s. Nature $\underline{362}$, 801-809

Ross R, Harker L (1976): Hyperlipidemia and atherosclerosis. Science $\underline{193}$, 10941100

Ross R, Glomset J, Harker L (1977): Response to injury and atherogenesis. Am J Pathol 86, 675-684

Rutherford RB, Baker JD, Ernst C, Johnston KW, Porter JM, Ahn S, Jones DN (1997): Recommended standards for reports dealing with lower extremity ischemia: revised version. J Vasc Surg 26, 517-538

Saida K, van Breemen C (1987): GTP requirement for inositol-1,4,5-trisphosphateinduced $\mathrm{Ca} 2+$ release from sarcoplasmic reticulum in smooth muscle. Biochem Biophys Res Commun 144, 1313-1316

Saida K, Twort C, van Breemen C (1988): The specific GTP requirement for inositol 1,4,5-trisphosphate-induced $\mathrm{Ca} 2+$ release from skinned vascular smooth muscle. J Cardiovasc Pharmacol 12 Suppl 5, S47-50

Salahudeen AK, Huang H, Patel P, Jenkins JK (2000): Mechanism and prevention of cold storage-induced human renal tubular cell injury. Transplantation $\underline{70}$, 1424-1431

Saltis J, Thomas AC, Agrotis A, Campbell JH, Campbell GR, Bobik A (1995): Expression of growth factor receptors in arterial smooth muscle cells. Dependency on cell phenotype and serum factors. Atherosclerosis $\underline{118}, 77-$ 87 
Sayers RD, Raptis S, Berce M, Miller JH (1998): Long-term results of femorotibial bypass with vein or polytetrafluoroethylene. Br J Surg $\underline{85}$, 934-938

Schaeffer U, Tanner B, Strohschneider T, Stadtmüller A, Hannekum A (1997): Damage to arterial and venous endothelial cells in bypass grafts induced by several solutions used in bypass surgery. Thorac Cardiovasc Surg $\underline{45}, 168-$ 171

Schwartz SM, Heimark RL, Majesky MW (1990): Developmental mechanisms underlying pathology of arteries. Physiol Rev $\underline{70}, 1177-1209$

Selvin E, Erlinger TP (2004): Prevalence of and risk factors for peripheral arterial disease in the United States: results from the National Health and Nutrition Examination Survey, 1999-2000. Circulation 110, 738-743

Silver PJ (1986): Pharmacological modulation of cardiac and vascular contractile protein function. J Cardiovasc Pharmacol 8 Suppl 9, S34-46

Skalli O, Ropraz P, Trzeciak A, Benzonana G, Gillessen D, Gabbiani G (1986): A monoclonal antibody against alpha-smooth muscle actin: a new probe for smooth muscle differentiation. J Cell Biol $\underline{103}, 2787-2796$

Snow AD, Bolender RP, Wight TN, Clowes AW (1990): Heparin modulates the composition of the extracellular matrix domain surrounding arterial smooth muscle cells. Am J Pathol 137, 313-330

Solberg S, Larsen T, Småbrekke A, Brox JH, Bertheussen K, Sørlie D, Osterud B, Jørgensen $L$ (1992): A new protective solution for hypothermic storage of free vein grafts in cardiovascular surgery. Scand J Clin Lab Invest $\underline{52}, 73-82$

Sottiurai VS, Yao JS, Flinn WR, Batson RC (1983): Intimal hyperplasia and neointima: An ultrastructural analysis of thrombosed grafts in humans. Surgery $\underline{93}, 809-817$

Srivastava RD, Kalitha M, Varma P, Bhatnagar VM (1977): A mechanism of action of phenylephrine on heart. Indian J Physiol Pharmacol 21, 167-174

Stegemann J, Hirner A, Rauen U, Minor T (2009): Gaseous oxygen persufflation or oxygenated machine perfusion with Custodiol-N for long-term preservation of ischemic rat livers? Cryobiology $\underline{58}, 45-51$

Stoffers HE, Rinkens PE, Kester AD, Kaiser V, Knottnerus JA (1996): The prevalence of asymptomatic and unrecognized peripheral arterial occlusive disease. Int J Epidemiol 25, 282-290

Szilagyi DE, Elliott JP, Hageman JH, Smith RF, Dall'olmo CA (1973): Biologic fate of autogenous vein implants as arterial substitutes: clinical, angiographic and histopathologic observations in femoro-popliteal operations for atherosclerosis. Ann Surg 178, 232-246 
Takagi H, Goto S-N, Matsui M, Manabe H, Umemoto T (2010): A contemporary meta-analysis of Dacron versus polytetrafluoroethylene grafts for femoropopliteal bypass grafting. J Vasc Surg $\underline{52}, 232-236$

Tangelder MJ, Algra A, Lawson JA, Eikelboom BC (2000): Risk factors for occlusion of infrainguinal bypass grafts. Eur J Vasc Endovasc Surg 20, 118-124

Thiemermann C (1991): Biosynthesis and interaction of endothelium-derived vasoactive mediators. Eicosanoids 4 , 187-202

Tinker JH, Michenfelder JD (1976): Sodium nitroprusside: pharmacology, toxicology and therapeutics. Anesthesiology $\underline{45}, 340-354$

Tsakok M, Montgomery-Taylor S, Tsakok T (2012): Storage of saphenous vein grafts prior to coronary artery bypass grafting: is autologous whole blood more effective than saline in preserving graft function? Interact Cardiovasc Thorac Surg $\underline{15}, 720-725$

Tung LH, Rand MJ, Louis WJ (1987): Calcium antagonists inhibit positive chronotropic responses to alpha 1-adrenoceptor activation in rat isolated atria. Eur J Pharmacol $\underline{133}, 177-184$

Ueda T, Chueh SH, Noel MW, Gill DL (1986): Influence of inositol 1,4,5trisphosphate and guanine nucleotides on intracellular calcium release within the N1E-115 neuronal cell line. J Biol Chem 261, 3184-3192

Upadhya GA, Strasberg SM (2002): Platelet adherence to isolated rat hepatic sinusoidal endothelial cells after cold preservation. Transplantation $\underline{73}$, 17641770

Vane JR, Botting RM (1992): The role of chemical mediators released by the endothelium in the control of the cardiovascular system. Int $\mathrm{J}$ Tissue React $\underline{14}, 55-64$

Veith FJ, Gupta SK, Ascer E, White-Flores S, Samson RH, Scher LA, Towne JB, Bernhard VM, Bonier P, Flinn WR (1986): Six-year prospective multicenter randomized comparison of autologous saphenous vein and expanded polytetrafluoroethylene grafts in infrainguinal arterial reconstructions. J Vasc Surg $\underline{3}, 104-114$

Veres G, Hegedüs P, Barnucz E, Zöller R, Klein S, Radovits T, Korkmaz S, Karck M, Szabó G (2015): Graft preservation with heparinized blood/saline solution induces severe graft dysfunction. Interact Cardiovasc Thorac Surg 20, 594600

Veres G, Hegedűs P, Barnucz E, Schmidt H, Radovits T, Zöller R, Karck M, Szabó G (2016): TiProtec preserves endothelial function in a rat model. J Surg Res 200, 346-355

Verhaeghe $R$ (1998): [Epidemiology and prognosis of peripheral obliterative arteriopathy]. Drugs $\underline{56 \text { Suppl } 3}, 1-10$ 
Vogt PR, Stallmach T, Niederhäuser U, Schneider J, Zünd G, Lachat M, Künzli A, Turina MI (1999): Explanted cryopreserved allografts: a morphological and immunohistochemical comparison between arterial allografts and allograft heart valves from infants and adults. Eur J Cardio-Thorac Surg $\underline{15}$, 639-644645

Walter U, Waldmann R, Nieberding M (1988): Intracellular mechanism of action of vasodilators. Eur Heart J $\underline{9 \text { Suppl } \mathrm{H}}, 1-6$

Warner TD (1996): Influence of endothelial mediators on the vascular smooth muscle and circulating platelets and blood cells. Int Angiol 15, 93-99

Weinberg JM, Venkatachalam MA, Garzo-Quintero R, Roeser NF, Davis JA (1990): Structural requirements for protection by small amino acids against hypoxic injury in kidney proximal tubules. FASEB J $\underline{4}$, 3347-3354

Welz A, Stadtmüller A, Schäffer U, Strohschneider T, Hannekum A (1991): Cytotoxicity of various crystalloid solutions to the endothelial cells of autologous grafts. Thorac Cardiovasc Surg 39 Suppl 3, 236-240

Whelan JF, Barry MH, Moir JD (1992): Color flow Doppler ultrasonography: comparison with peripheral arteriography for the investigation of peripheral vascular disease. J Clin Ultrasound 20, 369-374

Wicomb W, Cooper DK, Hassoulas J, Rose AG, Barnard CN (1982): Orthotopic transplantation of the baboon heart after 20 to 24 hours' preservation by continuous hypothermic perfusion with an oxygenated hyperosmolar solution. J Thorac Cardiovasc Surg $\underline{83}, 133-140$

Wiedemann D, Schachner T, Bonaros N, Dorn M, Andreas M, Kocher A, Kuznetsov AV (2013): Impact of Cold Ischemia on Mitochondrial Function in Porcine Hearts and Blood Vessels. Int J Mol Sci 14, 22042-22051

Wilbring M, Tugtekin SM, Zatschler B, Ebner A, Reichenspurner H, Matschke K, Deussen A (2011): Even short-time storage in physiological saline solution impairs endothelial vascular function of saphenous vein grafts. Eur J CardioThorac Surg 40, 811-815

Wilbring M, Tugtekin SM, Zatschler B, Ebner A, Reichenspurner $\mathrm{H}$, Kappert U, Matschke K, Deussen A (2013): Preservation of endothelial vascular function of saphenous vein grafts after long-time storage with a recently developed potassium-chloride and $\mathrm{N}$-acetylhistidine enriched storage solution. Thorac Cardiovasc Surg $\underline{61}, 656-662$

Wilkins LW\& (2006): ACC/AHA 2005 Practice Guidelines for the Management of Patients With Peripheral Arterial Disease (Lower Extremity, Renal, Mesenteric, and Abdominal Aortic): Executive Summary. Circulation 113, 1474-1547

Wille T, de Groot H, Rauen U (2008): Improvement of the cold storage of blood vessels with a vascular preservation solution. Study in porcine aortic segments. J Vasc Surg 47, 422-431 
Wille T, Gonder S, Thiermann H, Seeger T, Rauen U, Worek F (2011): Evaluation of functional and structural alterations in muscle tissue after short-term cold storage in a new tissue preservation solution. Cells Tissues Organs 194, 501509

Wise ES, Hocking KM, Eagle S, Absi T, Komalavilas P, Cheung-Flynn J, Brophy CM (2015): Preservation solution impacts physiologic function and cellular viability of human saphenous vein graft. Surgery $\underline{158}, 537-546$

Witter K, Tonar Z, Schöpper H (2017): How many Layers has the Adventitia? Structure of the Arterial Tunica Externa Revisited. Anat Histol Embryol $\underline{46}$, $110-120$

Wolf BA, Florholmen J, Colca JR, McDaniel ML (1987): GTP mobilization of Ca2+ from the endoplasmic reticulum of islets. Comparison with myo-inositol 1,4,5trisphosphate. Biochem J 242, 137-141

Wu K, Türk TR, Rauen U, Su S, Feldkamp T, de Groot H, Wiswedel I, Baba HA, Kribben A, Witzke O (2011): Prolonged cold storage using a new histidinetryptophan-ketoglutarate-based preservation solution in isogeneic cardiac mouse grafts. Eur Heart J $\underline{32}, 509-516$

Wu S, Wohlschlaeger J, de Groot H, Rauen U (2009): Evaluation of a modified HTK solution containing the new iron chelator LK 614 in an isolated rat liver perfusion model. J Investig Surg 22, 340-347

Xu D, Li J, Zou L, Xu Y, Hu D, Pagoto SL, Ma Y (2010): Sensitivity and specificity of the ankle-brachial index to diagnose peripheral artery disease: a structured review. Vasc Med 15, 361-369

Yamamoto R, Kawasaki H, Takasaki K (1984): Postsynaptic alpha-adrenoreceptor populations in several vascular systems of the anaesthetized rat. J Auton Pharmacol $\underline{4}, 231-239$

Young P, Bailey M, Beasley R, Henderson S, Mackle D, McArthur C, McGuinness S, Mehrtens J, Myburgh J, Psirides A, et al. (2015): Effect of a Buffered Crystalloid Solution vs Saline on Acute Kidney Injury Among Patients in the Intensive Care Unit: The SPLIT Randomized Clinical Trial. JAMA 314, 17011710

Zatschler B, Dieterich P, Müller B, Kasper M, Rauen U, Deussen A (2009): Improved vessel preservation after 4 days of cold storage: experimental study in rat arteries. J Vasc Surg $\underline{50}, 397-406$

Zeltsman D, Tzarnas CD, Kerstein MD (1999): Management of vascular prosthetic infections: results of long-term follow-up. Am Surg $\underline{65}, 331-333$

Zubilewicz T, Wronski J, Bourriez A, Terlecki P, Guinault AM, Muscatelli-Groux B, Michalak J, Méllière $D$, Becquemin JP, Allaire E (2001): Injury in vascular surgery--the intimal hyperplastic response. Med Sci $\underline{7}, 316-324$ 
Zwolak RM, Adams MC, Clowes AW (1987): Kinetics of vein graft hyperplasia: association with tangential stress. J Vasc Surg $\underline{5}, 126-136$ 


\section{Danksagung}

Ich danke Prof. Dr. med. T. Stojanovic für die Überlassung und die Möglichkeit der Bearbeitung dieses spannenden Themas als meine Dissertation. Er hat sich stets als ein motivierender Berater und Betreuer während der ganzen Zeit erwiesen.

Dr. med. A. Fawad Jebran, der sich fortwährend geduldig und fürsorglich um die Umsetzung und Fertigstellung dieses Projektes bemüht hat, danke ich für die Gelegenheit in seiner Arbeitsgruppe mitzuarbeiten. Besonders möchte ich mich für die operative Einführung in die Mikrochirurgie der Tierversuche bedanken. Ich durfte mir während dieser Zeit zahlreiche operative Techniken aneignen, die sich mir nun in einem kommenden Tierversuchsvorhaben zur Fortsetzung meiner jetzigen Arbeit als äußerst nützlich erweisen werden.

Frau Regina Waldmann-Beushausen, die aufgrund ihrer langen Berufserfahrung als MTA in unserer Abteilung und an der gesamten UMG in der Verarbeitung, Aufbereitung und Interpretation histomorphologischer und histopathologischer Präparate des kardiovaskulären Gewebes mittlerweile eine feste und unentbehrliche Institution geworden ist, danke ich für die Einführung in dieses sehr spannende Gebiet.

Dem gesamten Labor-Team von Prof. S. Sossalla (Abt. Kardiologie, UMG) danke ich für die Kooperation im Bereich der Funktionsmesungen. 